\title{
PROFESSIONAL GLAMOUR AND FEMININE MYSTIQUE: BARBARA MOON'S STYLE IN WORDS AND WARDROBE
}

\author{
by
}

Myriam Couturier, BSocSc

Toronto, Ontario, 2015

\author{
A MRP \\ presented to Ryerson University \\ in partial fulfillment of the \\ requirements for the degree of \\ Master of Arts \\ in the Program of \\ Fashion
}

Toronto, Ontario, Canada, 2015

(C) Myriam Couturier 2015 


\section{AUTHOR'S DECLARATION FOR ELECTRONIC SUBMISSION OF A MRP}

I hereby declare that I am the sole author of this MRP. This is a true copy of the MRP, including any required final revisions.

I authorize Ryerson University to lend this MRP to other institutions or individuals for the purpose of scholarly research.

I further authorize Ryerson University to reproduce this MRP by photocopying or by other means, in total or in part, at the request of other institutions or individuals for the purpose of scholarly research.

I understand that my MRP may be made electronically available to the public. 
Professional Glamour and Feminine Mystique: Barbara Moon’s Style in Words and Wardrobe, Master of Arts, 2015, Myriam Couturier, Fashion, Ryerson University

\begin{abstract}
'Glamour' is a term usually reserved to describe celebrities and fashion personalities. This research project proposes that glamour can also be performed by highly skilled professional women to assert themselves in the workplace and challenge gender expectations. Years before the publication of the Dress for Success books in the 1970s, women were already entering typically masculine environments and negotiating their professional identities through fashion and personal appearance. This paper provides a case study of one woman's wardrobe, donated to the Ryerson University Fashion Research Collection in 1997. Its owner, Barbara Moon, was a highly respected journalist and magazine editor who worked in Toronto from the 1950s to 1990s. Through material culture approaches, as well as textual and discursive analyses, Moon's wardrobe was examined and situated within the social and professional contexts in which it was worn. Connections were drawn between the themes she explored in her writing, and her elegant self-presentation.
\end{abstract}




\section{ACKNOWLEDGMENTS}

I want to sincerely thank my supervisor Dr. Alison Matthews David for supporting me with invaluable guidance, encouragement and enthusiasm throughout this research and writing process. I would also like to thank Ingrid Masak Mida from the Ryerson Fashion Research Collection for giving me continued access to Barbara Moon's wardrobe, introducing me to the garments that inspired this project, and helping me better understand these artifacts. Finally, I want to extend my thanks to Elizabeth Semmelhack for providing valuable comments and suggestions as my second reader. 


\section{TABLE OF CONTENTS}

Author's Declaration $\quad$ ii

$\begin{array}{ll}\text { Abstract } & \text { iii }\end{array}$

Acknowledgments $\quad$ iv

List of Figures vii

1. Introduction 1

2. Literature Review 6

$\begin{array}{ll}\text { Couture Consumption } & 6\end{array}$

$\begin{array}{ll}\text { Sociological Approaches } & 9\end{array}$

$\begin{array}{ll}\text { Gender and Journalism } & 12\end{array}$

$\begin{array}{ll}\text { Dress for Success } & 20\end{array}$

Clothes, Representation, Material Biographies 22

Glamour and Feminine Mystery $\quad 24$

3. Research Context and Methodology 27

4. Material Culture Analysis: Moon's Wardrobe Style 34

5. Written Works: Moon's Style On the Page 49

$\begin{array}{ll}\text { Class } & 51\end{array}$

$\begin{array}{ll}\text { French-ness } & 60\end{array}$

Glamour and Sophistication $\quad 63$

6. Discursive Analysis: Moon's Performance of Professional Glamour 71

$\begin{array}{ll}\text { 7. Conclusion } & 91\end{array}$ 
Appendix A - Images

Works Cited

109 


\section{LIST OF FIGURES}

Figure 1 - Givenchy linen sleeveless sack dress (FRC 1997.04.052). Photo by Jazmin Welch, Courtesy of the Ryerson Fashion Research Collection.

Figure 2 - Fabiani wool bouclé dress (FRC 1997.04.036); Balenciaga silk cloqué dress (FRC 1997.04.050); Givenchy linen sleeveless sack dress (FRC 1997.04.052).

Figure 3 - Balenciaga cloqué silk dress (FRC 1997.04.50).

Figure 4 - Dior silk linen dress (FRC 1997.04.046). Photo by Jazmin Welch, Courtesy of the Ryerson Fashion Research Collection.

Figure 5 - Dior wool coat (FRC 1997.04.044). Photo by Jazmin Welch, Courtesy of the Ryerson Fashion Research Collection.

Figure 6 - Courrèges cotton poplin coat-dress (FRC 1997.04.043).

Figure 7 - Pierre Cardin jacket and skirt (FRC 1997.04.001).

Figure 8 - Pierre Cardin wool dress and jacket (FRC 1997.04.002). Photo by Jazmin Welch, Courtesy of the Ryerson Fashion Research Collection.

Figure 9 - Patrick de Barentzen velvet evening jacket and skirt (FRC 1997.04.031).

Figure 10 - Nina Ricci wool cape (FRC 1997.04.049).

Figure 11 - A selection from Moon's wardrobe (FRC 1997.04.049; FRC 1997.04.042; FRC 1997.04.028; FRC 1997.04.050; FRC 1997.04.052; FRC 1997.04.058).

Figure 12 - Gudule wool bouclé smock dress (FRC 1997.04.042).

Figure 13 - Fabiani bouclé wool dress (FRC 1997.04.036).

Figure 14 - Valentino evening gown (FRC 1997.04.009). Photo by Jazmin Welch, Courtesy of the Ryerson Fashion Research Collection. 
Figure 15 - Nina Ricci raw silk evening gown and jacket (FRC 1997.04.048). Photo by Jazmin Welch, Courtesy of the Ryerson Fashion Research Collection.

Figure 16 - Saint Laurent jersey halter top (FRC 1997.04.038).

Figure 17 - Saint Laurent wool jumpsuit (FRC 1997.04.039).

Figure 18 - Valentino wool trouser suit (FRC 1997.04.040). Photo by Jazmin Welch, Courtesy of the Ryerson Fashion Research Collection.

Figure 19 - Balenciaga velvet and jersey cocktail dress (FRC 1997.04.051).

Figure 20 - Holt Renfrew quilted top and skirt (FRC 1997.04.055).

Figure 21 - Holt Renfrew wool sleeveless evening dress (FRC 1997.04.058).

Figure 22 - Barbara Moon in 1965, The Globe and Mail, in "Full Moon." Ryerson Review of Journalism Summer 2010, p. 46.

Figure 23 - Joan Didion in Céline Spring 2015 campaign. "It's great that Céline is celebrating Joan Didion - but to sell accessories?”, The Guardian Jan. 12, 2015, Web, retrieved Feb. $20,2015$.

Figure 24 - Barbara Moon, in "Full Moon.” Ryerson Review of Journalism Summer 2010, p. 45. Figure 25 - Barbara Moon, photo by Don Lee, The Banff Centre, in “Full Moon.” Ryerson Review of Journalism Summer 2010, p. 48. 


\section{INTRODUCTION}

The exclusive nature of couture makes it difficult for most people to imagine high fashion garments operating outside the runway, or beyond the pages of a fashion publication. Classic couture, especially when it resides in a museum or special collection, evokes distant historical references and iconic trends for the viewer, who does not necessarily connect the garment to a living body, past or present. However, as noted by Bruno Latour, "things do not exist without being full of people" (in Brown 12). Beyond what they communicate through their labels or silhouettes, garments retain a connection to the bodies they once adorned, and they relate to the society in which they were worn. Couture, like any other type of clothing, exists in a symbiotic relationship with its owner. It can play an important part in its wearer's life, and may even contain imprints of the wearer's activities. This paper provides a case study of one woman's wardrobe, donated to the Ryerson University Fashion Research Collection in 1997.

This previously unstudied collection—comprised of around forty-five garments ranging from the early 1960s to the mid-1990s_-includes pieces by couture and prêt-a-porter labels such as Balenciaga, Dior, Pierre Cardin, Courrèges, Pucci, Givenchy, Jean Patou, Saint Laurent and Valentino. Their owner, Barbara Moon, was a highly respected journalist and magazine editor at major national publications in Toronto, Ontario, from the 1950s to the 1990s. While she became well-known throughout her life and career, very little has been written about her, with the exception of a few obituaries published after her death in 2009. This project attempts to illuminate the biography/ies of Moon's wardrobe by examining the context in which her clothes were produced and purchased; by studying their owner and her written work; and by analyzing the socio-historical setting in which these pieces were worn and came to life. Drawing from an 
initial exercise in which Jules Prown's three stages of object analysis—observation, deduction, and speculation (24) — were applied to the garments, additional research situated them in their specific cultural and professional contexts. For the purpose of this study, the 1950s and 1960s were privileged, as this period corresponds to Moon's writing career at Maclean's and most of the time she spent writing for The Globe and Mail, two of the most prominent Canadian publications at the time. It is also worth noting that a majority of her donated garments date from the 1960s and 1970s.

To contextualize the material culture, textual and discursive analyses conducted for this study, this paper also examines historical couture consumption in a Canadian context (Toronto), issues around gender and journalism, sociological approaches to fashion, and theories around glamour. It aims to shed light on the life and career of a well-known, yet ultimately mysterious author and editor through the materiality and narrative power of her clothing, supporting Diana Crane and Laura Bovone's assertion that "fashion can be conceptualized as an example of a broader phenomenon, the creation and attribution of symbolic values to material culture." (320) Rather than serve as a simple vehicle for Moon's self-presentation, or the communication of her identity, her clothes were representative of a sometimes complex process of identity formation and expression, one that was surprisingly closely linked with some of the themes she explored in her articles.

This study attempts to illuminate points of convergence as well as certain tensions found between the clothing Moon chose to buy, wear, and donate, and the themes she wrote about; similarities and contradictions between material objects and her written words. This study explores how clothing is used, especially by women, to negotiate various roles-both social and 
professional—and the fundamental part played by fashion in identity construction and impression-making. I have taken into account sociological writings about fashion, notably the works of Pierre Bourdieu on the subject of cultural capital, and Erving Goffman on selfpresentation. These two authors were publishing their theories at the same time as Moon was working as a prominent journalist. The society they wrote about would have been relevant in understanding the way Moon wore clothing and used fashion to present herself and negotiate her identity in the workplace. This projects adds to the literature on how Bourdieu's ideas are applied to fashion-considering both what he has written about couture, as well as the way others have related his theories to fashion. It seeks to understand how a woman like Moon would adhere to, and perhaps even challenge, some of his ideas.

This project proposes professional glamour as an embodied practice, one that allows wearers to perform unique versions of glamour in specific contexts. Fashion editors were traditionally known for their glamorous appearance, however 'regular' journalists such as Moon also engaged in a process where fashion, couture and personal appearance were used to further their career and forge a distinct professional persona. While the concept of glamour is traditionally associated with celebrities such as movie stars, this paper suggests that it can also be performed by highly skilled professional women to assert themselves in the workplace and challenge gender expectations. This study attempts to reframe the concept of glamour to consider it as a highly performative, subjective, everyday experience for women. One that can be take place in a variety of contexts - such as the workplace - that would seem, at first glance, to be unlikely, even impossible settings for glamour. 
The performance of Moon's clothing in a professional context is significant for the purpose of this study, as this is where she made her most lasting impressions. Part of Moon's reputation as a writer and editor can be directly linked to the way she presented herself using high fashion objects. She owned a fascinating range of garments that all came together to create a glamorous, if slightly unconventional, personal collection. This paper seeks to redefine the ideas around professional fashion, especially as it is experienced by women. Most people are familiar with John T. Molloy's Dress for Success books of the 1970s, manuals that helped men and then women navigate sartorial codes in the gendered corporate sphere. The female business uniform promoted by Molloy, which eventually became known as the power suit, still symbolizes notions of competence and influence for women in the workplace, and it relies heavily on conformity. However, years before the publication of Molloy's manual, women were already entering typically masculine environments like journalism and negotiating their professional identities through fashion in their own unique way.

Material and textual approaches were combined to illustrate the complementary nature of both types of analysis. While a focus on fashion is often considered to devalue the professional contributions of individuals, especially women, this project seeks to challenge that proposition by demonstrating that clothes cannot be separated from the social and professional bodies that wear them. On the contrary, they can represent a powerful tool for a greater understanding of someone's life and work. Moon's wardrobe helped illuminate the themes found in her writing, but an examination of her written contributions also provided a deeper understanding of her clothing. Rather than simply support pre-established theories, objects, when positioned "in a 
dialogue with methodologies and narratives" (Riello 43) can also actively participate in communicating the different facets of their owners. 


\section{LITERATURE REVIEW}

\section{Couture Consumption}

Barbara Moon's donations to the Ryerson Fashion Collection include some of the most sought after designer labels from the early 1960 s to the mid-1990s. These garments reveal Moon's decades-long engagement with, and appreciation for, high fashion. Unlike today, where high fashion products are readily available online and may be purchased from various retailersincluding individual designer boutiques in Toronto - when Moon bought most of these garments, couture clothing was available only at the most exclusive local boutiques and department store salons. Alexandra Palmer's analysis of the postwar couture trade in Canada is useful in examining the context in which these clothes were bought and worn.

In Couture and Commerce, Palmer describes the couture consumption experience for Toronto women in the years between 1945 and 1960. Although this period of analysis predates the purchase of the donated artifacts by a few years, it remains relevant in understanding the meaning of couture, as well as how it was consumed, in a Canadian context. Couture clothing in the 1950s was characterized primarily by its elegance and exclusivity. In Toronto, women could purchase couture garments in stores such as Holt Renfrew, Eaton's and Simpson's, which replicated the "rarified European luxury setting" (Palmer, Couture, 58) of the Paris couture salons, complete with knowledgeable, taste-making vendeuses who formed intimate relationships with their elite client base (Palmer, Couture, 55). Indeed, many of Moon's garments include labels from these stores, Holt Renfrew being the most prominent. Out of 17 garments with a specified local boutique label, 14 came from Holt Renfrew. In this section I will focus on two 
designer labels with special significance-Balenciaga and Dior. Both were considered the epitome of couture in the last years of its 'golden age' in the 1950s and 60s.

Balenciaga was regarded as the most exclusive label in Paris, not only because it sold the most expensive products (Golbin 17) and appealed to the richest clientele (Palmer, Couture, 42), but also by virtue of its business operations and relationship with the fashion press. Cristóbal Balenciaga refused to produce ready-to-wear collections, and attempted to closely control the image of his house and products by limiting publicity (L. Miller 78). Exclusivity was an important part of the label's business model. To prevent piracy, Balenciaga showed his collections to the press four weeks after they had been unveiled to buyers-after all the other couture houses had staged their presentations - a practice that guaranteed the label exclusive space in influential fashion publications such as Vogue and Harper's Bazaar despite being a source of frustration for fashion journalists (L. Miller 76). Marie-Andrée Jouve, former archivist to the house, argues that "[a]t the start of the 1960s Balenciaga's supremacy was unquestioned." (100)

In the fifties and early sixties Cristóbal Balenciaga was often referred to as the 'King' of Paris couture by the fashion press, among various laudatory designations including the 'Leonardo da Vinci' of haute couture, or the 'Molière' of couturiers (Golbin 20). Christian Dior famously called him "the Master of us all", but also stated that "[h]aute couture is like an orchestra, whose conductor is Balenciaga. We other couturiers are the musicians and we follow the directions he gives." (L. Miller 16) Despite this established, distinguished reputation, Balenciaga's clientele included professional women, along with more traditional society figures. He considered the issues of time and busy schedules when designing simplified silhouettes, as well as incorporating 
more practical elements - some of which will be examined in the context of this study — into his clothing (L. Miller 41-44). His functional, pared-down designs could be worn at work, or for an elegant evening out, a versatility that surely appealed to a woman like Moon, whose wardrobe includes daytime and evening pieces that range from classic and understated, to glamorous.

Dior's prestige in the post-war years is also well documented. "Dior's first collection was an unqualified success, and he achieved a renown that has arguably been unmatched by any designer since." (Parkins, "Nostalgia", para. 2) The label, both under its founder Christian Dior and his successors, Yves Saint Laurent and Marc Bohan, was widely influential in setting trends, and it epitomized European luxury. Moon donated 4 Dior pieces from the 1960s. Even though the brand was licensed in a way that made it accessible to a variety of consumers across different economic classes, and enjoyed great financial success, it was able to maintain a high level of cachet and cultural capital; its elegant aesthetic 'transcending' such market considerations (Parkins, "Nostalgia", para. 3) and alluding to a distinctive, tasteful French tradition (Pochna 13). Just like Balenciaga, Dior was considered to be an artist, the values of his aesthetic vision and his craft superseding his status as a businessman. The designer's personal 'impeccable taste' in both design and all aspects of stylish, elegant living (Palmer, Dior, 102), extended to the prestige accorded to the label both under his direction and under Saint Laurent's, after Dior's death in 1957. As argued by Marie France Pochna, the Dior name still represents "a sort of perfection of discretion, elegance, femininity, and taste.” (5)

Givenchy, another designer that gained prominence during that period, and was closely aligned with both Dior and Balenciaga, is also represented in Moon's collection. She donated 3 Givenchy dresses, from the 1960s and 1990s. In the 1960s, the designer was known for dressing 
Audrey Hepburn in some of her most iconic, elegant looks, including the black dress she wore in Breakfast at Tiffany's. From the early 1950s, Cristóbal Balenciaga was a mentor and friend to the young Hubert de Givenchy and the two were in often in contact (Major para. 2). Like Balenciaga, Givenchy has been described as possessing a kind of majesty emanating from shyness (Mohrt 16); as being "almost compulsively meticulous" (66) and exacting in his work; and as designing clothes characterized by their simplicity, fluidity (72), timelessness, and attention to fabric. $\mathrm{He}$ aimed for a comfort and practicality (Join-Diéterle 91) attuned to different women's lifestyles, especially in a (North) American setting (92). "The clothes he proposes to his American customers are therefore always perfectly suited to their needs. Though well-to-do, these women are not the idle rich" (Join-Diéterle 92). Like Dior, Givenchy's creativity and elegant designsboth in fashion and in his personal life-were informed by his own embodiment of "French taste at its best" (Mohrt 201).

\section{Sociological Approaches}

In the 1950s and early 1960s Paris was still the source of most fashion information. Couture clothing confirmed a certain social standing and luxurious lifestyle for the wearer, with French style considered to be the epitome of elegance (Kawamura para. 28). As such, couture represented cultural capital for the few Canadian shops that had access to it (Palmer, Couture, 71). In addition to providing cultural capital and prestige to the boutiques, couture was also considered to be an important personal investment, similar to collecting high art (Palmer, Couture, 47). This corresponds to Bourdieu's classification of art and haute couture as forming part of the same cultural subfield of restricted production (in Rocamora 344). This analysis questions the traditional distinction between fashion and 'legitimate' cultural products such as 
music, poetry or philosophy (Bourdieu, "Haute couture", 196). Fashion objects are made rare, and therefore desirable, based on their label or griffe (Bourdieu, "Haute couture", 197)—the signature of the producer. Bourdieu describes this as a kind of magical or alchemic act, in which the social value of an object is increased without its physical properties being modified ("Créateurs" 219). While the labels in Moon's wardrobe certainly would have carried prestige based on name recognition, a close examination of her clothing - which will be detailed in Chapter 4 -reveals an intrinsic, material quality to her clothes that would have distinguished them from non-couture garments. Details such as the fabric, construction, aesthetic, drape and durability of her pieces were embedded in the objects, giving them a concrete, long-lasting material quality in addition to their socially determined value. This could potentially challenge, or at least add to Bourdieu's assertion that couture's desirability is largely determined by labels.

Also linking fashion with more traditional notions of 'taste', in 1967 the famous Hollywood costume designer Edith Head compared dressing appropriately to being a connoisseur of fine wine, building on this idea of individual fashion choice as cultural distinction (207). The European, specifically French, provenance of many of Moon's garments would have conferred them a special rarified status. As argued by Georg Simmel in his 1904 essay Fashion, the foreign, or immediately unattainable nature of fashion objects is what makes them appealing to many consumers (and observers); a garment's 'exotic' origins signal the exclusiveness of its wearer (545). As such, applying Bourdieu's concept of the habitus, an individual's perceived level of distinction or 'good taste' is often communicated through the dressed body (Entwistle, Fashioned Body, 51), especially when his or her clothes are imported, thus exclusive. 
Balenciaga designs, specifically, were associated with a particular kind of prestige and considered to be timelessly classic (Jouve 59) in the 1950s and 60s. Along with Dior, Balenciaga held what Bourdieu refers to as a 'monopoly of distinction' ("Haute couture" 202) in the couture world. In Fashion-ology, Yuniya Kawamura describes the potential of fashion to communicate an individual's image, and its capacity to secure approval or respect for the wearer by projecting their level of sophistication, evaluative judgment, or elegance (para. 14-16). This is an elaboration of the themes put forward by sociologists such as Erving Goffman who, in his 1959 publication The Presentation of Self in Everyday Life, highlights the importance of appearance management in modern social interactions. Goffman describes the "personal front" as an individual's social performance — combining appearance and manner-which comes to define him or her in a generally fixed fashion for a given audience (22-24). The question of setting is important in Goffman's assessment. When individuals enter unknown settings or undertake new tasks, they may come across pre-established, 'acceptable' social fronts and expectations that need to be understood and negotiated (Goffman 27). Referencing Kenneth Burke, Goffman also addresses the notion of social distance as a way for individuals/performers to create a sense of mystification for their audiences (67). Both of these concepts will be examined in more detail in following sections, especially with regard to Moon's position as a professional woman and journalist.

Kurt W. Back describes the consumer's use and display of fashion in various settings as a creative occasion in itself (3-4); beyond the production process, cultural creativity is established through the wearer's interpretation of fashion, as well as its reception by the intended audience (in Kawamura para. 1). Back defines style as "a combination of personal expression and social 
norms, influenced by dominant values" (6), highlighting the individual negotiations required in everyday image-making. Herbert Blumer, writing in 1969, described this process of image and impression-making as a deliberate gesture: "On the individual side, the adoption of what is fashionable is by and large a very calculated act. The fashion conscious person is usually quite careful and discerning in his effort to identify the fashion in order to make sure that he is 'in style'; the fashion does not appear to him as frivolous." (277) Fashion in the late 1960s was starting to be recognized as a social happening (Blumer 278), as opposed to a trickle-down process where style practices were learned and adapted from the élite, or traditional fashion authorities.

Gender and Journalism

Born in 1926, Moon began working for Maclean's in 1948 as a clerk-typist, becoming one of ten assistant editors in 1950, this promotion making her of the few women who were able to progress beyond typing and filing positions at the magazine (Persaud 45). She worked at Maclean's as a staff writer until 1964, where she produced critical profiles, and developed an interest in science writing. After leaving Maclean's she contributed features to The Globe and Mail, wrote scripts for The Nature of Things, and published a book on the Canadian landscape and collective imagination called The Canadian Shield (Persaud, 45-46). A selection of her works will be examined more closely in Chapter 5. According to Fraser Sutherland, a Canadian author of fiction, nonfiction, critical works and poetry, the Maclean's of the late 1950s is considered by many to be the best Canadian magazine ever produced (219). He describes the magazine's writers at the time-mentioning Moon specifically—as a cast "that would come to dominate 
Canadian print journalism." (220) Moon was also characterized as forming part of "a future literary Canadian Who's Who" (Aston \& Ferguson para. 18) during her time at the magazine.

According Betty Friedan, the popular press in the 1950s and 1960s actively participated in creating a model, or 'mystique', that promoted married life and homemaking as the ideal avenues for feminine fulfilment (34). Although Moon did not work for women's magazineswhich, according to Friedan, were instrumental in perpetuating this idealized feminine image under the guidance of a largely male editorship (54) — general interest magazines and newspapers were also active in this kind of female myth making (124). Women writers themselves, including Friedan when she worked for publications such as Mademoiselle, engaged in this process (56). A six-part LIFE magazine series in 1948, titled "Career Girl", chronicled the life of Gwyned Filling, a young woman who had recently moved to New York City from Missouri to pursue a career in advertising. Readers were outraged at Filling's life choices but were reassured to learn, in an update six months later, that she had quit her job in order to marry one of her co-workers (LIFE, “Career Girl Marries”, in Bern).

Interestingly, Filling was around the same age as Moon, and started working in advertising the same year Moon began her work at Maclean's. In journalism, ambition and the pursuit of hard-hitting stories were often considered to be unbecoming, or unfeminine. 'Big' or aggressive personalities were discouraged, and women were often described as types, not as individuals (Mills 61). In order to gain mainstream acceptance of their work, women writers were often required to negotiate their own positions, demonstrating the necessary professional objectivity, with the positions of their publications (Beasley \& Gibbons 21). Women had to prove their credibility and legitimacy by covering topics that were respected by the 'male power 
structure' (Mills 61), even if those opportunities were rare. Moon's role as a woman in journalism implied a negotiation of her identity as a woman with her status as a talented, professional agent, a struggle women journalists were still facing decades later (van Zoonen 45).

Moon's career path sets her apart from the conventional image of postwar women journalists, and the type of work that was expected of them. In Canada, as in the United States and Europe, women were usually relegated to writing for specific women's pages in newspapers and magazines. During WWII, women had had opportunities to cover a greater variety of news stories and to advance their careers because of operational needs and a sense of emergency in men's absence (Beasley \& Gibbons 177). However, once male journalists returned to the workforce, women's contributions were once again confined to the women's sections. They were discouraged from pursuing newspaper work altogether (Beasley \& Gibbons 17) and urged to go back to domesticity and homemaking (Chambers, Steiner, Fleming 35). The editorial rationale for women's pages was that women had their own interests, usually centred around fashion, homemaking, family life, and high society events, which could all be combined in one section (Kesterton 146, Marzolf 75). These 'soft news' items are often summarized (or simplified) as the 'Four Fs': family, food, furnishings and fashion (Mills 110). Women's pages were seen as more uplifting than other news items, and they maintained a firm link between the woman and the home (Beasley \& Gibbons 177-78).

Women's pages were not an entirely negative product; in fact, they often provided a platform to discuss serious social issues — such as education, health, and welfare (Marzolf 74) that may not have been deemed important enough, or too feminine, for the 'regular' sections. They were significant in their own way, as they reflected women's everyday experiences and 
could assist in "giving women a sense of themselves" (Mills 117). They helped women journalists become experts in areas, mainly social issues, where competition from male reporters was not a concern (Mills 237). Women's sections became problematic when they implied that women were not concerned with other important local, national or international issues (Kesterton 146); that they were simply not capable of writing 'regular' news stories because of their unpredictable emotional and biological dispositions, or general lack of knowledge (Beasley \& Gibbons 17; Marzolf 75; Chambers et al. 47); or when they presented important feminist issues as a side note to entertainment or fashion stories (Beasley \& Gibbons 22-23). The segregation of women's content into specific women's sections—rebranded as 'lifestyle' or 'style' sections in the 1960s and 70s (Beasley \& Gibbons 179) — continued for many years, although it was already being commented on and criticized in a Canadian context in the late 1960s. In his 1967 book $A$ History of Journalism in Canada, Wilfred H. Kesterton-a leading scholar in the field of Canadian journalism history and law—highlighted the differences in style and content between 'regular' and women's pages in Canadian newspapers, and recognized the prevalent yet "unjustified impression" that women were not interested in the world beyond these women's sections (146). What distinguishes Moon is that she did not appear to operate simply as a woman journalist, given the publications she worked for over the years and the personal interests she explored in her writing.

Women were typically barred from "the news side" by many editors, and the content they produced was often appropriated for the regular news pages (Kesterton 146-147). Women were hired primarily as researchers, while men were in charge of writing and publishing their findings (Beasley \& Gibbons 3; Marzolf 98). In 1963, Betty Friedan wrote the following: “A woman 
researcher for Time magazine, for instance, cannot, no matter what her ability, aspire to be a writer; the unwritten law makes the men writers and editors, the women researchers." (185) Unless they had family connections, women were unlikely to advance to editorial positions (Chambers et al. 43-44; Beasley \& Gibbons 236). This practice of excluding women from the newsroom, or limiting the scope of their contributions, continued until the $1970 \mathrm{~s}^{1}$ (Chambers, Steiner, Fleming 47).

Although the content of women's pages was beginning to shift in the 1960s, as these sections started covering more serious social, political stories and feminist issues (Kesterton 147; Chambers, Steiner, Fleming 36-38; Beasley \& Gibbons 22-23), this segregation of male and female actors and devaluation of women's contributions certainly would have been widespread when Moon began her career as a writer in the 1950s. At the time, "the very phrase 'women's journalism' was a term of disparagement" (Chambers, Steiner, Fleming 37). Along with a rise in the number of women journalists in the 1960s, their contributions helped shift the general tone and topics covered by newspapers, as the industry recognized their ability to communicate ideas as women (Chambers, Steiner, Fleming 61-62). In the 1960s, life narratives became worthy news items, whereas major events had once been exclusively privileged (Mills 8). The emergence of women journalists in male-dominated newsrooms coincided with women's movements pushing for greater professional equality with regard to hiring practices, working conditions, salaries, and promotion opportunities. This included high profile class-action lawsuits against major newspapers like the New York Times and Washington Post in the 1970s (Beasley \& Gibbons 26),

\footnotetext{
1 This reference was part of a study on female journalism in the United States and Britain, but likely applies to a Canadian context as well.
} 
initiated by female staff at these publications. It would take twenty years before equivalent legal action was undertaken in Canada (Robinson 154).

The women's movement was particularly critical of mass media, and the role news played in shaping popular discourse (Beasley \& Gibbons 1-2). Although it is not known if Moon identified as a feminist or advocated for greater inclusion of 'feminine' contributions in the mainstream, high-profile publications that employed her, she worked during a time of great change for women in journalism, and in the broader professional sphere. While many female journalists of the period did not necessarily feel that they were directly discriminated against in the newsroom, they were still working in a male structure that, through a lack of female presence and mentors - female role models being particularly important for women in the industry (Mills 87) — did not incorporate women's perspectives. The notions of negotiation and ambivalence are significant when discussing women and journalism. Linda Steiner found that many women journalists, while proud of their work and membership in an institution that they described as glamorous, meaningful, and capable of inspiring reform, also felt a conflict between their jobs as reporters and their identity as women, which they felt could affect their professionalism (155-158). The expectation that news stories were to be covered in a strictly objective mannerin which a reporter's personal experience and identity were considered irrelevant — meant that any injection of personal tone, feeling, or experience by women journalists in their work would have signalled a departure from this critical standard of "disembodied subjectivity", one that was largely based on the dominant, disembodied, 'rational' male perspective (Steiner 147). Women journalists, therefore, would have had to be particularly careful not to compromise this objectivity and risk having their work discredited. 
Journalism can function as a social system, with its own power structures that engender specific feelings around individual roles and tasks (Robinson 11). Gertrude Robinson argues that, through workplace social structures, female professionals do not have the same opportunity to translate their cultural capital into economic or political influence (14). Assigning mainly 'soft news' assignments, or beats, to women, as opposed to more hard-hitting stories, represents an obstacle to equality (Robinson 38). In 1975 in Canada, male journalists still dominated over half of all beats, which represented "a formidable gender-based barrier to gaining experience in important news areas" (Robinson 39). At the time female journalists still constituted only $21 \%$ of the workforce in Canada (Robinson 37). Until the 1970s, mass publications used language that was heavily gender biased against women (Beasley \& Gibbons 296-7) and women sometimes found themselves excluded from social or networking events with their male colleagues.

In a 2008 feature about the appointment of Sarah Fulford as editor of Toronto Life magazine - the first ever woman to hold that title — the Ryerson Review of Journalism highlighted the gender divide still present in the city's top publishing positions. While women tend to hold prominent editing positions at women's interests magazines (which are economically successful), these publications are not considered to be influential to broader public discussions, as the more politically or current affairs-oriented titles are (Rose para. 11). The 'image problem' (Rose para. 8) associated with these types of publications persists, and hints at the devaluation of women's content that Kesterton was already addressing in the 1960s in Canada.

Although she did not work in a fashion specific context, there may be a parallel between Barbara Moon's professional image — which will be explored in greater detail in the following chapters - and the one usually associated with fashion editors in the popular imagination. Editors 
such as Carmel Snow and Diana Vreeland, who held top editing positions at the most influential fashion magazines of the time, Vogue and Harper's Bazaar, were fashionable women who helped establish the notion of editor-as-tastemaker (Benson para. 2), which still informs the narrative around fashion editors today. There is a resemblance between the discourses around both Vreeland and Snow - they were described as being elegant, intimidating, demanding, and well respected, while often difficult to work with - and the way former colleagues spoke of Moon. Both Snow and Vreeland personified the fashion world's "tough elegance" (Cecil Beaton in Stuart 125). While working together at Harper's Bazaar, they were known to make memorable entrances, with coworkers taking note of their impeccable appearance (Stuart 157). Snow was credited with introducing Pucci and Simonetta (two labels that feature in Moon's wardrobe) to the readers of Harper's Bazaar in the 1950s, and loved Balenciaga's designs, which she wore almost exclusively (Stuart 157, 161). She was also a mysterious figure: "Carmen was an elusive monarch. She kept out of sight, but when she appeared, everyone responded with awe." (Dwight 81). Vreeland elicited "respect, love and terror" (Dwight 86) from her coworkers.

While Moon and Vreeland worked in the publishing industry in the same era, there were fundamental differences between the two. Vreeland operated at a time where fashion magazines were adapting and responding to broader changes in fashion, needing to address a younger, working female demographic rather than older, wealthy élite audiences—social circles that traditional fashion editors were themselves members of (Benson para. 3). Vreeland herself was famously out of touch with Vogue's younger, professional female readership, considering herself primarily a woman of leisure (Stuart 259,261 ) who had "never seen the inside of an office, and rarely dressed until lunchtime" (Esten 12) before working at Harper's Bazaar. The period of 
Vreeland's editorship at Vogue also aligned with the shift in fashion from the dominance of Paris couture to the emergence of ready-to-wear designs, and the 1960s "youth market" (Benson para. 5), a change that is also reflected in some of Moon's pieces, albeit in a unique way.

\section{Dress for Success}

Barbara Moon donated a varied collection of clothes to the Ryerson Fashion Research Collection, garments that would have been worn to the office, to social functions, as well as in her everyday life. The studied garments date from a period where a specific discourse around workplace appropriate appearance for women was emerging. As women were entering the workforce in greater numbers, the tone of the fashion advice offered to them shifted. Style advice transitioned from traditional, instructional magazine articles advising women on how to dress and behave properly (mostly with the intention of gaining social acceptance and, ideally, a romantic partner) to instructions on how to present (and promote) one's self in a business setting. Considering Moon's prominence in Toronto publishing during her lengthy career, it is important to address how her professional wardrobe was assembled and interpreted by others. In the 1970s, amid greater competition for employment, some considered 'masculine', severe and classical business attire for women as marking a certain equality (Thesander 197), a look that Moon did not subscribe to.

Edith Head, in her 1967 book How to Dress for Success, reminded women that they were not unique — rather, they were "manufactured by the dozens, the hundreds, the thousands" (viii). Fashion could help women distinguish themselves from their peers, in both social and professional settings. In a telling illustration of social attitudes of the time, Head urges women to be realistic with their professional (and, by default, romantic) ambitions: “Don't set your heart on 
a job or a man you can't handle." (x) She outlines 'private secretary to the President' as a 'genuine career status' that women could aspire to (Head 11), also proclaiming "Who knows, you might marry the boss." (Head 3) Interestingly, Head advises women not to wear obviously expensive things to the office, as they need to fit in and be relatable to other women, and cannot inspire any jealousy (5).

Head's instructions are at times complex: clothes should reflect quality and taste rather than current trends (12-13) or a "slavishness to fashion" (81), but this demonstration of elegant refinement is only appropriate if a woman has already 'made it' professionally, as she needs to be otherwise relatable. Originality is key, to differentiate one's self from the other 'office girls', but this distinction should occur without any flamboyance (Head 14). Immaculate grooming is crucial, but a woman cannot look "too elegantly put together" (Head 6). According to Head, "She's my kind of person" is the ultimate compliment for women (75). The notion of other women serving as fashion references for professional dress was still prominent in the $1980 \mathrm{~s}$ - in a 1985 study on women and career dressing decisions, Rabolt and Drake found that "women friends and coworkers offered the most information on career dress" and were valuable fashion reference persons $(377,372)$.

While Barbara Moon worked through the era of the power suit— the female office uniform promoted in the late 1970s by John Molloy in The Woman's Dress for Success Manualin her early professional days such sartorial codes had not yet been defined. She does not seem to have adopted any variation of this uniform, consisting of a dark skirted suit worn with a contrasting shirt and blouse (35), at any point in her career. Joanne Entwistle defines power dressing as having structured "the career woman's everyday experience of herself" ("Power 
Dressing” 312); however the concept had not yet been identified for much of Moon's career, and she had her own way of negotiating and structuring her place in the professional world. Her fashionable self-presentation seemed to be informed — whether consciously or not—by a reinterpretation of models of elegance inspired by the fashion editor, artists, stage performers, and society figures. Power dressing implies a certain rejection of fashion, a more rational approach to dressing and a rejection of impulse buying ("Power Dressing" 322), none of which is evident in the material analysis of Moon's wardrobe.

\section{Clothes, Representation, Material Biographies}

The wearing of clothes represents, as stated by Joanne Entwistle, an everyday "situated bodily practice" ("Dressed Body" para. 4). Even for those who are not admittedly or outwardly concerned with fashion, clothing choices are an important tool in self-presentation. They can assist in understanding facets of someone's identity, as well as tracing life narratives through what individuals choose to wear in both private and public settings throughout their lives, as well as what they choose to document and preserve. Susan Kaiser defines the concept of 'minding appearances' as "the visual, embodied representation of 'who I am and who I am becoming' along with ideas, possibilities, ambivalences and anxieties with which I may find it difficult to grapple, much less resolve, in a verbal, linear, conscious manner." (para. 6) She touches on the importance of the visual cues provided by clothes, similar to what Goffman articulated with the notion of personal front, but speaks to the deeper ambivalences and agency demonstrated by individuals when they make conscious fashion decisions.

Fashion allows people to communicate (emerging) truths about themselves, with style becoming a nonverbal—and for some, easier—way to do so (Kaiser para. 9). Moon was a highly 
private person, meaning that much of what was known or understood about her would have emerged from her written work, and her self-presentation. Part of the process of minding one's appearance involves negotiating different possibilities, fluid identities as well as personal or social ambivalences (Kaiser para. 6). Anxiety forms a crucial part of women's relationship with clothing, even for those who are considered knowledgeable and are thought to possess good fashion taste (Clarke \& Miller 192-3). Women use clothing to express different, coexisting views of the self- “'The woman I want to be', 'The woman I fear I could be' and 'The woman I am most of the time"" (Guy and Banim 313).

Sophie Woodward focuses her analysis on women specifically, articulating how style preferences and women's unique biographies can be used to manage social expectations (para. 1) Clothing can be used to actively construct an individual biography (Woodward para. 9), with garments having the ability to recall various life changes, memories, or special events. Beyond communicating a person's biography, objects themselves hold their own stories. Igor Kopytoff, arguing that commodities have a cultural biography, encourages us to ask similar questions about objects as we would about people. He suggests inquiring about the biographical possibilities of an object in relation to its status, as well as the period and culture in which it existed (Kopytoff 66). He even identifies different 'career' phases for objects (Kopytoff 66), as their use changes. In the case of this study, Moon's wardrobe will be examined, and individual garments assessed as they progressed from work or social wear, to 'retired' objects in a wardrobe, to collection artifacts, to objects of academic inquiry, once they had reached the end their usefulness for the wearer (Kopytoff 67). 
With regard to workplace-specific clothing, even in more recent years, professional women have found themselves using clothing to negotiate complex identities and ambiguous spaces at work (Kimle and Damhorst, in Kaiser, Chandler, Hammidi para. 48), making sure to balance their appearance with professional expectations, without compromising how their work or intellectual integrity are perceived. As highlighted by Nancy Rudd and Shannon Lennon, feminine power is often expressed through the body, conventional beauty, and attractiveness, but this can create tension for some women who fear that they might be taken less seriously, since this kind of embodied power has historically been considered more superficial (para. 9). In a professional setting, the more hedonic power that comes through clothing and adornment can be mistrusted, as it is not considered to be as legitimate as 'real' power accrued from importance or competence (Rudd and Lennon para. 9). Moon's use of designer clothing in the workplace, including couture, is worth noting. She would have been negotiating her professional identity and authority by using a more individualistic, rarified sartorial vocabulary than most.

\section{Glamour and Feminine Mystery}

The term 'glamour' is usually employed to refer to female celebrities, particularly movie stars, exhibiting a certain type of iconic beauty and timeless elegance. The word itself, in its Latin and Scots origins, refers to both grammar as well notions of mystery, the occult and magic (Wilson, "Glamour”, 95; Gould 238). In Greek, charisma refers to light while glamour suggests something that is hidden (Gould 238). Tracing the evolution of glamorous characters in history, Wilson singles out the dandy's version of glamour as being seamless and impenetrable ("Glamour" 98). "[A] glamorous person, with his or her air of the hidden, makes others want to 
know more about him or her and makes it easy for them to project fantasies, that is, to consider hypotheses about him or her that they want to confirm or to bring into focus." (Gould 238)

This idea of distance, whether emotional or physical, is important to such interpretations of glamour. Wilson adds that "glamour depends on what is withheld, on secrecy, hints, and the hidden" ("Glamour" 100) and suggests an engaged, yet ambiguous process in which the individual negotiates what may be seen and what should be concealed (101). Ilya Parkins describes the enigmatic persona of Elsa Schiaparelli as "glamorous unknowability" ("Schiaparelli" 190), a phrase that would also apply to Barbara Moon, a woman who gained public visibility and praise, yet remained mysterious even to those who were close to her. This implies a mediation of different identities - 'true' glamour, rather than being a purely aesthetic manifestation, indicates a complex psyche (Gould 239), "intuited secrets" (Parkins, "Schiaparelli" 191) and the projection of a creative, elusive self (Gould 240).

Carol S. Gould also highlights the agency required of glamorous persons, arguing that, rather than just being a trait someone possesses and passively exhibits, "glamour has a crucial first person, subjective aspect" (237). This air of mystery, rather than being seen as something deceptive or suspicious, can be positively interpreted by others. In line with Goffman's idea around the performance of mystification, Parkins states the following: "Not only does glamour have a profoundly interior dimension, then, but it is also a social mode that sustains a relationship of active knowledge-making between the glamorous figure and her observers." ("Schiaparelli" 192)

Wilson goes on to define 'true' glamour as "icy indifference" ("Glamour" 106), a common theme in the discourse around female figures such as Moon, Snow and Vreeland. 
Glamour can be created through a combination of personality traits and the consumption of luxury clothing, however it is also dependent on a departure from convention, and on the wearer's individuality (Wilson, “Glamour”, 98), imagination, and uniqueness (Gould 246). In these interpretations of glamour, character singularity is crucial, a model that contradicts the advice for successful dressing offered by Edith Head and John Molloy, but applies perfectly to someone like Moon. 


\section{RESEARCH CONTEXT AND METHODOLOGY}

The relationship between women and fashion in male-dominated professional spheres remains complex. In most contemporary histories of journalism, a woman's fashion sense is usually mentioned only in those contexts where she is employed as fashion editor, or fashion reporter. As discussed in Chapter 2, for the influential fashion editor, clothing becomes an integral part of her aura and public persona. While in recent years academics have paid increased attention to the work experiences and specific contributions of women journalists, the process was long thought to undermine the crucial notions of journalistic neutrality and transparency—or what Linda Steiner defines as "[t]he demand for disembodied objectivity" (146-147)—by focusing on the reporters behind the news stories rather than objective news production itself. Women themselves were often hesitant to identify primarily as 'women journalists', for a variety of reasons.

This reluctance on the part of women to share their experiences has changed somewhat since the 1980s, which witnessed an increased interest in collecting women journalists' oral histories. One valuable example of this kind of scholarship is The Washington Press Club Foundation's "Women in Journalism" Oral History Project, initiated in 1986 (see Fuchs for an overview of the project and interviews). However, studies have not focused on how these women used professional fashion themselves, whether they worked for fashion publications or not. There is understandable reluctance to discuss fashion at all in such a context, given its traditionally gendered associations and supposedly frivolous character in the popular, journalistic, and academic imaginations. 
Women often feel a need to distance themselves from fashion when trying to prove the value of their work, even when they are employed by fashion publications. It is sometimes noted, or at least implied, that a woman's more intellectual contributions to the development of a publication must come as a result of a certain rejection of fashion and its superficial character. Audrey Withers, editor of British Vogue during World War II, was educated in Philosophy, Politics and Economics at Oxford (Conekin 80-83), and was said to have "little feeling for fashion" (Conekin 91). Lee Miller, a former model, muse to the Surrealists, and fashion photographer for Vogue who was eventually employed as a war reporter for the magazine, similarly came to a point where she distanced herself from fashion, remarking the following in a 1940s letter to her family: "It seems pretty silly to go on working on a frivolous paper like Vogue, tho it may be good for the country's morale it's hell on mine." (Conekin 136). During wartime, magazines like Vogue encouraged patriotic consumption practices from their readers. Whether it promoted creative ways to work around material restrictions, or urged readers to support local or national industries, the fashion press tied women's beauty habits to a larger patriotic narrative, a journalistic landscape in which Miller felt constricted, since she wanted to write about the realities of wartime outside of this narrow lens.

Conekin presents Miller's accomplishments as a writer as being the result of her departure from the codes of fashion journalism and, arguably, from fashion in a broader sense. She found her strengths in writing accounts of the war that were hard-hitting and did not conform to the content usually found in the 'glossy' pages of a fashion magazine (Conekin 138). However Miller was also said to use rich descriptions whose tones were influenced by art and couture (Conekin 139), meaning that the language of fashion informed her work even though she was 
apparently not all that interested in it, despite her extensive professional background as a model and fashion photographer. After the war, when Vogue returned to focusing exclusively on fashion, once again, Miller lost interest and motivation in working for the publication (Conekin 204) and eventually stopped writing for it.

For most women journalists, clothing is presented as an object of analysis or commentary rather than something that is experienced in an embodied, quotidian way. In a profile on Eleni Epstein — who was born the same year as Barbara Moon and served as the fashion editor of the Washington Star from the late 1940s to the early 1980s-Kimberly Voss and Lance Speere highlight the ways in which Epstein's fashion pages positioned Washington as an influential city for fashion; how her coverage emphasized the role of fashion in the city's social history; and how she acknowledged the importance of everyday workwear for the modern American woman. She had a distinct persona, but one associated with her role within the fashion journalism system: "She was a petite 5-feet-2 inches tall with an often-towering mane of black hair and became a celebrity figure in fashion journalism as much as she was someone who reported on it. She became a one-word moniker, identified by her byline of 'Eleni' and recognized for her laughter and clicking high heels." (Voss and Speere para. 14)

This project proposes fashion as an active, professional practice for women journalists themselves — even those operating outside of fashion journalism — by considering Barbara Moon's garments as the basis for inquiry and research. A focus on clothes or fashion does not necessarily discredit, as it is often assumed, the professional contributions of women in maledominated work spaces. Clothing choices are an integral part of self-presentation and social reception —especially for women, and particularly in Moon's case, as appearance and style 
became such dominant themes in the posthumous discourse around her. This study combines material culture approaches with textual and discursive analyses to demonstrate that Moon's clothing, whether this was an intentional act or not, communicated something about her as a writer and as a person, and complemented rather than devalued her written contributions. By using garments as the primary point for research, a different interpretation of her published work is possible, and a different definition of 'glamour' emerges.

Additionally, Barbara Moon's wardrobe engages us in a unique kind of fashion case study. Typically, celebrities and 'fashion personalities' are the ones whose wardrobes are studied, written about and sometimes even displayed in museums. Individual exhibitions have focused on 'women of style' such as Isabella Blow, Iris Apfel, Jackie Kennedy, Daphne Guinness, Diana Vreeland, and Princess Diana, whose clothes were displayed at Toronto's Design Exchange in 2011. Moon's wardrobe represents a fascinating intersection between everyday wear and the types of high fashion or couture garments that would be displayed in an exhibit such as Alexandra Palmer's “Elite Elegance: Couture in the Feminine Fifties", which took place at the Royal Ontario Museum in 2002-03. Moon's garments cross the artificially drawn borderline between the spheres of professionalism and glamour. Moon also represents a local figure that differed from the typical post-war couture buyer profiled in Palmer's exhibit and related publication, Couture and Commerce. As a professional woman, Moon departed from the figure of the society wife couture buyer, a type that had dominated the couture consumption landscape until then. Moon was not married until 1968 (Persaud 46), when she was forty-two years old, and after she had already personally purchased several pieces from her collection. Additionally there are no obvious references to family wealth, her parents being described as an engineer and a 
homemaker (Persaud 45). This projects focuses on Moon's professional status and identity, and their intricate relationship with fashion, rather than on the consumption practices behind her clothes.

Someone like Barbara Moon challenges Bourdieu's notion that the old consecrated couturiers are largely worn by "women of a venerable age from the highest and most established fractions of the high bourgeoisie" (in Rocamora 352). Moon was not necessarily part of the working class as Bourdieu defines it, but she does not appear to have been highly bourgeois, according to what has been written about her. Women like Moon have not typically been considered in anthologies of Canadian fashion, such as Palmer's Fashion: A Canadian Perspective, which focus on historical Canadian designers, illustrators and industry members but not on those public figures who performed fashionability and glamour in unexpected social and professional contexts.

This project began with a material culture analysis of around forty-five garments donated by Moon to Ryerson's Fashion Research Collection in 1997. Based on Jules David Prown's assertion that artifacts "can be used actively as evidence rather than passively as illustrations" (18), the garments were used as primary objects of focus that were then socially and historically situated through contextual research relating to couture, sociology, journalism, and glamour. Prown's three steps of object analysis — deduction, description and speculation (24) were essential in studying Moon's wardrobe. As the author notes, "[a]dornment, especially clothing, has, like the applied arts, the advantage of touching on a wide range of quotidian functions and of embodying a relatively uncomplicated partnership of function and style that permits the isolation and study of style." (Prown 30) 
By closely examining these clothes, their material properties, their construction, and their intended function, and attempting to contextualize them in Moon's everyday life and professional interactions - part of what E. McClung Fleming describes as 'cultural analysis' (in Steele 332)— we may get a better sense of how she was perceived by her peers in a specific professional place and time. As argued by Valerie Steele, the interpretation of objects represents one of the most valuable methodologies in the field of fashion history (327). In addition to the posthumous accounts written about Moon, her clothes communicate various meanings about her, in a way that is much more tactile and intimate than a printed image or statement, supporting Daniel Miller's argument that the "study of clothing should not be cold" (41) and should instead rely on material narratives, textures, colour and first hand observation.

The second stage of analysis consisted of an examination of selected articles written by Moon, from 1950 to 1984, when she worked for two national publications, Maclean's magazine and The Globe and Mail newspaper, and before she turned to full-time editing in the 1980s. This time period is significant, as it corresponds to an era of great change and progress (albeit slow) for women journalists, as discussed in Chapter 2. The topics she covered, as well as the style and tone of her articles, were assessed to see how they fit into the models of female journalism examined earlier. The Maclean's articles, dating between 1950 and 1964, were consulted on microfilm at the Toronto Reference Library. Moon's Globe and Mail pieces, dating from 1965-68 as well as $1983-84$, were retrieved online.

A discursive analysis of the obituaries written about Moon was also conducted. These documents contained valuable commentary on her appearance, style, and working practices, provided by individuals who once had a professional relationship with her. A concluding 
analysis, combining the results of all three stages of research, attempts to relate the study's

findings to the concept of Professional Glamour, which will be described in detail in Chapter 6 . 


\section{MATERIAL CULTURE ANALYSIS: MOON'S WARDROBE STYLE}

On the topic of clothing as material culture, Sophie Woodward summarizes the social relevance of fashion objects worn by women: "a crucial part of this materiality is that it is lived and embodied; the material relationship between women's bodies and the items of clothing they wear must always be considered as specific to social contexts" (para. 37) This line of inquiry is significant when studying Moon's donations. Most of the garments, despite their prestigious labels, appear to have been 'everyday' pieces that could have been worn in a variety of contexts, including at the office. However there is a fascinating variety in the material Moon donated. Garments range from the conservative, to the revealing, to the exquisitely glamourous. At Prown's speculative stage of analysis, it is quite interesting to try guessing in which contexts some of these outfits would have been worn, and who their audiences might have been. A selection of items will be described in detail in this section.

Moon's clothing is generally characterized by simplicity, yet with subtle, interesting details. A 1960s Givenchy black sleeveless coat dress (Fig. 1; Fig. 2, right) contains metal discs inside the hem, weighing it down, which would presumably help the dress hold its shape. Mounted on a mannequin, it acquires unexpected volume at the back. This dress looks completely different and has a more unique structure and silhouette when worn on a 'body'. While it appears quite conservative yet casual when examined flat on a table, it looks surprisingly modern and visually interesting when mounted, and would not look out of place in boutiques today. The inside of the hem seems to be hand stitched. This hidden detail suggests a level of quality and craft specific to couture or tailor-made clothing. As mentioned in Chapter 2, the Givenchy label in the 1960s symbolized elegance and exclusivity. The designer 'signature' of 
the dress, along with its subtle details in cut and finish (some only visible to the wearer) produce a garment that would have been considered sophisticated, perhaps mostly by those familiar with high fashion.

One of the most interesting pieces in this collection is an early 1960s cream coloured Balenciaga sack dress made of cloqué silk (Fig. 2, centre; Fig. 3). The dress is sleeveless, with a draped blouson at the back and a matching belt. Balenciaga's evening wear at the time is described as being quite elaborate and lavish in comparison to his more understated daytime clothing: "While he strove for simplicity and practicality in day suits, dresses and even hats, his evening creations allowed room for frivolity and excess" (L. Miller 45). This description stands in contrast to the understated nature of the sack dress, in its cut, colour and lack of adornment. Moon's choice of such a dress may have reflected the context in which it was worn. She may have had to carefully select what type of Balenciaga pieces were appropriate for her situation, and the social and professional circles she interacted with. This negotiation would have been especially relevant in Toronto, which at the time would have represented a more conservative fashion setting than other major American or European cities. One feature that makes the dress unique, and well suited to the use of a woman like Moon, is its simplicity.

Perhaps the most striking feature of the dress is the fact that several large perspiration stains are visible on it. This means it was probably worn often and, it would seem, was not always dry cleaned. The stains - some suggesting she did not wear a slip with the dressrepresent visible traces of past actions. They indicate a certain level of ease and nonchalance visà-vis the dress, a position that contradicts our common understanding of the way haute couture is worn and presented in the world. This is something Alexandra Palmer addresses in Couture and 
Commerce, noting that in a Canadian context—where couture may have been more difficult to acquire and was therefore considered more of a long-term investment—it was treasured, kept, altered and sometimes worn out to justify the cost of its consumption (220-21). Moon used something conservative, Parisian haute couture, to negotiate her space in a changing social world and workforce. Alterations — such as the restitching of buttons, hems and closures—were made to many of her garments, which may have affected their monetary value, but also help illustrate their history and their owner's long engagement with them.

The Balenciaga dress, at some point, was altered with a false hem, which added about five centimetres in length, suggesting that Moon may have worn it for several years, either through changing trends in hemlines, or as she got older. Other signs of wear are visible on the dress, including repairs made to its hook-and-eye closures. The matching thread colour suggests that these changes were made by the same person, after the dress had been worn for some time. These alterations and stains contradict the popular image of vintage couture as a collection of pristine, somewhat untouchable artifacts. They combine various signatures (Hauser 299, 310), from the original maker, to the wearer, to the individual who performed the alterations. These elements give the dress a personal, even private dimension, connecting it to its owner in a visually striking way. This specific dress also illustrates the materiality of the fashion object, the idea that body and clothes are complementary in producing a "sensually meaningful whole", as well as the notion that clothes are actualized by the body (Rocamora 355 ).

A 1964 sleeveless yellow Dior silk linen dress and yellow bouclé wool coat (Fig. 4-5) are quintessentially 1960s, both in their shape and colouring. The dress has two large wooden buttons along the waist, connecting the belt, and a series of snap button closures along the left 
side. Many of these garments have several sets of closures and buttons that are carefully concealed as to allow for practicality of wear without compromising their streamlined, elegant silhouette. A few of Moon's sleeveless dresses also include small bra strap holders, a practical touch that Edith Head had identified as being de rigueur in the 1960s: "As far as shoulder straps are concerned, the sleeveless dress has made it a must that you sew little ribbon 'anchors' in every dress so your slip and bra never show. There's nothing in the world that makes a woman look sloppier faster than a dangling shoulder strap, unless it's dirty fingernails." (171) Although women's clothing was becoming less constricting in the 1960s, the expectation remained for them to always look impeccable. Head's comments reflect the rigid, gendered codes around appropriateness that still governed women's social and professional self-presentation at the time. This standard of female perfection in appearance - both at home and in the workplace-was also highlighted by Betty Friedan and Simone de Beauvoir, who claimed that stains, bad hairdos and dressmaking flaws were catastrophic for fashionable women who, having turned themselves into objects through fashionable consumption, were therefore required to look flawless (in Goffman 236).

André Courrèges, Pierre Cardin and Yves Saint Laurent were all instrumental in defining a new era of prêt-à-porter fashion in the 1960s. All three are represented in Moon's wardrobe. Courrèges is perhaps best known for his 1964 'Space Age' collection, however the Courrèges ensemble in Moon's collection (dated between 1965 and 1970) is a camel-coloured cotton poplin coat-dress with a matching knee length panel skirt (Fig. 6). It has a bright plaid lining. While it would have been a practical, fashionable ensemble, and has modern, almost geometrical detailing on the pockets and cuffs, it is much more classic-looking and conservative than the designs one 
would typically expect from Courrèges. The designer was known for his futuristic clothing, often incorporating unusual materials such as metal and plastic in the construction of his dresses. However, in "Haute couture, haute culture", Bourdieu references Cardin, Dior (197) and Courrèges as communicators of social and cultural values through fashion. He states that Courrèges's discourse largely transcends fashion; he does not discuss fashion, but rather the modern woman who must be free, unconstrained, active and comfortable (200). His more pareddown, day-to-day designs would therefore have been perfect for a professional woman like Moon, with the features elaborated by Bourdieu engineered into his clothing.

The two Cardin daytime ensembles owned by Moon — a pink wool jacket and skirt (late 1960s), and a taupe wool dress and matching jacket (1970s) (Fig. 7-8) —are also surprisingly classic looking. Moon was obviously well versed with the designers of the moment, but had a distinct way of wearing them based on her age, and her unique professional and social circumstances. She actively engaged with fashion in the 1960s, even with more up and coming fashion houses, but adapted these designs in a way that did not fit into the dominant narrative of sixties fashion, largely centred around London and the youth-quake. Many accounts of 1960s fashion focus on the popular images of 'swinging London'; the Chelsea Girl; playful, conspicuous and frivolous consumerism; sexual revolution; mini-skirts; democratized fashion; and youth-oriented shops such as Biba and Mary Quant's Bazaar (for example, see Breward "The Dolly Bird: Chelsea and Kensington 1960-70"). This fashion scene was not at all representative of the life of a woman like Moon.

This observation does not mean to suggest that Moon did not wear any eccentric or original pieces. One of the most unusual ensembles in her collection is a Patrick de Barentzen 
black velvet evening jacket and skirt (Fig. 9) from the 1960s. The bolero jacket has a white organza ruffled collar and cuffs. This outfit combines the visual language of a woman's skirted suit, usually associated with daytime or workwear, and places it in a more formal evening setting with the use of dramatic trimming and rich materials such as velvet. It would surely have been eye-catching no matter where Moon wore it.

A Nina Ricci cape (1962-1968) (Fig. 10; Fig. 11, far left) provide the perfect example of workwear that would have produced a dramatic impression, even in the simplicity of its cut and colour. The camel-coloured cape appears shapeless but, when tied at the front, reveals different layers, panels and construction details. It is heavy and voluminous and would have created a very interesting silhouette for the wearer. While capes are worn in a variety of settings-as costumes, as part of military uniforms, or in various forms of religious or institutional dress - they may indicate a certain level of formality. Capes are also the ultimate accessory in concealment. While we often discuss how garments alter the body by constricting it, clothing also "forms a spatial extension of the body and alters our image of the body's surface and form" (Loschek para. 1). Looser, structured garments such as capes can add a sense of mystery (and perhaps, authority) to the wearer by visibly transforming the space around his or her body. Capes were fashionable for women in the 1960s, appearing on the pages of fashion magazines as well as on commercial sewing patterns, but this one, in its cut, fabric and colour, could be reminiscent of classic men's outerwear silhouettes.

The front and back pleats and kimono sleeves on a Gudule smock dress from the early 1970s (Fig. 11, second from left; Fig. 12) also add distinct touches to a simple garment. A Fabiani rust boucle wool sack dress from the early 1960s (Fig. 13; Fig. 2, left)—unlined and with 
an unfinished hem-is very original in texture, colour and construction details, including a cowl collar and fringed sleeves. Both dresses evoke classical, even vaguely medieval or monastic styles of dress. Looser-fitting silhouettes such as these were in fashion in the 1960s and 70s. However these two examples are quite interesting because on one hand, they are overly simple in shape but on the other, they include fashionable detailing that invites a second look. As with the cape, the shape of these dresses could have suggested a certain sense of modesty or mystery for the wearer, but their added construction details and textures would have made Moon stand out, especially in a professional setting.

The most classically glamourous garment in Moon's collection is a 1965 Valentino red crepe strapless evening gown (Fig. 14). The dress appears deceptively simple in construction; on a mannequin, it seems to effortlessly hang on the body. However, it contains an inner corset and boning, suggesting that a very specific posture and limited movements were possible when wearing it. The dress has a famous history. It was worn by Italian actress Virna Lisi, who was photographed wearing it in Valentino's atelier, and by the model Verushka on the pages of Vogue. The dress has been featured in two Valentino retrospectives, at the Ara Pacis Museum in Rome in 2007, as well as in the 2013 "Valentino: Master of Couture" exhibition at London's Somerset House. In 2015, the house of Valentino posted a picture of the dress on Instagram as a Valentine's Day style inspiration. Hamish Bowles of Vogue picked it as one of "The Top Ten Looks from the Valentino Archives" in 2011, describing it as follows: "The dress was designed to be worn beneath a red tulle evening coat embroidered with an impasto froth of scarlet ostrich fronds and clusters of beads. Wildly elaborate. And then you shrug it off and this startlingly pure-lined, 
unembellished dress with its sly bodice detail is revealed. It is a classic, bravura Valentino gesture that takes a woman with great presence and a sense of drama to wear it."

Moon does not seem to have owned the accompanying coat, instead wearing the dress in its more understated, yet still visually striking form. However, the fact that this dress was worn by some of the most glamorous women in the world at the time, and eventually became a consecrated artifact in the Valentino archives, confirms that Moon was acutely knowledgeable about fashion and had a very discerning eye. Even if she did not consider herself glamorous in the traditional sense, this particular dress represents pure Hollywood glamour, and would not look misplaced on a modern-day red carpet. Contrasted with Moon's more understated pieces, this dress is remarkable, and I cannot help but wonder when and how she wore it to perform her own version of glamour in 1960s Toronto.

Another notable evening ensemble is a Nina Ricci pink saw silk evening gown and jacket (1965-1970) (Fig. 15). The bolero jacket is embellished with large black plastic beads which, from afar, look like a necklace. An interesting practical detail on this dress is the inclusion of thin pads of fabric along the sleeve, under the armpit. This would have ensured that visible stains did not compromise the pristine visual aesthetic of this valuable garment, and would have helped Moon subscribe to the kind of spotless self-presentation advocated by fashion commentators like Edith Head, and criticized by authors like de Beauvoir.

Saint Laurent Rive Gauche provides two of the most surprising ensembles in the collection. The first is a white jersey halter top (Fig. 16) paired with matching floor length skirt. The top has a very low neckline and would have left the back exposed. Given the pieces' estimated production date (1980-1990) this outfit would have been a daring choice for a woman 
of Moon's age, who would have been around sixty at the time. On one hand the outfit could appear quite casual, but it may also have been worn for a night out. The level of formality of this ensemble would have been determined by Moon's accessories and what she would (or would not) have worn over it. A Saint Laurent gray wool jumpsuit (Fig. 17) from the same period looks very utilitarian, and quite different from Moon's other pieces. Both of these garments contain small holes or rips, suggesting they may have been worn on multiple occasions.

The only trousers in Moon's collection form part of a black and cream houndstooth wool trouser suit by Valentino (Fig. 18), dated from the late 1980s or early 90s. The dramatic jacket has a ribbed velvet collar and the pockets are also trimmed with velvet. This suit is markedly different from anything else in Moon's collection, in its departure from her more traditionally feminine dresses or skirted ensembles. It is the closest thing to a power suit—albeit one that John Molloy surely would have deemed too masculine — in her wardrobe. While most of Moon's clothing is distinctively feminine, her wardrobe's overall lack of overt embellishment and its reliance on subtle or interior detailing — such as diagonal darts, pocket details, beautiful square gold buttons on a Louis Féraud coat that would not have been visible when the coat was closed, curved linings, interesting collars, corsets, and belts that provided hidden support in evening dresses - are all somewhat reminiscent of men's tailoring. Whether this was an intentional act or not, Moon's use of neutral colours, rich materials and streamlined silhouettes all suggest power. Given the emerging discourse on women's workwear in the 1970s, the changing professional landscape in which Moon worked, as well as a certain blurring of formerly rigid gender boundaries in fashion at the time, these subtle details encourage reflection. 
A 1980s black Balenciaga cocktail dress (Fig. 19) made of rayon with a velvet v-neck collar includes a label from the house's George V Avenue boutique in Paris, with no additional local shop labels. This suggests it was bought in Paris. The bodice of the dress is somewhat sheer and, while it is a classic looking dress, it might not have been an obvious choice for a woman in or nearing her sixties, when Moon would have purchased it. As elaborate as Balenciaga evening dresses could be, the two owned by Moon are noticeably sleek and simple, with no decorations or unnecessary details. One is cream coloured and the other black, but fabric textures in both dresses add an element of visual interest to their otherwise simple silhouettes.

A Holt Renfrew pale green quilted top with matching knee-length skirt (1985-1995) (Fig. 20) in a boxy, structured cut, appears very simple but the quilted pattern adds visual interest and makes it look classic yet very much of its time. This is one of the ensembles that look most different on a mannequin, which gives the seemingly casual fabric and somewhat drab colour of the suit a more 'dressed up' appearance. A floor length navy blue wool evening dress, from Holt Renfrew (1990-1996) (Fig. 21; Fig. 11, far right), appears very sleek and minimal from afar, but a closer look reveals a large zig zag pattern along the waist seam.

The aesthetic nuances in Moon's wardrobe do not immediately jump out at the viewer; rather, they require reflection, close observation, and a certain knowledge of what makes a garment valuable (both materially and culturally). These subtle details - thin, gauzy linings in the Dior pieces, the floral lining of one Cardin suit, hand sewn or decorative stitching, ribbon and lace trims, decorative buttons, hand written labels indicating French and Italian provenance-all highlight the refinement of detail and materials that define couture consumption. Cultural capital is often expressed through these subtle markers of value, and the audience's implicit knowledge 
of what makes an object desirable, rather than being communicated through more conspicuous design features. As stated by Bourdieu, such objects are meant to be admired by those who have learned to recognize the signs of what is admirable (Distinction 41). Entwistle further relates this to fashion by identifying quality — translated through proper fabrics, seams, and linings — as "the key distinguisher of class", appealing to the cultural knowledge of both wearers and readers of clothing (Fashioned Body 134). Describing Givenchy’s designs, Catherine Join-Diéterle highlights his careful use of fabrics, materials, structure, and subtle ornaments to achieve the "sober discretion" that became his trademark (148-156). Almost every piece Moon donated had points of visual or textural interest, details that would have been seen and interpreted differently depending on the viewer's own social background, but also as a result of his or her distance and personal relationship with Moon. She would have produced various impressions on her audience —at first glance, while entering a room, while sitting down in her office, or while socializing. Questions of distance and mystery, as the discursive analysis will demonstrate, were central to how people viewed Moon throughout her life. To truly appreciate many of these garments when they were actually worn, one may have had to be close to Moon — both physically and personally — something that was unavailable to most people.

With the exception of a few eye-catching pieces, Moon's wardrobe works as a rather coherent whole in its colours, textures and silhouettes. Her garments, as a collection, exude a sense of fashionable awareness and effortlessness; the kind of style unique to people with cultural knowledge. Their wearer's sophistication and elegance may have been acknowledged by many, and this visual performance may have required much personal or financial effort, but this effort was never visible, at least to most people. The clothes just appeared to form part of the wearer, a 
natural, permanent component of Moon's identity, of her lifestyle, complementing her body, her mannerisms and her speech as bearers of her socio-cultural status (Entwistle, Fashioned Body, 134). Moon's wardrobe is representative of the fashion of her time in a sense, but in another it is highly personal, and unique, and is modern in a way that also borrows from more old-fashioned codes of elegance that she adapted to her own life. Some of her clothes-especially her evening wear-were surprisingly revealing given the age she would have been when she bought them. Her clothing choices as a whole suggest a combination of awareness, rejection, and ambivalence toward social and fashionable conventions, themes that will also become apparent in the survey of her written work.

Moon's garments were first produced as commodities, products that could communicate the values associated with haute couture, but also the ones specific to their houses, such as elegance, timelessness and exclusivity, and even more modern, avant-garde messages in the sixties. How did the identity of these clothes change along their lifetime, or through the different phases of their 'careers'? (Kopytoff 66) Day dresses by Givenchy, Yves Saint Laurent and Christian Dior, dated from the same period, revealed similar wear patterns, torn linings, underarm stains and loose fastenings. The stains and signs of wear contradict the notion of distant glamour, they illustrate the tension between fashion as a disembodied visual phenomenon and as an everyday, active practice. Many of these garments may have been worn at the office, on a regular basis, through the various phases of Moon's career progression. While she may have only worn some of these clothes during the evening, or for special events, these settings may have represented different creative occasions and opportunities for the performance of her clothes, 
complementing (or perhaps, in some cases, even challenging) the professional image she projected at work.

The garments' status as couture or designer pieces is also significant. This is what guaranteed their continued existence as special collection objects after they were donated. Their inherent and attached value (Prown 20), dictated by their labels' status and prestige at the time of their production, played a part in securing their survival and conservation in a university setting. It is important to note, however, that going through the listing of Moon's donations, some objects were appraised at prices that seem quite low today, even considering inflation since 1997. The market value attributed to some of these garments reflects shifting ideas associated with vintage couture, and the stigma around vintage clothing that still existed 18 years ago. Some of these pieces would likely sell for significantly more today.

The most expensive outfits at the time of appraisal — the beige Courrèges suit and the red Christian Dior dress-were likely appraised based on their labels, materials, and the condition of the garments (Dior pieces were generally priced higher, likely given the brand's history and general prominence). The Valentino evening gown was only appraised at $\$ 225$, and the Balenciaga cream dress and Givenchy black dress at $\$ 50$ and $\$ 25$ respectively. The variety of labels found in Moon's wardrobe is also important. She appreciated the classics but also lesserknown designers and labels such as Fabiani and Simonetta, Louis Féraud, de Barentzen, and Gudule. She wore French and Italian designers exclusively—Paris, in the popular imagination, would still have epitomized traditional luxury, craft expertise, and "the natural haunt of the cultured and elegant woman of leisure" (Breward, "Fashion Capitals" 172). The fact that Moon combined French labels with Italian ones-Milan having only recently emerged as a fashion 
capital (Breward, "Fashion Capitals" 209) — may have helped shaped her personal aesthetic as someone who was neither a woman of leisure, nor a young fashionable Chelsea Girl.

Interestingly, Moon did not own (or at least donate) any Chanel pieces. Surveying her wardrobe, as well as her written works in the next chapter, one could speculate that she would have considered Chanel suits, at the time, to be a little too overtly bourgeois for the modern Toronto context in which she lived and worked. While most of Moon's clothes appear to have been bought at Toronto boutiques, some seem to have been acquired in Paris, which would have made them even more culturally valuable. As argued by Bourdieu, the cultural products that hold the highest power of distinction are those that suggest a certain quality of acquisition, and by extension, signal the intrinsic quality of their owner, as this investment exercise requires time, money and effort (Distinction 320).

When Moon donated these pieces, they had reached the end of their career as garments, the end of their usefulness for the wearer (Kopytoff 67). In this latest period of their life, the objects' meanings had shifted, as they became historical records rather than wearable garments. Moon was a very private person but she recognized the value of these clothes as documents to be preserved. She did not ultimately explain her decision to donate parts of her wardrobe to the university. Whether she did so as a means of conveying her biography, or because she simply recognized the value of these garments as designer pieces, they are still artifacts that ended up comprising a material archive around her life, in addition to her written legacy. The signs of wear and alterations visible on Moon's clothes add a personal dimension to these objects, one she surely would have been aware of. The use of clothing as a personal documentary practice is a largely gendered process. " $[\mathrm{W}]$ hen women are ordering their clothing, they may also be ordering 
their lives and their biographies in order to make sense of their current identity." (Woodward para. 9) Moon's appreciation for fashion lasted until late in life; her husband joked that she agreed to move to their country home after retiring, even though there would be no Holt Renfrew out there (Persaud 49). Although it is unclear if Moon was fully aware of the impression her clothes made on the people she encountered throughout her life and career, the fact that she chose to donate them to an institution such as Ryerson suggests that she wanted to show someone how much she appreciated and valued fashion, at least on a personal level.

At this stage, Moon's clothing has also "ma[d]e salient what might otherwise remain obscure" (Kopytoff 67) about its former wearer, offering glimpses into her relationship with her clothes, and her embodiment of them, that were not evident in the general commentary about her elegant appearance. Arjun Appadurai argues that "[e]ven though from a theoretical point of view human actors encode things with significance, from a methodological point of view it is the things-in-motion that illuminate their human and social context." (in Brown 6) Moon's clothing, in the context of this research project, did exactly that. Examining pieces from her collection, made some of the observations written about their owner-which will be examined in Chapter 6 —even more resonant. 


\section{WRITTEN WORKS: MOON'S STYLE ON THE PAGE}

Moon's career as a journalist spans over thirty years, during which she worked both as a writer and assistant editor at various publications, before turning to full-time editing at Saturday Night magazine in the 1980 s. Although she gained a reputation as an exacting, sometimes difficult editor throughout her career, this section focuses on her own written works produced between 1950 and 1984. What is significant about these articles is that they appeared in two of the most high-profile contemporary Canadian publications, Maclean's magazine and The Globe and Mail newspaper. At a time where women were struggling to make a place for themselves in journalism, and often had their contributions either confined to the women's pages or dismissed as 'women's interests', the fact that Moon's work appeared in the pages of such prominent publications - and that she was listed as an assistant editor at Maclean's for the first time in 1950 at the age of twenty-two-is noteworthy. Over 100 of her articles were scanned to establish what kind of pieces Moon wrote, which topics she was asked to cover, and the personal tone she conveyed in her writing. Her work was then situated in the literature on gender and journalism, to see how she corresponded to - and challenged - the profile of the typical woman journalist of her time. I paid special attention to the way she covered topics such as class (including questions of belonging, and tensions around social expectations and rituals); French-ness as cultural capital; as well as appearance, elegance and glamour. Moon's writing was very much engaged with Toronto, and it provides a fascinating glimpse into a changing city, and her own place within it (despite her position as an 'objective' journalist).

Moon's earliest pieces for Maclean's are surprising in their subject matter. Her first published article, in 1950, was about the murder of a Canadian gold miner in the Bahamas. She 
also wrote about the first ascent of Mount Logan (the highest mountain in Canada), and contributed articles on the Western province of Alberta, covering topics such as the badlands, the Chinook winds, and the leader of the Social Credit Party — a provincial party founded on the principles of production, consumer purchasing power, and conservative Christian values. Then, after 1954, she seems to have been assigned pieces that were more typical of 'women's journalism' of her time. This could be a delayed (or continuing) manifestation, in a Canadian context, of the postwar trend for women journalists to revert to feminized content, as identified by Betty Friedan. Moon began covering topics such as weight loss machines, consumer protection agencies, education, illiteracy, poverty, and rock 'n roll. She also wrote several profiles on television and theatre personalities, both male and female.

In these profiles there were various references to female stars' weight or appearance, with special mention given to those women who had progressed from the "plump and crosseyed' teenager type to beautiful, graceful adults. In a 1958 profile on Laurette, a middle-aged television writer from Quebec, Moon mentions the fact that Laurette is divorced—and therefore alone, even though she is close to her daughter and has enjoyed great professional success - more than once. The author wonders: "Can she ever hope to find the happiness every woman seeks?" This was very typical of the way women, especially older ones, would have been portrayed in the media at the time. This open-ended conclusion is a perfect example of the dominant cultural narrative, as identified by Friedan, in which domestic happiness represented the ultimate aspiration for female subjects (both real and fictional). It would also be interesting to study how women were portrayed on Laurette's shows; how they were developed in relation to careers, home life, and marriage. Laurette also uses a man's nom de plume, Jean Despréz, which was 
necessary at the beginning of her career. This illustrates the gender dynamics that still characterized the discourse around female public figures. The unmarried Moon was occasionally referred to as Miss Moon in print during her years at Maclean's. This was the case during two interviews she conducted in 1958 with then-Prime Minister John Diefenbaker and future Prime Minister Lester B. (Mike) Pearson, along with two other male journalists from the magazine. At first glance Moon seems to be asking typically 'feminine' or somewhat superficial questions (on the topics of family, television, favourite books), however the male journalists are also asking similar questions, and do not seem to distance themselves in subject and tone from Moon. This is interesting and could suggest the kind of position and respect Moon held at the magazine. At Maclean's, Moon was among only a handful of women who regularly published articles.

Throughout her career, Moon was able to write on a range of topics, including provincial and national politics; Toronto universities; the death of a Canadian-born nuclear scientist in Los Alamos, an article for which she won a 1962 University of Western Ontario President's Medal prize (Persaud 45); science; urbanism; nuclear fallout; art; crime; and immigration. She would become especially interested in science and nature, leading to her writing a book on the Canadian landscape, The Canadian Shield, in 1971. This reveals a diverse career for Moon, one not defined by the limitations many contemporary women journalists faced. The following sections explore the way in which Moon wrote about specific issues. Class

Moon's writing often presents a commentary about class dynamics. In September 1954, she wrote an article about the debate surrounding the name of the mining town of Wawa, in northern Ontario. At the time, the town was divided between those who wanted to keep Wawa as 
a name, and those who wanted to change it to Jamestown, in honour of Sir James Dunn, the wealthy industrialist at the head of the company that employed most of the town's working population. Moon calls Dunn 'irascible', and highlights the fact that '[h]e has his Scotch specially blended, his Cuban cigars individually rolled and he brings his own drinking water when he pays his annual or semi-annual visit to Wawa, where he speaks of 'my people.'” In just one sentence, Moon effectively profiles an upper-class businessman who is fundamentally detached — geographically and socially_-from the people whose livelihoods depend on his business, and with whom he assumes a somewhat paternalistic role. References to upper class individuals and institutions being out of touch with contemporary society are frequent in Moon's work. She also wrote more extensively about economic development in rural Ontario in her "Rural Slum" series for The Globe and Mail in 1965, which will be examined more closely later in this chapter.

Her following piece that year, "They like being old-fashioned at the Ritz" profiles the Ritz Carlton hotel in Montreal. Its directors are French and Swiss_-"the Swiss" she claims "understand better than any other race the art of coddling the distinguished, the discriminating and the wealthy" - and are committed to maintaining Old World traditions at the small, exclusive hotel. The article explains that, while the hotel has made recent concessions to a changing clientele that now tends to come from the business world rather than the old elite, it still retains some of its anachronistic, extravagant touches. Moon describes the old-fashioned décor (including a luxury room styled in the traditional French Canadian habitant style, an exotic attraction for European visitors); the managers' painstaking demands; the wife of the general manager ("a chic Parisienne with a throaty voice, a flair for interior decoration and a taste for a 
certain flat, angry red known as Pompeian red"); and the hotel staff's attempts to maintain a certain level of decorum by asking female guests to dress appropriately and by shooing undesirables (women whose "faces are garish with paint, their eyes bright and appraising") away from the sidewalk. While other writers may have produced such a profile in a more celebratory or reverent tone, Moon comments on the Ritz's practices with humour and subtle critique. The caption accompanying a picture of the hotel's resident ducks — intended to be conversation pieces for guests dining outside—is especially funny: "To liven the garden dining area ducklings swim in a pond. The Ritz first tried snooty Brome ducks but they drowned. These are barnyard kind." She also adds that the ducklings need to be "replaced every two weeks, before they $\operatorname{gr}[\mathrm{o}] \mathrm{w}$ too big to be cute."

Similar articles about high society were written for The Globe and Mail in the 1960s, focusing on specific elite Toronto institutions. In 1966 Moon wrote two articles exploring the changing nature of the Toronto Establishment. In these pieces Moon describes a complex and ambiguous membership system for the modern-day Toronto élite, which is becoming increasingly hard to define, and finds itself in decline. After surveying what may or may not guarantee someone entry into this new Society, Moon adds her own wry commentary:

So, with their friends and their friends' friends, and the gay, wholesome families of U.S. corporate executives who've moved into the neighborhood, and the cosmopolitan ex-Guardsman whose wife has two ancestors who signed the Declaration of Independence, and the old schoolmates re-encountered on cultural committees, and a celebrity if she's vivacious and her manners are good, and a worldly bachelor or two to make up the table: to the Royal Winter Fair ... to O'Keefe opening nights ... to the Hunt balls ... to the Op-Pop party at the Art Gallery ... to the Stratford first nights ... to all the fashionable events you read about in the papers. 
Interestingly, Moon wrote several pieces about Stratford actors for Maclean's, as well as an article about the aforementioned Op-Pop event for The Globe and Mail the previous month. She seems especially critical of rich society mothers, whom she often calls 'matrons'-a term she uses in several other articles, sometimes paired with the qualifier of 'Rosedale', a historically affluent Toronto (WASP) neighborhood. She refers to these women as wearers of "French frocks from Creed's", a boutique Moon frequented herself. She quotes two mothers, who describe organizing dances to introduce their daughters to successful young men. One compares their efforts to 'community service'; a way to teach young ladies proper etiquette. The other argues the need to be 'organized' with such a campaign. After both statements, Moon repeats the terms 'community service' and 'organized' in italics—a simple yet effective way to illustrate the absurdity of the women's comments. Another segment of the Toronto elite profiled by Moon favours martinis and 'English nursery desserts' as well as tailor-made English suits. "The ticket is a certain town-and-country not-quite-smartness and a dressmaker's name to drop", for this type of society wife.

Moon also wrote about exclusive gentlemen's clubs in Toronto, 'anachronistic' institutions that modeled themselves after traditional London clubs, and tried to reproduce their inherent mystique. In a 1965 article about the recently founded Massey College—an exclusive residence for male graduate students of the University of Toronto, modeled after Oxford's Balliol College-Moon describes the ambivalence some students feel toward the college's 'genteel' style and protocols. Some refuse the maid service (an attempt to challenge their 'implied privilege') or do not adhere to the strict dress code. Some feel uneasy about the highly British character of the institution, and have difficulty reconciling their 'anti-luxury' and 'anti-status' intellectual 
principles with their membership in the college. As with her piece on the gentlemen's clubs - in which she pointed out she could never belong as a woman-Moon is writing from the position of an outsider, on both class and gender bases, who is afforded temporary access to this society as a result of her professional position.

In this article Moon highlights tensions and contradictions within a site of established elegance and social status. The highly exclusive (and gendered) character of this controversial new institution is sometimes at odds with students' evolving identities as modern Canadian scholars. In many of these articles Moon describes shifting ideas around luxury and status that were characteristic of her time. Moon's own academic background is also relevant in this case. She attended Trinity College at the University of Toronto in the 1940s, "the High Anglican factory that manufactures leaders and thinkers, whose students still wear academic gowns to dinner" (Persaud 45). She herself was a product of an old-fashioned upper middle-class academic institution, and worked a profession that was still highly regulated in favour of (upper-middle class) men, which may have informed the way she approached such topics.

Moon's writing illustrates an ambivalence toward the 'bourgeois' life- a term she uses frequently and seems to apply to a privileged, middle-class segment of society. This ambivalence might have been part of an attempt to cater to both publications' broad audiences. By looking at her written work alone, one could guess she was largely critical or dismissive of this scene; however, an examination of her wardrobe problematizes this assumption. Moon could only have worn the 1965 Valentino dress in the fanciest of settings in Toronto. Occasionally she would have found herself in the very circles she commented on, either through professional or social functions. While she could have used couture as a kind of élite camouflage, when required, her 
engagement with it seemingly extended beyond posh parties and into her everyday life. The fact that I looked at Moon's clothing first is significant, because it allowed for a much different interpretation of her written work. Whenever she covered an event and described the (chic) appearance of the crowd, there was often a detached tone in her writing. She was often critical of snobbery, of individuals attempting to be trendy, in a range of contexts. In the article about the Op-Pop event at the Toronto Art Gallery, she describes the discourse around one attendee's Pucci 'patio pyjamas': “The pyjamas may have been—as style decrees this season—both kooky and colorful, but when one woman so clad protested she was carrying out the Pop art theme, a bystander murmured, 'She's not asking you to notice Pop art; she's asking you to notice Pucci."' While Moon wore and appreciated high fashion (including Pucci), she did not really follow trends.

Her articles often present a subtle critique of individuals (mostly women) who dress according to specific social codes, whether they are part of an exclusive club or are attending a trendy art opening. This is significant, given the process of negotiation Moon had to engage in with her own clothing. While she likely attended soirées wearing Nina Ricci or Valentino evening dresses, she was wearing couture garments in a professional setting where they were not usually prevalent, which required a specific, deliberate mode of self-presentation. This presentation was very context-specific, as Moon also enjoyed spending time in nature, bird watching, while wearing very casual clothing (which she did not donate). When Moon criticizes what some 'bourgeois' women are wearing, she could be describing herself, which is intriguing. The difference between Moon and a rich Toronto matron, possibly, would have been the audience watching (and interpreting) these clothes, as well as the intentions and the agency with which the 
garments were worn. Moon seemed especially cynical toward Old World or affected, strictly defined elegance, but she was performing her own kind of elegance in various settings. This question will be examined further in this chapter, as well as the next, when discussing the concept of Professional Glamour.

Questions of class are also evident in the articles Moon wrote about specific Toronto neighborhoods and landmarks. In a 1960 article about St. Lawrence Market, she provides an expressive description of the different types of shoppers one might encounter there on a Saturday: "Mink-coated dowagers, trailed by liveried chauffeurs, come here to find plum-sized hot-house strawberries in midwinter; shawl-wrapped immigrant women fresh from Europe seek out eels and anise root; soft-cheeked housewives, who take an old-fashioned pride in their table, buy fresh-laid eggs from the descendants of farmers who supplied their grandparents." Here she is describing a city in transition, a meeting place where thousands of people from different classes and cultures "go marketing hand in hand with a homelier past", from the aforementioned dowagers to those who carry their purchases in burlap sacks or used shopping bags. She makes a careful distinction between the early morning shoppers- "the serious cooks and the gastronomes who make their own bouillon"- and the afternoon crowd, composed of snobbish "ardent cosmopolitans", "[g]irls in black stockings and suede greatcoats" buying carnations, young men in expensive parkas, and a jockey buying carrots for his horse. These observations reveal a certain ambivalence toward the upper-middle class, especially when it is contrasted with those whose presence at the market, at least in the context of this article, appears to be more authentic, legitimate, or inherited; immigrants who would have known these types of establishments back in Europe. 
Moon wrote about class dynamics and social mobility in the Toronto suburbs, in the 1960s and the 1980s. In 1965, she profiled the architecturally homogeneous, American-style Don Mills suburban development, which was already being labeled 'Bourgeois Nirvana' and considered by some urbanites to be 'Hell with a luxury label'. Moon explores the social dynamics within the suburb - its upwardly mobile residents engaging in typical suburban rituals, but also exhibiting a certain awareness and self-consciousness toward their middle-class existence. Moon describes Don Millers as "hip to the point of sophistication about sociological phenomena, even the ones in which they are exhibits", a descriptor that could apply to many urban groups even today. Continuing this socio-cultural observation exercise, she describes the Don Mills housewives who take art classes, always keep busy, "read The Feminine Mystique and write emotional letters to the neighborhood weekly taking sides on it" and demonstrate a concern for disadvantaged children.

In 1983, on the topic of the often-ridiculed Toronto suburb of Scarborough, she wrote "Scarberia: in praise of urban banality". In the article she claims that an "attempted duplication of chichi available elsewhere" is not the way for Scarborough or other suburbs to make a name for themselves. Instead the suburb should embrace its unique character-defined by family motels, waterbeds, 'velvet painted cheetahs', aluminum flamingoes, Harlequin novels, polyester, Hamburger Helper, surf 'n' turf, and a newly opened wedding chapel—as something that should be celebrated, or is at least crucial in defining Toronto's own pretensions by comparison. These markers of urban kitsch—and, more importantly, the fact that Scarborough has become the only place for some people to find affordable housing — are contrasted with Toronto's "current reputation as a cosmopolitan with-it sort of place: infill and gentrification, pink peppercorn 
cuisine, post-New Wave pink, bunka embroidery, billboards in Latin, the lot." The piece had a more personal dimension for Moon, as she was apparently a part-time resident of the suburb: "They call us Scarberia? Let us point out how essential a Scarberia is to any metropolis worthy of the name." As argued by Bourdieu, a central part of the affirmation of what constitutes 'good taste' is the identification of differences, and opposites (Distinction 59-60).

In her articles Moon often seems concerned with exclusivity, and with the way metropolitan habits or affectations influence popular opinion and discourse. She highlights the relational quality between big cities and small towns or suburbs, challenging the dominant notion that one should be considered better, or more culturally authoritative than the other. Even within the city she criticizes the emphasis put on "that mythical downtown arena where fashion leaders and opinion molders dispense insights and promote causes", a chic inner circle that, again, Moon would have been a part of herself, dividing her time between that scene and its cultural antithesis: the suburbs. Her writing demonstrates an engagement with Toronto, but also with small-town Ontario.

In 1965 Moon wrote a five-part series for The Globe and Mail titled “Ontario's Rural Slum" in which she chronicled an ongoing economic crisis in rural Eastern Ontario. She was careful to emphasize the sociological issues underlying the problem, noting that education, skills, and popular middle-class assumptions around poverty were important factors in the continuation of this crisis. She claimed that the legislation established to address this problem-the Agricultural Rehabilitation and Development Act—had a bourgeois name. She also described the tendency of the middle class (and government agencies) to oversimplify the question of poverty based on the perception that the poor had their own, set, occasionally reluctant behaviour 
patterns. She says: "In most studies of the rural poor there is an underlying note of exasperation: The poor do not behave as they ought, which is to say sensibly, which is to say like the middle classes." This relates to Bourdieu's notion of the habitus, which refers to the unconscious dispositions, value systems, and tendencies of individuals; tastes and lifestyles that are determined by social and educational background, as well as class status (Sturken and Cartwright 443). Rather than blame the rural poor for their reluctance to change or to participate in ambitious government development programs, Moon provides her readers with a nuanced, sociologically informed view of poverty that challenges dominant social assumptions, practices, and discourses.

\section{French-ness}

French references, as well as the idea that French-ness represents a symbol of distinction and sophistication, are very present in Moon's work. In a May 1958 profile of Montreal's Théâtre du Nouveau Monde, she suggests that the theatre company would seem exotic to most 'middlingsensible' English Canadians. This is due partly to the troupe members' flamboyant style of dress. Where the clothes worn by English-speaking actors "range from sober to scruffy", the TNM's artistic director, Jean Gascon, chooses "rich Italian-style suits, cut narrow in lapel and leg. Thus clad, with his battered nutcracker face and the elegance of a fencing master, he looks like a star." She singles out clothing, more specifically details in style and cut, as being fundamental to how Gascon projects himself. Moon was clearly attuned and responded to male versions of theatrical elegance. In a follow-up article on Gascon in 1963, she calls him "stylish, vital, exuberant" both on and offstage, and likens him to a broad-shouldered musketeer fit for a "romantic rescue by 
moonlight". At first read it is unclear if Moon is describing Gascon in performance, or in his personal life, which highlights how fundamentally performative his elegance was.

Even with his weathered physical appearance, he still manages to exude elegance, and to embody a certain star quality, through his clothing. Another actress, Denise Pelletier, "was chosen one of Canada's ten best-dressed women" the previous year. Moon describes the company's actors as temperamental, whimsical, passionate, and very particular in their tastes for French food and wine. She again contrasts them to their anglophone counterparts: "Let Englishspeaking actors stay in Toronto, be businesslike, put up with blasé English audiences, live private lives, eat English-style cooking, worry about money and pretend they're sane, normal people just like everyone else. This sort of thing is not for the TNM players." Moon was not alone in her assessment of the TNM's distinctively French character. She quotes a 'Toronto matron' who, after struggling to explain what makes the company so unique, settles for "They're so ... so French."

The same year, Moon wrote her profile on Laurette, whom she describes as 'fiery', extravagant in style and mannerisms, and as embodying a "tempestuous, entirely Gallic femininity." Laurette "dresses with actress-y elegance and is famous for her massed arrays of bangles, her four-inch cigarette holders, her smoked glasses and her headgear", theatrical hats that she repurposes herself. In both of these cases, the idea of French-ness-even in its specific Canadian version—-lends a certain cachet to Moon's subjects, one that may or may not be understood by a mainstream Canadian audience. By communicating her appreciation, or at least her recognition, of these specific markers of distinction, Moon subtly confirms her own cultural 
capital (as well as Maclean's) to her audience. She also seems to find appealing individuals who perform a very specific kind of cultural elegance, both on and off the stage.

France was long recognized as a center of artistic production and authority; this would have been especially true in the 1950s and 60s. In a 1961 article on the recent popularity of modern art in Toronto, Moon relates the anecdote of a society surgeon who returned a recently purchased painting by local abstract artist Harold Town, when "he remembered that he collects only paintings of the fashionable French school." What Moon does in her profiles on the TNM and Laurette is to transfer this notion of cultural capital from artistic products themselves - such as art, literature, music, or even couture clothing, in line with Bourdieu's ideas in "Haute couture, haute culture"-and she applies it to self-presentation, behaviour and aura in a more general sense. This will become especially relevant in the next chapter, which considers the discourse around Moon's style and personality.

Moon also uses French words in some of her articles. Writing about a young Chatelaine employee who became stuck in an office elevator overnight, Moon describes her as having a 'retroussé prettiness'. Referring to a ballet dancer pouting as she discusses her busy work schedule, she uses the term 'moue'. In one of the 1966 society articles, she describes the 'rich amusing parvenu' of the new, socially ambitious local élite, and deems an interest in military social life to be 'recherche and square'. She describes the Québécoise singer Fernande Hudon (who will be discussed in the following section) as a 'cabaret diseuse' using even more specific language than the presumably better-known expression chanteuse in this context. By using these terms casually and assuming that readers will understand them, this is a subtle way for Moon to 
add a certain layer of refinement and cultural authority to her texts. French references may have been used, and interpreted, in a similar way in her wardrobe.

\section{Glamour and Sophistication}

Perhaps the most fascinating article I found was a 1963 piece titled "Who's sophisticated anyway?" in which Moon tries to define the traits that make someone sophisticated; first by asking others, and then by reflecting on the topic herself in a very personal, subjective and amusing way. Despite the almost satirical tone of the article in some parts, certain markers of sophistication she describes would have applied directly to her, if not at the time of writing, then later in life. This suggests she either considered herself sophisticated, or would use these guidelines (whether she was serious about them or not) as a sort of model for future sophistication. Moon initially finds six different definitions for the verb 'sophisticate', including to mislead or to make artificial, giving the term possibly similar connotations of deceit as the word glamour, with both occupying a fine line between positive valuation and deception. Age seems to be defining a characteristic of the sophisticated; most people apply the term to individuals who are older than them.

Studying uses of the word both in print and in conversation, she found the term was largely applied to visual, social or cultural forms of behaviour and rituals, including "food, drink, languages, conversation, manners and the arts. Also, fashion and the intellect." She then lists Dead Giveaways that indicate a person is unsophisticated. One of these is to "have nothing wearable in your wardrobe but clothes less than four years old (for women)". This comment relates to the notion of timeless elegance and 'investment pieces', ideas promoted by many fashion commentators both at the time and in the present day. It implies a rejection of fashion 
trends, and an inherent knowledge of what constitutes quality. In essence, this observation signals a certain level of cultural capital evidently possessed by Moon, considering the clothes she owned and how long she kept, altered, and cared for them. It also alludes to the concept of having style — something that is innate, long-lasting —over being fashionable, a condition that might be considered more frivolous and temporary.

Having a high voice, according to Moon, is also unsophisticated. She was a smoker for many years and was known, at least later in life, for her "distinctive husky voice" (Persaud 47). In order to be sophisticated, women should also be at least ten pounds underweight. This observation may have reflected the beauty ideals of the time, but would have also applied to Moon personally who, based on the analysis of her wardrobe, was quite svelte. Moon also recognizes the importance of effort in the pursuit of sophistication, comparing it to the sociological concept of upward mobility —as a person becomes more sophisticated, so do their standards of sophistication, which constantly need to be maintained or revised. She continues: "By seventeen I had added the notion of travel, intrigue, suffering, mysterious adventures and iconoclasm to my idea of sophistication." In addition to intrigue, mystery, wit, and subtletytraits that certainly applied to Moon and will be explored in the following chapter-she adds poise as a marker of sophistication. While she used to think that one could pretend to be poised "by looking inscrutable [...] and bluffing your way through unfamiliar situations", she no longer believes that pretending is sophisticated. Sophistication remains, however, something that is quite performative and relational. One is only sophisticated to the people directly below them, either in age or on the sophistication scale, and it is possible to give the impression of sophistication 
through concrete gestures and manners, whether they be deceitful or authentic. Moon argues that the following things cannot be sophisticated:

suburban living, Hilton hotels, corsages, shrimp cocktail, Rotary, fabrics woven with Lurex thread, Pink Ladies, Baptists, 5BX and 10BX [basic exercise plans developed for the Royal Canadian Air Force], the Prairies, Christmas cards containing family snapshots, canaries, indoor bowling, rhinestone buttons, budgets, sports cars, the use of middle initials, family outings, colored telephones, Niagara Falls, individual wooden salad bowls, professional interior decoration, all motorcar accessories, any form of plastic slipcover or carpet guard, and leaving the cellophane on lampshades.

Even though this list is probably not meant to be serious, it reveals a certain level of cultural knowledge on Moon's part. The reader could assume, by reading the list, that Moon does not own any of these items or participate in any of the activities enumerated. However, reading the rest of her work, being aware of her unease with overly formalized or established codes of elegance, and knowing, for example, that she eventually lived in the suburbs at least part time and would defend many of these things as culturally legitimate, all suggest that Moon engaged in a constant process of negotiation with regard to markers of sophistication. She concludes her article by presenting a nominee for an 'Outstanding Canadian sophisticate' designation. The woman in question, Fernande Hudon, is twenty-eight, French Canadian, fifteen pounds underweight, bilingual with a husky voice, well-traveled, she "dresses with notable personal authority in a Gallic tradition" and enjoys "steamed hot dogs, cheeseburgers with French fries, and red wine." While this description may not, at first glance, register as sophisticated by the standards outlined above, Moon considers her engaging and the most charming of all nominees. This implies a certain appreciation for unconventional sophistication, or at least, unique interpretations of the concept. Moon approaches the subject with humour, hinting that traditionally sophisticated individuals (and those who spend time arguing the topic) may take 
themselves a little too seriously. Being sophisticated, according to Moon, is not the same as being glamorous, a concept that she explores in two other articles.

In a 1958 piece “The stage manager who looks like a star”, Moon profiles Grania Mortimer, a glamorous woman who works as stage manager for the theatre. Although she is invisible to theatre-goers, Mortimer "is not only as glamorous as many stars onstage front and centre; she is also ranked by many experts as the best stage manager in Canada." What makes Mortimer special is not only her talent as a woman working in a traditionally male occupation, but also her poise and the authoritative air she projects, and the intimidating effect she has on actors working with her, some of whom have stopped swearing backstage in her presence. All of these descriptions will prove relevant when analyzing the discourse around Moon. As with some of her other profiles, Moon informs the readers that as a younger woman Mortimer was “overweight, stolid, shy” but that seven years later "she is svelte, self-possessed.” This woman's glamorous character is not so much a result of the clothes she wears, but rather it operates through her physical mannerisms, her thinness, her calmness, and her general aura.

In a 1960 article titled "Four American heroes: Ruth, Hemingway, Lindbergh, Monroe", Moon profiles Marilyn Monroe, calling her look "full-blown blonde bourgeois". She highlights the fact that Monroe's adoring fans know very little about her. Moon seems critical of Monroe's brand of glamour. "Her personal additions were the tousled coiffure, the moist, half-opened mouth and the moist, half-closed eyes. She looked, well, willing." This description puts Monroe firmly in contrast with the other elegant, glamorous women Moon has written about. Monroe's image fits into the dominant discourse around women celebrities of her time. Men find her attractive, and women forgive her for this because of her difficult life narrative. Moon qualifies 
Monroe's bad girl image as having a particular resonance in North America. She claims that in France, for example, the bad girl category does not register in the popular imagination. As opposed to the some of the other 'glamorous' women profiled by Moon, Monroe's allure does not originate in her individual elegance, her poise, style, and personal achievements; it is expressed, rather, through her sexuality and its popular reception. Perhaps unsurprisingly, this does not appear to be a model of glamour that Moon is personally receptive to.

In many celebrity profiles Moon mentions spending, financial concerns, feelings of being out of place, or a difficulty affording certain things. In a 1957 profile on the young actor William Shatner — who had recently moved to Hollywood from Canada — she mentions Shatner's 'going Hollywood' celebratory spending after signing a contract with MGM, which included buying an Austin Healey sports car and drinking champagne adorned with gardenias out of a coconut. However, the article also relates a certain awkwardness and unfamiliarity felt by Shatner in his new life. Moon describes that he and his wife live in a small flat rather than a glass mansion (an expense they had initially planned but were advised against by Shatner's agent), and she ends her article on a more sober note: "In short, Shatner has found nothing in Hollywood that he can't relate to his familiar routine as an actor or to the film world he's read about. He knew it would not be glamorous. He was not really surprised to find that it was nerve-racking, occasionally lonely, often uncertain." The piece concludes with a publicity agent wondering if Shatner would "be willing to do beefcake" for a promotional beach photo shoot, underlining a crucial yet less romanticized side of Hollywood stardom. Moon also talks of stars making it 'against the odds'. Some are reluctant about fame, and some are challenging social expectations, especially as young women. Moon was always careful to inject a certain level of reality into the 
profiles she wrote. In "Portrait of a Dancer", she describes the backstage reality of ballet performances, the humans behind the artifice: "The beautiful, spare, fit stage-people are, of course, ordinary people who slump and scratch as soon as they reach the wings, who mop the sweat with towels pinched from their hotel rooms and chew gum and speak in the accents of Yorkshire or Pimlico."

In a 1965 article about art 'happenings', where Moon was tasked with attending a happening and reporting her findings back to the Globe and Mail readers, she seems to deliberately separate herself from the artistic crowd who knows about these things. She asks "a Chelsea beatnik of [her] acquaintance, who had assisted at several Happenings-by-invitation (and thus contrivance) back in London" to explain to her what makes a happening successful. This is interesting, considering how Moon wore sixties fashion. She was very much involved in the fashion system at the time, but she wore sixties designers in a unique way, not by following the dominant, Chelsea-influenced youth-quake trends. In a 1956 article about rock ' $n$ roll, where she tries to explain this recent phenomenon to the Maclean's readership, she seems confused and out of touch with this new music, even though she would only have been thirty at the time. Moon presents herself as somewhat of an outsider to these events or cultural phenomena, which makes sense given her role as an objective journalist, but could also be understood in terms of her age and personal style, especially when she wrote some of these articles in the 1960s. Moon's work reflects the complexity of social status and social convention, of self-presentation (especially for women), which is often directly linked with fashion.

It has been suggested that the historical contributions made by women journalists provided a human, emotional response that was generally absent from 'regular' news stories, and 
that their work led to a change in the topics covered, and approaches used, in mainstream news outlets (Chambers, Steiner, Fleming 38). While the purpose of this project is not to assess the broader influence writers like Moon had on Canadian journalism, there is a noticeably sympathetic tone in much of Moon's work, a voice that would still have been considered feminine at the time. The consciousness around class, social institutions, self-presentation and appearance she demonstrates in many of her articles is relevant in understanding her own presentation and performance of fashion at the time. After Moon's death, many commentators (mostly fellow writers and journalists) emphasized the fact she wrote 'hard-hitting', 'serious' pieces throughout her career, on a variety of topics that were not typically assigned to women. These contributions are remarkable; they confirm Moon's talent as a writer and set her apart as a journalist who was not limited by the gendered conventions of her time. Young women were still encouraged to "play down their intelligence, skills, and determinativeness" in the 1950s, especially in the presence of (datable) young men (Goffman 39). Moon never had to do this in her work, at least judging by the insightful, thoughtful and witty articles that make up her written archive.

Interestingly, at both publications, Moon seems to have been assigned society piecesalong with articles more typical of women's journalism — after having published hard-hitting features and proving her worth as a writer. This is something that surely would have bothered her. In fact, an obituary written by Sandra Martin suggests that Moon quit her position as an op-ed writer at The Globe and Mail, in 1968, because she was made to write these profiles and other lush commentaries, rather than articles with a more political and economic tone. However, this project argues that her society profiles do have value. Moon demonstrated an obvious talent for 
‘serious' writing, but her profiles too were critical, ambivalent, funny, and sociologically relevant in 1960s Toronto, and they communicated her unique voice and approach to writing. They are valuable documents of a specific place and time and, along with Moon's wardrobe, help illuminate how she and other women lived and worked in their historical context. In line with the more recent academic literature on gender and journalism — which encourages a reevaluation of women's sections or traditionally 'feminine' pieces to view them not as purely restrictive, but as records with a value of their own - these types of articles should not be dismissed, just as fashionable objects themselves should not be regarded as purely frivolous artifacts. 


\section{DISCURSIVE ANALYSIS: MOON'S PERFORMANCE OF PROFESSIONAL GLAMOUR}

The posthumous discourse around Moon typically focuses on three main elements: praise for her personal style; recognition of her talent as a writer; and discussion of her intense working practices as an editor. The obituaries published after Moon's death in 2009 reveal a fascinating consistency in the way former co-workers and professional acquaintances spoke of her, combining admiration for her work with an appreciation for her personal elegance and the sense of mystery she embodied. In these accounts, Moon is presented as an intense, intimidating and sometimes relentless editor in her pursuit of quality. At a time when female editorships were still rare — especially in those publications that were not specifically targeted to women—and as women were establishing themselves in the male-dominated magazine and newspaper trades, this kind of approach would have made Moon stand out as a memorable, at times controversial figure. As respected as she was by most people who worked with her, Moon's difficult nature meant that many viewed her with a sense of deferential ambivalence, her talent and demanding ways perhaps overshadowing other personal qualities. Sandra Martin, who worked with Moon at The Globe and Mail, tellingly used the following title for her obituary: "She was tough and smart and (some) people loved her".

Moon is described as being an absolute perfectionist both in her own writing and in what she expected from others - as John Fraser stated rather plainly, she liked "totally perfect writers" (in Martin). She was called 'brutally frank', ruthless, overbearing, and often difficult to work for, as she could inspire and discourage her writers in equal measure (Persaud 44, Martin, Manguel para. 1). This may have been influenced by the style of her own editor at Maclean's early in her career. Ralph Allen, Maclean's editor between 1950 and 1960, was admired by his 
staff despite his exacting editing style, which often included requests for multiple rewrites before a piece was fit for publication. An anecdote pertaining to Moon illustrates this tendency: "[I]t was sufficiently remarkable when Barbara Moon wrote a profile of Nathan Cohen, the drama critic, that required only one word change, for the other writers to buy her champagne." (Sutherland 228)

Years later, Moon proved to be equally demanding of her own writers. In a similar story, Alberto Manguel recalls his enthusiasm after Moon had him rewrite a piece only three times, instead of the usual six (para. 2). Martin speaks of "the rigours of Moon editing", demonstrating how much this unforgiving working style came to define her. She was known to make such pronouncements as "I will not tolerate that sentence in this magazine." (Persaud 47) This personal intensity eventually extended beyond the editorial directives she gave her writers. It became something she embodied, part of her distinctive aura. Not unlike the descriptions written about famous fashion editors, her entrances could instantly provoke a change of mood. David Macfarlane recalled her arrival on a rooftop patio during the 1994 Banff Centre literary arts journalism retreat: "someone new, and not very happy, had arrived—he could feel the chill. There, standing before him, was Moon, glaring." (in Persaud 44) These comments about Moon are evocative of the discourse around Diana Vreeland, who was known to inspire feelings ranging from respect to love and terror (Dwight 86) and Carmel Snow, the "elusive monarch" who inspired awe when she finally emerged (Dwight 81). Through a combination of appearance, demeanour, and language, Barbara Moon the Editor became a sort of mystifying, intimidating presence for those surrounding her. This was a performative, context-specific act. The lead in a 2010 Ryerson Review of Journalism article about Moon uses three key words to describe her: 
“Obsessive. Temperamental. Brilliant.” (Persaud 44) As in Moon’s profile of the Théâtre du Nouveau Monde actors, whom she described using almost identical language in the 1950s, the notion of drama seemed crucial to her craft, and to the expression of her personality. Anne Collins also alludes to this sense of the dramatic: "She was outsized in character and glamour, elegant, ferocious, witty" (in Martin). On the other hand, Moon did not seem to appreciate this kind of temperamental display in written form. She was rumoured to allow her writers the use of only three exclamation marks per year (Persaud 45), which suggests that while she responded to theatricality in dress, mannerisms, and attitude, in writing she likely advocated a more composed or restrained approach (as demonstrated by the articles she wrote herself).

This intensity was also fundamental to Moon's career progression as a writer. As soon as she started working at Maclean's, she appears to have been a highly independent, ambitious employee, which would explain—in conjunction with her writing talent—how she was able to progress from clerk-typist to assistant editor in only two years. Early on, according to Robert Fulford, "[h]er shrewd comments on the magazine's contents impressed her bosses" (para. 3). Martin suggests that Moon "insinuated herself as a writer" at Maclean's "because she had the brains, the grit and the guts to write loops around most of the other scribblers", describing a somewhat forceful yet merited progression. This uncompromising attitude would remain one of Moon's defining attributes. Alberto Manguel maintains that even when she wrote for other editors "Barbara Moon served 'under' no one" (para. 1). Later on, while she worked on scripts for television show "The Nature of Things" at the Canadian Broadcasting Corporation, "she both delighted and infuriated producers, as she delighted and infuriated magazine editors." (Fulford para. 6) 
It becomes evident that this kind of attitude is not something Moon developed later on in her career, once she had 'made it' as a writer and later as an editor. This approach was a fundamental part of her personality. Her fierce quest for perfection meant that she could be unpredictable, often kept people waiting until the last minute to submit her work, and sometimes missed deadlines (Fulford para. 6, Martin, Janes para. 4). She did not hesitate to write hardhitting, critical pieces. Not only did these help to legitimize her as a journalist, but they also conferred her a reputation as a controversial writer. Peter C. Newman stated that "[p]eople would read her to get mad" (Persaud 49), hinting at a voluntary exercise in argumentation on Moon's part. Knowing her personality, she may have found more traditional, less contentious writing to be uninspiring, and not worth the effort.

Moon's obituaries are full of glowing assessments of her written and editorial work. Sheila Kieran calls her "the best magazine writer this country ever produced"; Alberto Manguel, "the best magazine editor [he] ever worked with." (para. 1) Newman reiterates that, during her time at Maclean's, she was "justifiably considered one of the half dozen best Canadian magazine writers in the trade." (in Martin) Robert Fulford describes her in highly expressive language: "She was a star turn, a virtuoso who could bring style and intelligence to almost any subject". (para. 6) What is most interesting, however, in the context of this study is that this celebration of her written and editorial work was almost always combined with a commentary about her sense of fashion and her elegance, her style both in terms of personality and fashion choices. While in many cases, attention to a woman's personal appearance may devalue the way she is perceived in a professional setting, in Moon's case this type of discourse seemed to complement the overtly positive assessment of her work. References to her style, not only as she expressed it through 
clothes, but as an embodied whole, are common. Robert Fulford offers this evocative description of Moon:

It was as if a bird of paradise had alighted among sparrows. [...] She came from St. Catharines, Ont., but looked like one of nature's Parisians, a woman who made chic self-presentation seem easy and inevitable. She was elegant in clothes, hair, speech, and, above all, prose. She turned a sentence as gracefully as she arranged a scarf. She was educated at Trinity College at the University of Toronto but spoke with an accent that seemed to issue from some mythically perfect corner of the Empire. (para. 2)

This passage highlights Moon's comprehensive, unquestionable elegance, and how naturally sophisticated appearance seemed to come to her. Fulford makes a direct connection between her writing abilities, her fashion knowledge, and her skill for self-presentation. He does not distinguish between her written and her embodied, physical, or fashionable elegance. While Moon seemed critical of overly affected elegance, her own version of it was quite performative. Even though she was born in small-town Ontario, she eventually transformed herself into a 'natural' Parisian, drawing on the cultural capital associated with French-ness. This was a largely fashionable exercise, partially achieved through the French labels she wore, but one that would also have been supplemented by the deliberate French cultural references she used in her written work, as highlighted in the previous chapter, as well as in her personal life.

In her obituary, Sheila Kieran makes a special mention of Moon's personal recipes for boeuf bourguignon and pâté Helene. While the first is a quintessential, universally known French dish, the second merely sounds French. In a way, Moon seems to have constructed herself a French, European identity through a careful combination of clothing, writing, speech, and lifestyle. Fulford's mention of her vaguely mythical European accent is also very interesting. This is not presented as a trait that is fake, or deceitful; rather, it seems natural and effortless. 
Why did she adopt such an accent? Where did she learn it? How did she manage to be seen as somehow authentically Parisian, as opposed to the Rosedale matron wearing "French frocks from Creed's"? These markers of elegance were not something she was born with, their origins were shrouded with a certain level of mystery, but they did not seem any less authentic in the eyes of Moon's audience.

Other commentators link Moon's elegance to all aspects of her life, not just clothing. "Barbara had style, in every possible meaning of that word: She was an elegant dresser, picked exactly the desired gift, always knew precisely the mot juste" (Kieran). Again, her ability for elegant expression is directly linked to her style of dress and comportment. Moon exhibited small, specific gestures of refinement, all part of the distinguished person's habitus where material property can becomes part of the body, an integral component of the individual (Accardo \& Corcuff 93) and tastes in cultural consumption - whether in fashion, art music or décor-are all derived from (and communicate) a specific class position (Sturken and Cartwright 443). Even in her old age, Moon was known to have an "exquisite sense of design" (Martin). Other accounts make specific references to fashion. According to George Galt, who worked with her at Saturday Night in the 1980s (in Persaud 48):

She would come to editorial meetings wearing her dark glasses, sitting at the very end of the table. She had a certain heft in the place. She was much older than any of us, including Fraser. She had decades on me and John, even. She was a very powerful presence and with her voice, her deep growly voice, she was an impressive figure.

Here Galt refers to two traits identified by Moon in her sophistication article, age-also described as an important component of glamour by Gould (239) — and a deep commanding voice. Alberto Manguel also mentions "Barbara's wise, gravelly, witty voice” (para. 4). Moon 
was in her sixties at that point, which means she may have had a certain sense of wisdom to her — a distinctive, heavy presence as alluded to by Macfarlane - partly a result of her reputation as a demanding and intimidating editor. Again, these physical attributes are combined with a reference to fashionable self-presentation; in this case, her dark glasses. Galt's illustration instantly evokes the image of the silent yet omnipresent fashion editor, who is able to command everyone's attention by her presence alone. Simmel singled out fashion as a way for individuals to extend a strong aura, something adjunct to power (in Wilson, "Glamour", 98). Galt’s description is also reminiscent of someone like Vogue editor Anna Wintour, who is known to wear sunglasses inside, for example, when she is attending fashion shows.

At the start of her obituary, Sandra Martin describes Moon as "stylish, elegant in a Mary Quant kind of way, with a pixie cut, raccoon glasses, a cigarette in one hand and a drink, or a cup of coffee, in the other" (see Fig. 22). While others have referred to Moon's timeless sense of chic, these two accounts comment on specific style markers used by Moon. Her large, raccoon glasses would have been fashionable at some point in the 1960s or 70s, but would also have become a dramatic, trademark look for her. Especially if she wore dark lenses, these glasses would have added another layer of mystery to a woman that was already deliberately inscrutable. Her short 'Mary Quant' haircut would have been of the moment in the 1960s, and may have become a signature in her later years; Moon's own version of a timeless, elegant look. The addition of a cigarette, a coffee or a drink immediately suggest a kind of elegant, detached nonchalance. While all of these elements may not be sophisticated on their own, when utilized and combined in the right way with other modes of elegant presentation, they can confer to the individual a sense of cool effortlessness, still praised today when fashion commentators talk about the kind of 
'effortless style' usually associated with French women. Moon combined "a relaxed sense of authority with an acerbic wit" (Fulford para. 4), something she surely would have considered sophisticated based on her 1963 "Who's sophisticated anyway?" article.

This kind of casual (or, to use a Moon-ism, décontracté) elegance was in fact a critical facet of Moon's performance to her audience. It was a careful combination of seemingly insouciant elements, such as smoking, with a very intense professional attitude and reputation, expensive French clothes, and specific fashionable (yet, not trendy) markers of elegance. Just like the glamorous theatre manager who intimidated her actors into appropriate behaviour backstage, Moon's stylish demeanour also encouraged those around her to adapt their selfpresentation accordingly. Seema Persaud describes how a meeting with Moon may go: "You feel as if you had been summoned; you might even dress up, at least by freelance writer standards." (47) Part of why Moon was considered so glamorous, presumably, was by opposition. Her specific brand of glamour would have stood out even more in a conservative Toronto context, especially if she was often surrounded by individuals who did not necessarily dress up, such as freelance writers. Glamour, like distinction, relies on this exercise in contrast. Individuals or objects that are unique and unavailable often seem more alluring.

\section{Professional Glamour}

Christina McCall, who worked with Moon at Maclean's in the 1950s, struggled to think of anyone having "as much glamour as Barbara Moon who wrote all night and was said to own a Balenciaga" (Sutherland 227). Here, interestingly, Balenciaga is referred to specifically with a certain tone of mystery. This signals the reputation the label enjoyed at the time, in that it would have been somewhat remarkable for a woman to own its designs. "[G]lamour could be said to 
have reached a fashion high point with Christian Dior's New Look and Balenciaga's sculptural garments in the 1950s." (Wilson, "Glamour", 100) Balenciaga is also directly tied to the specific type of glamour that was being performed by Moon early on in her career, one that involved a negotiation of different versions or elements of glamour in a professional setting that was only slowly opening itself to women. European, Parisian designers specifically, would have played an important role in this construction of glamour, in establishing a certain kind of otherness for Moon vis à vis her peers. However, considering the subtle character of Balenciaga's clothing, it would also have required a certain level of cultural/fashionable knowledge to recognize what Moon was wearing at the time, and why it was so unique. As argued by Fred Davis, clothing helps people locate others "symbolically in some structured universe of status claims and lifestyle attachments.” (16)

By wearing such a prestigious label to work, or at least projecting the impression that she might be (the rumour-like tone of McCall's comment is worth noting), Moon was probably not making herself relatable to her work peers. This kind of behaviour would have contradicted the advice offered by fashion commentators like Edith Head, who stressed that it was imperative for women to seem as relatable and charismatic as possible to other women, especially early on in their careers, before they had 'made it'. Moon's houndstooth Valentino pantsuit would have registered as a "failure outfit" according to John Molloy, as it would have appeared too masculine (72). How would her coworkers have interpreted such an ensemble? Considering Moon bought this suit in the 1980s, when she was of a certain age and had already established a kind of fashionable authority, did this mean she could afford to take greater sartorial risks? While Moon certainly achieved success and, arguably, established herself enough professionally that she did 
not need others to identify with her, relatability did not seem to be a concern for her at any point in her career.

Moon was always a distant figure, somebody that few people ever got to know intimately. The idea of distance was important to her projected image. She was even called a “totally professional loner" (Martin). The distance she kept from most people probably contributed to create the sense of mystification that many felt around her, relating to the theories presented by Goffman in Chapter 2. Goffman writes: "often the real secret behind the mystery is that there really is no mystery; the real problem is to prevent the audience from learning this too." (70) As stated by Parkins, implied secrets and silence are an important part of the construction of glamour ("Schiaparelli", 191). Even if most of Moon's friends and coworkers did not know much about her, in truth, there might not have been anything more significant to know. Simply creating and maintaining this kind of social distance would have made others ask questions about her, and wonder what the 'real' Moon was like underneath her elegant facade, even if there was no real difference between her 'real' and performed selves. As argued by Gould, the air of mystery surrounding glamorous persons invites their audience to ask questions, create hypotheses about them, and project fantasies onto them (238).

Although many elements of her personal image were performed, one does not get the sense that there was any overt deception associated with this glamorous display. In The Second Sex, Simone de Beauvoir identified makeup and fashion as tools for women to perform artifice, to disguise and transform themselves into imaginary characters that they represented (but were not); as a way to identify with an intangible ideal such as an actor onstage, a picture, or a statue (in Goffman 57-58). As discussed earlier, Moon's performance of glamour somehow felt natural, 
authentic. It did not seem to register (at least to her friends and coworkers) as a "mask of manner" that required both inner and outer body discipline (Goffman 57). It is worth noting that Moon herself referenced Goffman in a 1960 article about the secrets people keep, and what they choose to reveal about themselves. Moon has her own interest in secrets and writing: "She had a favourite line she delivered to young writers when trying to stimulate them: 'Everyone has a secret. Your job is to find it.'” (Fulford para. 8)

Goffman also referred to individuals having to adapt their social performance when they enter unknown settings or perform new tasks. Moon alludes to some people pretending their way to sophistication in her 1963 article, a kind of 'fake it 'til you make it' attitude that may have been relevant in her early professional days, when she likely would have felt intimidated and uncomfortable at times in a new professional setting, but needed to persevere and prove herself in the workplace. A professional context would have required a certain kind of detachment, however Moon seemed to take this further than most. "She always predicted that when she retired she would disappear like the Cheshire Cat [...] And all that would remain is the shadow of her smile." (Persaud 49) Moon did disappear to a certain extent, even while she was still alive, but made the careful decision to leave her wardrobe behind.

In a way, Moon embodied some of the couture designers' personal characteristics. Balenciaga was known to be a severe, mysterious perfectionist who led a "monkish, solitary existence" (Givenchy Style 42); Hubert de Givenchy entertained a series of "secretly cultivated enthusiasms" (16). Moon's portrayal as a solitary figure, and the idea of distance, were very important to the construction of her glamorous image. In a way, going from being a writer to an editor strengthened that aura. She became like the theatre manager who was never seen but was 
nevertheless glamorous, influential and intimidating. Moon also embodied 'French taste at its best' like Dior and Givenchy. As noted by a former colleague. “[s]he wasn't a person you were casual with. You know, there are folks you can call up to chit-chat. Well, I never felt I could do that with her." (Persaud 47) Her donated wardrobe, in a way, allowed for the kind of intimate glance into Moon's life that may have been unavailable to most people who knew her. Moon alludes to ideas of personal solitude in her article on sophistication, in which she mentions that not having a visible family makes someone more sophisticated. This idea seems confusing at first - Moon herself is perplexed at the suggestion — but the proposition is also logical. The less people know about an individual's personal life, the more captivating they may seem. Moon was also apparently uneasy around children; while she demonstrated a certain interest in her colleagues' lives (while, evidently, not volunteering much information about hers), she usually closed her door when children visited the office (Persaud 48). Her close friends were not invited to her wedding, nor did they find out about it until casually hearing about it after the fact (Persaud 46). Echoing Wilson's description of true glamour as "icy indifference" (106), Moon spoke of her own editing style—acknowledging how demanding it was—with a "chilling nonchalance" (Martin).

As argued by Goffman, individuals adapt the performance of their personal front depending on the specific settings in which they find themselves. Moon was most glamourous (in the traditionally understood sense) with her evening wear, especially the red Valentino dress discussed in Chapter 4, but her glamorous impression was mostly made in a professional setting. All of Moon's obituaries were written by former coworkers, which is significant in this contextthey were people who knew her, some for several years, but few people seemed to know her 
well. Nonetheless, these were the individuals who were best positioned to talk about Moon's style and everyday elegance. This association with couture and glamour came to define Moon in a way without, however, limiting her in a professional setting. Some of her clothes tended to be conservative, likely as a result of the context in which they were worn, but they conferred her a stylish and memorable air. The collection of comments about her glamorous look confirm this ongoing creative process and the impression it left on her contemporaries. Even Moon's conservative clothes were not mundane; as a whole, her collection of garments is truly unique and coherent.

The gender-specific nature of the commentary around Moon's appearance cannot be ignored. Despite her achievements and recognition, she was still the subject of gendered viewing, which may have been inevitable in her professional context. The direct juxtaposition of observations on her style with praise for her writing is noticeable, but also representative of the fact that most pieces written about her were obituaries, attempting to condense personal highlights in short pieces. Both men and women praised her fashionable image, but it is difficult to imagine such accounts being written about any of her male counterparts. "The fashionable ideal aligns the ideal body with the well-dressed body. Getting it right is not as straightforward as simply following whatever the current fashion is dictated to be. Conformity is often seen as the easier, unimaginative relation to dressing in an individual manner.” (Woodward para. 45). Moon 'got it right' to the point where most people commented on her style, meaning that she achieved a complex process of appearance management, but she did not conform to the dominant fashion of the time. Her clothing and elegance became memorable but not in a 'negative' way—as was (and is) often the risk for women — when appearance is considered to overshadow their 'real' or 
'authentic' selves, a mind/body dichotomy that can rarely be clearly delineated. "Thus spaces impose different ways of being on gendered bodies: women may have to think more carefully about how they appear in public than men, at least in some situations, and how they experience public spaces such as offices, boardrooms, quiet streets at night, is likely to be different to how men experience such spaces." (Entwistle, Dressed Body, para. 31) This statement remains true today, and would have been even more resonant throughout Moon's career, when women were only starting to establish themselves as professional actors and were constantly judged on how they presented themselves in the public sphere. Through the years, Moon would have had to choose among a series of "well-established fronts" (Goffman 27) and negotiate which ones she adopted and which she rejected.

The idea of the 'appropriate body' still exists today—both in professional contexts and in everyday lives — and is a concept that still applies to women almost exclusively. Appropriate bodies are largely defined through their level of conformity, as promoted by Head. Whatever doubt and ambiguity Moon may have felt around the issue of self presentation largely remained hidden. Betty Friedan refers to the idea of necessary perfection at work and in life, standards that men did not have to worry about (in Mills 342). How would Moon have managed these expectations? Her garments were not perfect, many of them contained hidden stains, tears, alterations and other signs of life. Moon would have had to closely monitor which parts of her (both physical and emotional) were seen and which were concealed, an ambiguous practice central to the performance of glamour (Wilson 101). It would have been very difficult for Moon, or any other woman, to always look impeccable. Women were urged, on one hand, to be respectable and relatable and not too daring in their fashion choices if they wanted to get ahead. 
On the other hand, contemporary fashion experts admonished them for being too afraid to take sartorial risks. A 1961 Maclean's article—not written by Moon, but published when she worked the magazine - titled "A fashion expert speaks her mind: Women are cowards about clothes", lamented the fact that most women only wore things they had seen on a 'platoon' of other women, and were reluctant to adopt new, unconventional fashion silhouettes (Maclean's 1961, 23). Already there was a proliferation of fashion advice from a variety of sources that would have made the process of self-presentation anxiety-inducing, even for Moon.

Moon was an important creative public figure of her time, at the same time as Edith Head was writing about women marrying their bosses, and aspiring to be executive secretaries. She exercised talent in the publishing world and in her self-presentation, reaffirming the potential of fashion to be a creative occasion itself, which could influence the way people (especially women) were professionally received. It probably helped that Moon worked in a creative field; her reception likely would have been different in a regular office. Even though Moon's couture purchases were a personal, private affair, they made a public impression, one that was tied to her success as a writer and editor in the few accounts published about her. In Moon's case glamour did not devalue the individual but rather added to her mystery and positive assessment by others (Gould 237). She embraced high fashion but in a unique way. Moon questioned old-fashioned elegance but did not necessarily “overtur[n] the pre-war strictures of elegance and restraint in dress" (Breward, Dolly Bird, 151) by participating in the dominant, youth-oriented fashion trends of the 1960s.

$[\mathrm{M}]$ inding appearance is one of the few avenues available to acknowledge and articulate embodied subjectivities that are otherwise stifled or muted. As an epistemology of ambiguity, it enables the expression of complex 
intersections among and spaces between diverse subject positions and bodily experiences. It helps to blur the boundaries between such binaries as mind and body, inner and outer self, linear and nonlinear, the visual and verbal, concrete and abstract, political and aesthetic, critical and creative, personal and social, local and global. (Kaiser para. 53)

The notion of ambivalence is crucial in the context of this study. Ambivalence, around class, society, fashion and sophistication, is demonstrated both in Moon's written work and in her wardrobe. Moon embraced fashion, but not blindly, and in her own unique way. She was familiar with Toronto high society—and may even have aspired to be a part of it to a certain extent—but still proved critical of many of its members and institutions. Moon seems to have had somewhat firm ideas around sophistication and good taste, but she was also interested in the rest, the unsophisticated, the kitschy; maybe not for herself, but at least for others. This sense of ambivalence is only fully understood when one looks at both the material and textual records of Moon's life. Describing Eleni Epstein, Voss and Speere argued that "[s]he may have been attending fancy balls, but she was dressed on a journalist's paycheck." This statement would have applied to Moon as well. She may have been involved in some high society circles, but her membership there was perhaps temporary, and contingent on her professional status. Head's book assumes that men were always in charge of women's clothing budget in the 1960s, however, as previously mentioned, Moon was not married until after she had personally purchased most of the clothes that make up her donation to the Ryerson collection. For much of her career she was a single, working woman, an identity that would have informed the way people viewed her. Moon was also known to swear (Janes para. 2), which does not constitute elegant behaviour, but somehow corresponds to Moon's unique version of elegance, with a few 'stains' that challenge traditional notions of pristine appropriateness and sophistication. "We expect, of course, some 
coherence among setting, appearance, and manner" (Goffman 25) in self-presentation, but this elegant coherence does not always occur.

Along with ambivalence, the notion of anxiety is also worth exploring. Martin writes of Moon: "No matter how effortless she made writing seem, she wrote - as all good writers do from the edges of her nerves, under stress, weighted down with anxiety about trapping the elusive phrase or image that encapsulated the essence of a subject or a personality." Clark and Miller argue that women's personal relationships with clothes are constantly informed by anxiety; an apprehension influenced by questions around setting, appropriateness, and social expectations. Both Moon's writing and her fashionable self-presentation seemed easy, natural, but this was likely not the case. Both required a constant negotiation of social expectations based on factors such as the writer/wearer's social or professional status, gender, and age. One cannot help but be curious about the rest of Moon's self-presentation mechanisms, including the shoes or jewellery she wore. How would these types of accessories have changed or enhanced her social reception? Examining her clothes in an institutional setting was a valuable exercise, but I was still missing an important physical, real world context for all of her individual garments.

Moon worked for her couture clothes, her markers of distinction and elegance, which distinguishes her from Rosedale matrons and other more old-fashioned elegant types she wrote about. Moon challenges Bourdieu's idea that the 'consecrated couturiers' are only worn by upperclass women. Agnès Rocamora addresses this disconnect, or this modern way of consuming couture, by referring to the diverse ways in which a product can be appropriated across different classes (352). Moon appreciated couture and adapted it to her unique social and professional position, at a time when appearance in the workplace was even more important for women than it 
is today. Moon rejected 'Fashion' to a certain degree in her writing - probably because she felt a certain obligation to, in order to maintain legitimacy as a writer - but not in practice. She may have shunned fashion trends, but not the kind of fashion objects that signalled a 'legitimate consumption of legitimate products' (Bourdieu, Distinction, 41). Moon took standards of elegance, glamour, or sophistication that were given, automatically, to some, and adapted them to her life. She likely recognized the fundamental differences between herself and her subjects. Friedan wrote about the tension between the way women lived and what they wrote or advocated in the media; one wonders how this would have affected Moon. She performed a creative exercise that somehow made fashion (among other bourgeois behaviour) acceptable, because it was different from how other people displayed it. How did this practice work so effectively for her? As discussed in Chapter 2, both Wilson and Gould argue that glamour requires thought, creativity and intelligence beyond/behind surface-level performance. Perhaps Moon considered conventional genres of elegance — either bourgeois, or old fashioned and inherited — to be too easy? Her own version of glamour was earned, deliberate, and she came to embody it so well that it became a central part of the popular discourse about her following her death.

Most of Moon's commentators refer to her elegance, rather than her beauty—with the exception of Robert Fulford, who describes Moon in these complimentary terms: "It was a truth universally acknowledged among Barbara Moon's colleagues at Maclean's magazine that no one had the right to be both that beautiful and that brilliant. In the 1950s and 1960s, beauty was not totally unknown at Maclean's, nor was brilliance. But she demonstrated both, and to an unforgettable degree." (para. 1) Elegance is something that is largely performative, not naturally given. Moon's wardrobe and her writing illustrate the active, deliberate nature of glamour and 
fashion, but also demonstrate how context-specific and performative class can be (with clothing playing an important role in class distinction). Moon's wardrobe perfectly illustrates how she privileged elegance over trends, and the attention she gave to tasteful, refined fashion objects. Many scholars, including Prown, stress the correlation between clothing, identity and values (30).

While it is impossible to know exactly what motivated Moon to acquire so many couture pieces, or what she intended to communicate with them, these garments are still representative of her fifty years after they were first purchased and worn. Even though very little was written about Moon in her lifetime - considering the reputation she enjoyed as a writer and editor - the accounts that were produced all demonstrated a strong focus on her specific brand of glamour. The garments, through their silhouettes, labels, and the quality of their construction and materials, remain elegant even as artifacts in a university collection. However, as standalone objects removed from a living body, they can no longer convey Moon's embodied glamour, the traces of which only remain in written form, and in a handful of public photographs of her. Her clothes represent valuable but somewhat incomplete documents. In their state of 'special limbo', as garments that were clearly worn by a body but are no longer connected to it, they communicate a certain sense of unease, "link[ing] the biological body to the social being, and public to private." (Wilson, Adorned, 2)

Peter C. Newman labeled Moon Canada's own version of Joan Didion (in Martin). Didion - the celebrated American novelist, essayist and key figure of the New Journalism of the 1960s and 1970s — wrote news stories in a literary, emblematic, and visually detailed manner, highlighting socio-cultural phenomena and anxieties symbolic of individuals' 'status life', by 
combining factual reporting with more figurative techniques (Muggli 407). Both women's similarities in writing styles and approaches are immediately apparent, however Newman's comparison is also significant given Didion's emergence as a recent fashion icon in advertisements for French fashion house Céline (Fig. 23). The celebration of Didion as an alternative, perhaps more intellectual fashion icon refers to some of the same traits embodied by Moon - intelligence, fashionability, wit, and mystery. 


\section{CONCLUSION}

Glamour was considered by Friedan and other contemporary feminist theorists as something negative or restrictive for women, as a distraction from more pressing personal and social concerns. This study attempts to challenge this type of reading. Glamour and fashionable appearance were not a way for Moon to blindly conform to some vague feminine ideal, to buy in to the feminine mystique identified by Friedan; instead she used fashion in her own way to create an individual type of mystique, one that was equally informed by her professional skills. Her couture clothes and her choice of accessories, such as the dark glasses, may have acted as a barrier to keep certain people away but her wardrobe ultimately served as an entry point for academic research into her life and career. Moon's clothes do help us understand her better, even after her death. She was very aware of the fashion of her time, something she demonstrated both in her writing and what she chose to include and preserve in her wardrobe, but she had a distinct way of wearing fashionable labels and silhouettes.

Moon privileged French and Italian labels that were sometimes conservative and communicated an established cultural capital, but she also wore lesser-known designers, confirming her active, knowledgeable engagement with fashion. Her wardrobe, at a glance, could be considered quintessentially 1960 s, but not in the way that most have come to expect. Historical records of sixties fashion tend to focus on London, or more youth-oriented styles. Moon did not participate in these trends even though she wore Cardin and Courrèges, two designers closely associated with these new prêt-à-porter looks. Her age, background, and professional position all contributed to her individual interpretation of fashion. The study of Moon's wardrobe constantly reaffirmed the fact that dress is not simply a tool for covering the 
body; rather, it needs to be understood as "an embodied activity and one that is embedded within social relations.” (Entwistle, Fashioned Body, 10).

Moon's writing demonstrates that she appreciated French-ness in all aspects of life, but especially when it came to performative self-presentation, something she engaged in herself. A certain critical consciousness and ambivalence around questions of class and status can be found everywhere in her writing. These written themes are illustrated, questioned, and sometimes even problematized by the designer labels prominent in her wardrobe. Her clothes, along with the fascinating discourse around her after her death all confirm that she was a glamorous person, one whose reputation and appearance were largely informed by the ideas of glamorous mystery, intimidation, and talent. Despite its positive tone, the commentary about Moon's elegance reaffirms the gendered nature of the consciousness of bodily appearance (Entwistle, Fashioned Body, 31).

This examination of Moon's clothing —along with the effect it had on her peersconstantly prompted questions around her own belief in the impression of reality that she attempted (whether consciously or not) to engender in those around her (Goffman 17). However, to which degree does this intentionality matter? Fashion is such an integral part of our everyday lives that sometimes we may not realize that we are projecting a certain image or communicating certain values, and may not fully appreciate how these are being interpreted by those around us. As highlighted by various theorists, ambivalence, ambiguity and anxiety are fundamental aspects of the embodiment of fashion, especially for women. It is interesting to wonder what kinds of meanings Moon would have wanted to project, especially considering that she chose to archive her clothes in a formal, institutional setting. Perhaps Moon did not intend for this donation to 
constitute a biographical record of herself, but in a way it does, especially when these clothes are situated within her work and the public commentary around her. By choosing to archive a collection of curated, or edited, high-end pieces - rather than including all the clothes she may have worn in more private, casual settings-Moon may not have communicated her complete biography, but she certainly provided a material narrative that corresponds to and confirms her glamorous public image. Moon's clothing, with its multiple signs of life and wear, illustrated her cultural capital, but not a pristine version of it.

Meanings, in fashion, are fluid and highly dependent on audience and context. Moon's wardrobe - along with the way she wrote about class and appearance - highlight the difficulty in ascribing fixed models of image and identity communication in fashion. Moon's professional style did not adhere to the codes of power dressing, yet she corresponded to (and, in part, challenged) sociological fashion writings of her time. She confirmed the tensions and contradictions between "the artifice or authenticity of appearance, conformity or innovation, anxiety or possibility." (Woodward para. 1)

A woman like Moon challenges the stereotype that being interested in fashion is frivolous. She did not write directly about fashion (except in the few instances where she used subtle criticism to comment on women following certain socially dictated trends) and it would have been surprising to see her embrace it on paper, especially when she wrote for such publications as The Globe and Mail and Maclean's. One wonders how she talked (if at all) about fashion on a personal level, in private. Somehow, I get the impression that she did not need to articulate anything about her appreciation for fashion, that her clothes spoke entirely for themselves and revealed all that their owner wanted them to, just as they continue to do today. 
This study provides a very brief overview of Moon's writing career. Her other articles and publications could be studied in greater detail, including her 1970 book, The Canadian Shield. It was written on the topics of nature, geography and science, but still manages to communicate some of the same themes as her newspaper and magazine articles - in one passage, she contrasts the untouched Boreal forest with the bourgeois urban landscape. In this book Moon succeeded in writing beautifully, even poetically, about an immense region of Canada that does not necessarily resonate in the popular imagination. She approached highly scientific, technical phenomena with the same literary skill she would have applied to any other assignment. This research projectwhich originated from the examination of one dress - used Moon's wardrobe as the starting point for inquiry, and sought to establish connections between Moon's clothes and ideas on a few specific themes, centered around class, cultural capital and glamour. However a more detailed study of her career as a journalist, including an evaluation of the larger contributions she made to Canadian journalism, would be warranted.

Moon struck a careful, rare balance between receiving praise for her work and praise for her style, the type of commentary that is often reserved for women who work in fashion. This study does not aim to disregard her more 'serious' articles; instead, it seeks a reconsideration of the type of work that others, and even she herself, might not have considered as challenging or valuable from a journalistic perspective. This project attempts to situate Moon's case study among recent academic reevaluations of women's contributions in journalism; of fashion scholarship; and of material culture approaches. Like Didion, Moon was able to convey the "sophisticated poetics of factual literature" (Muggli 421). 
The performance of fashion is complex. Most people struggle with choices between conformity and individuality, a conflict that has long been at the center of sociological assessments of fashion. There exist many different theaters for the performance of fashion, glamour and elegance, and Moon demonstrated this creative potential quite well, with a uniqueness that few ever manage to achieve. Looking at pictures of Moon in the 1990s (see Fig. 24-25), she would not be out of place in the current fashion landscape, on popular blogs such as Advanced Style which, in recent years, has promoted a reconsideration of fashionable ideals by showcasing the unconventional glamour performed by older women. 


\section{APPENDIX A - IMAGES}

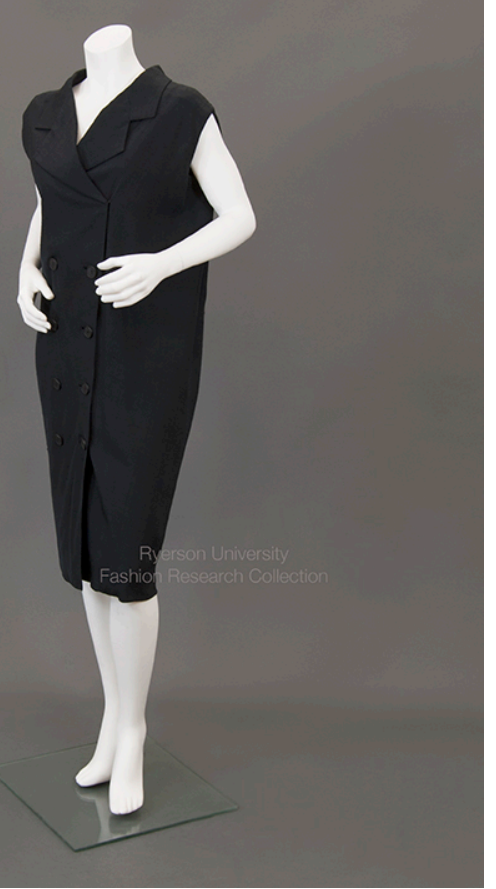

Fig. 1 - Givenchy linen sleeveless sack dress (FRC 1997.04.052). Photo by Jazmin Welch, Courtesy of the Ryerson Fashion Research Collection.

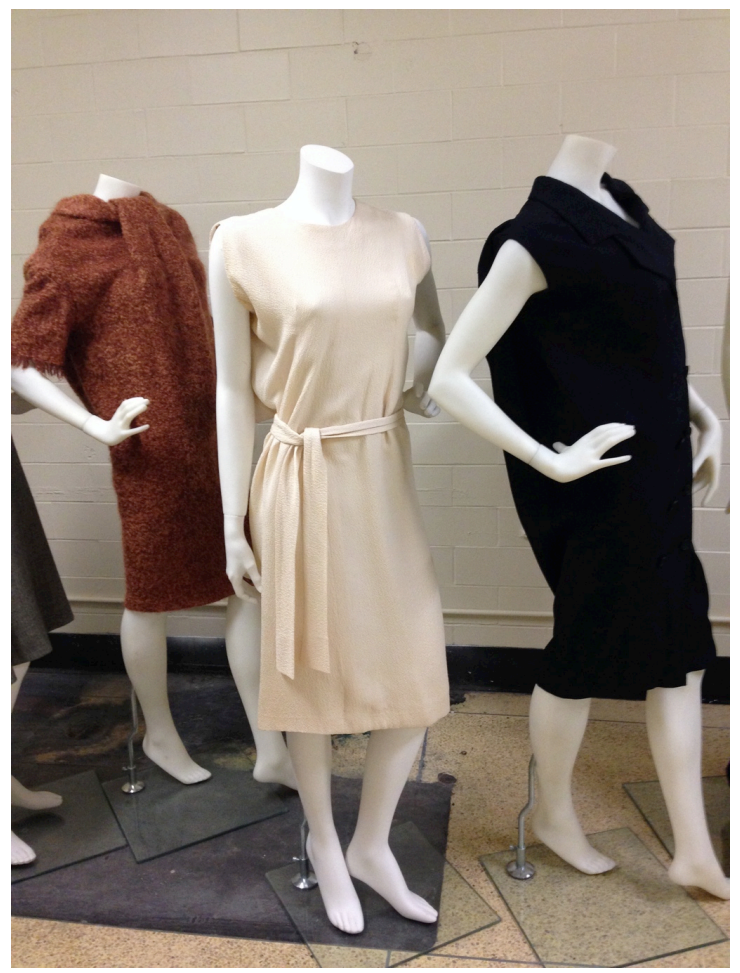

Fig. 2 - Fabiani wool bouclé dress (FRC 1997.04.036); Balenciaga silk cloqué dress (FRC 1997.04.050); Givenchy linen sleeveless sack dress (FRC 1997.04.052). 


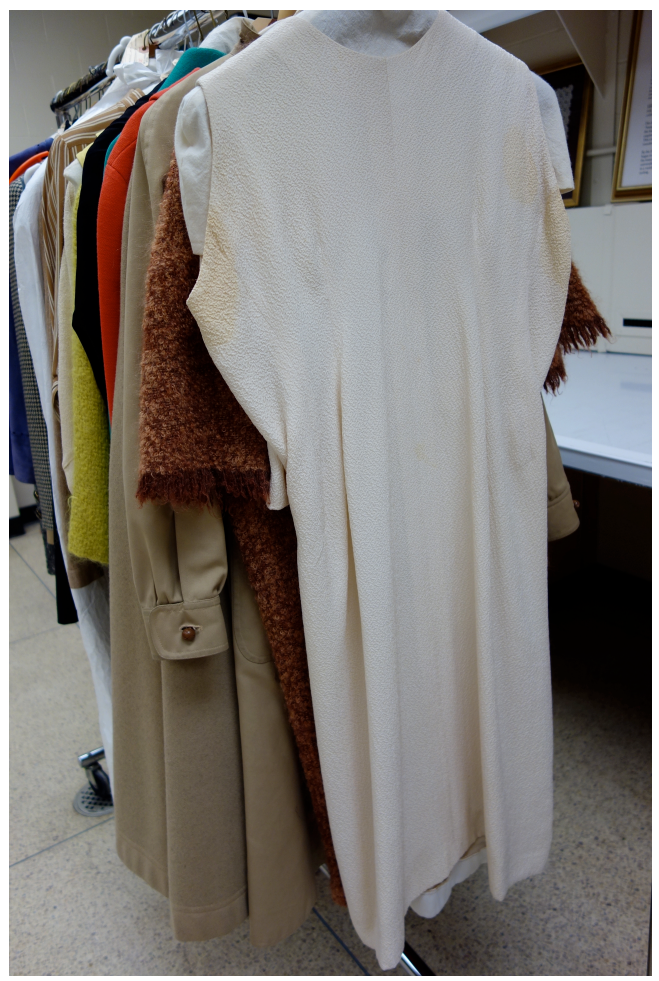

Fig. 3 - Balenciaga cloqué silk dress (FRC 1997.04.50).

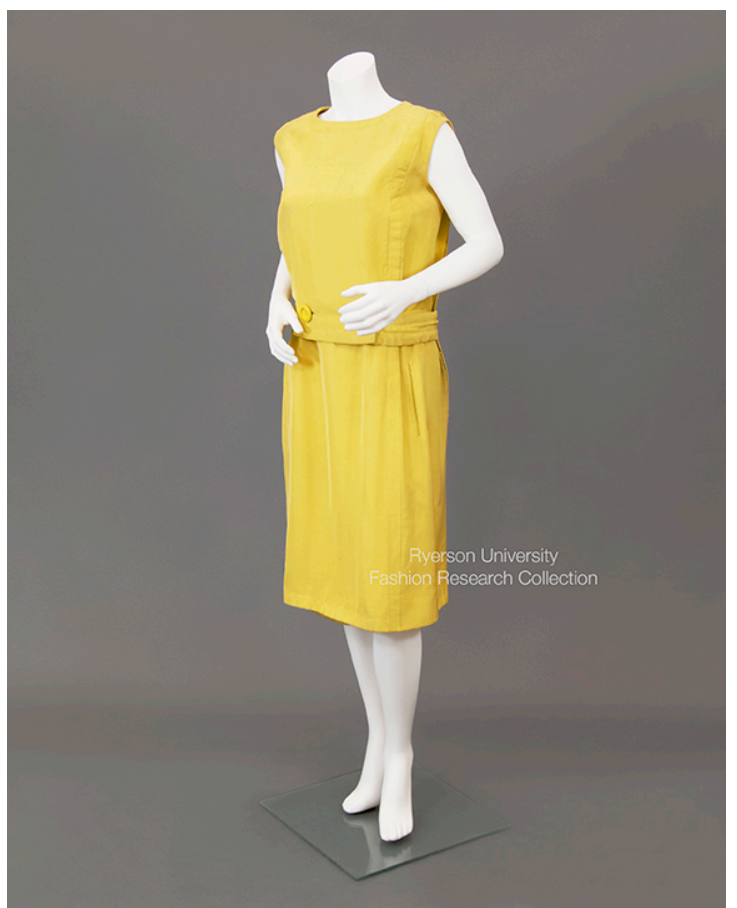

Fig. 4 - Dior silk linen dress (FRC 1997.04.046). Photo by Jazmin Welch, Courtesy of the Ryerson Fashion Research Collection. 


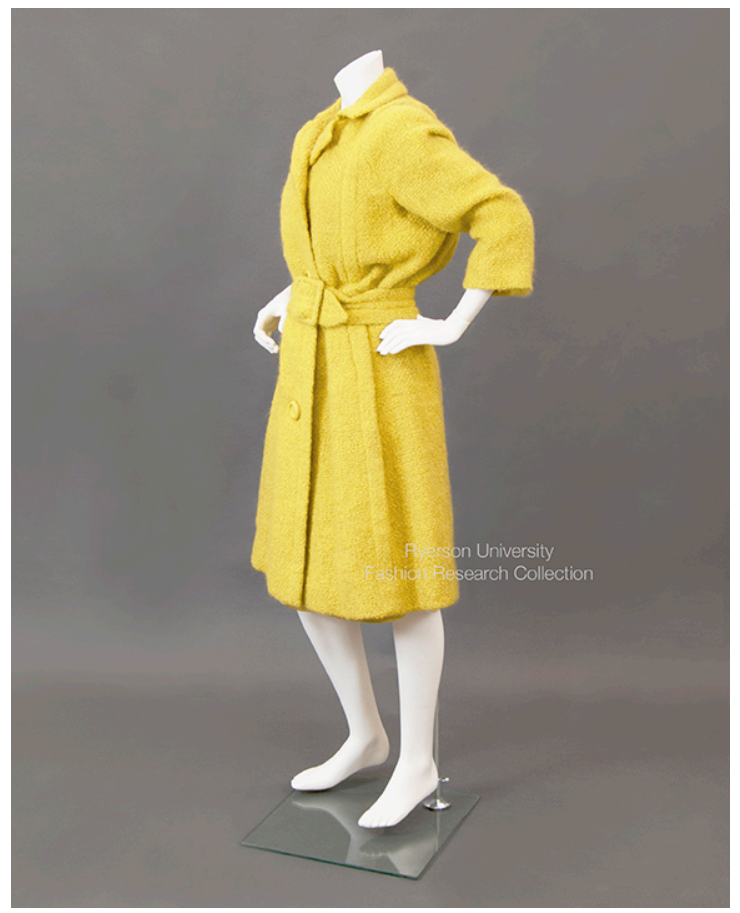

Fig. 5 - Dior wool coat (FRC 1997.04.044). Photo by Jazmin Welch, Courtesy of the Ryerson Fashion Research Collection.

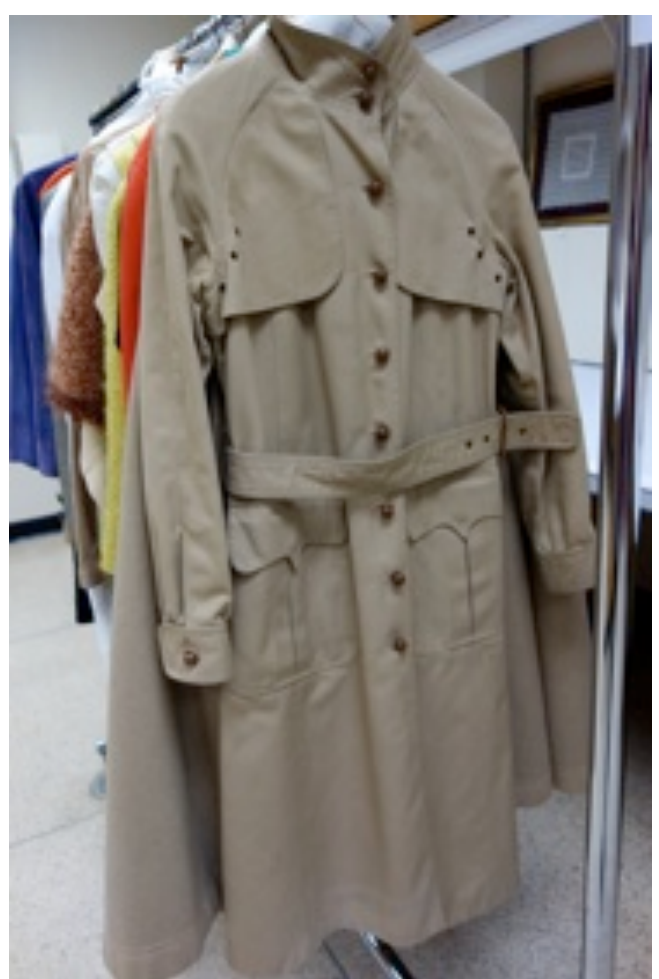

Fig. 6 - Courrèges cotton poplin coat-dress (FRC 1997.04.043). 


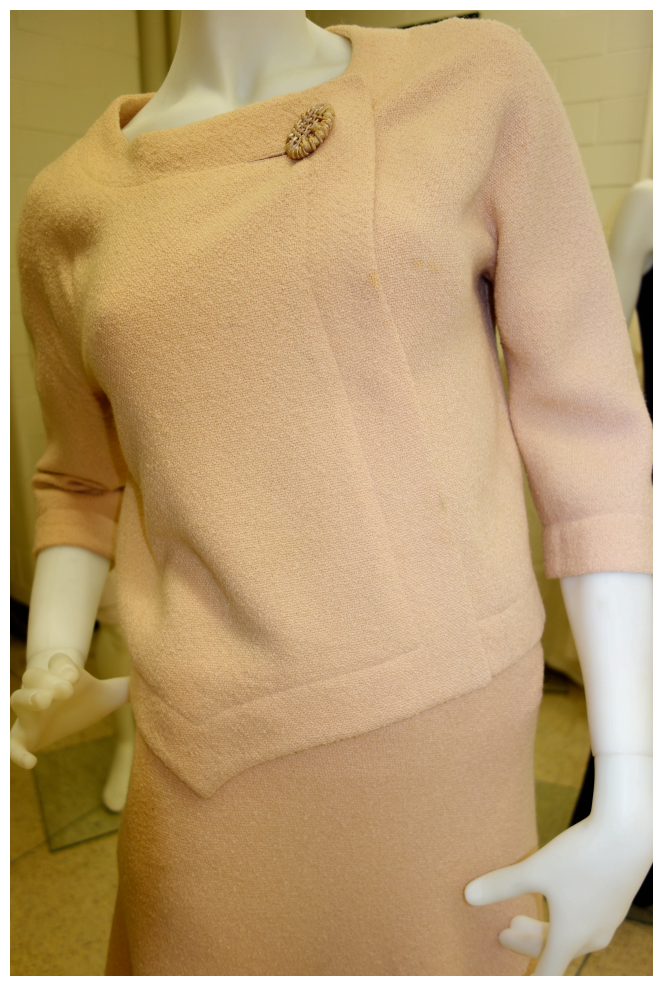

Fig. 7 - Pierre Cardin jacket and skirt (FRC 1997.04.001).

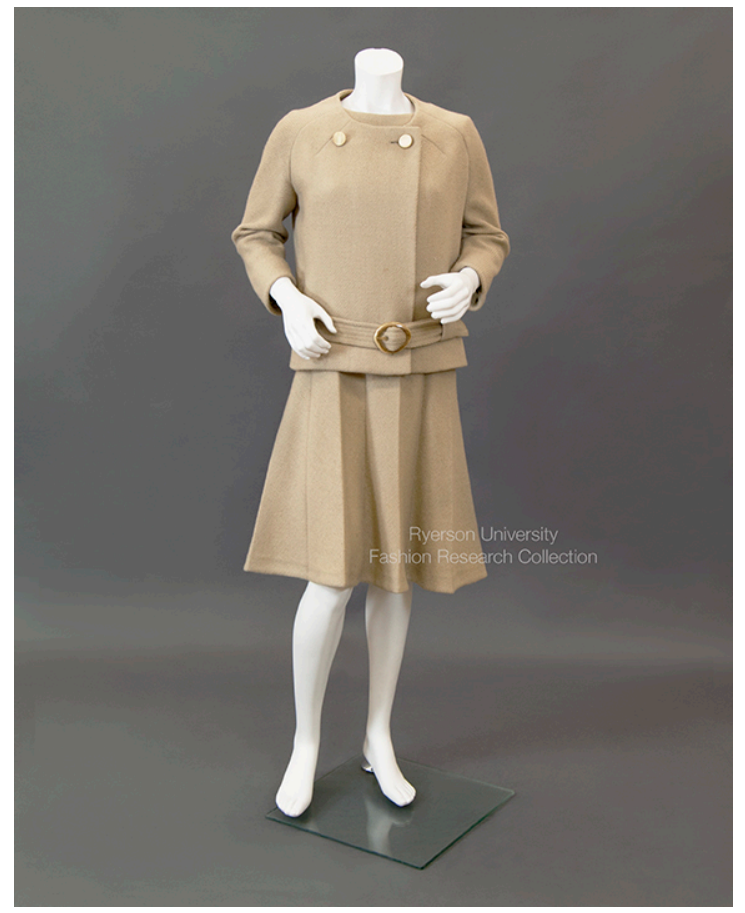

Fig. 8 - Pierre Cardin wool dress and jacket (FRC 1997.04.002). Photo by Jazmin Welch, Courtesy of the Ryerson Fashion Research Collection. 


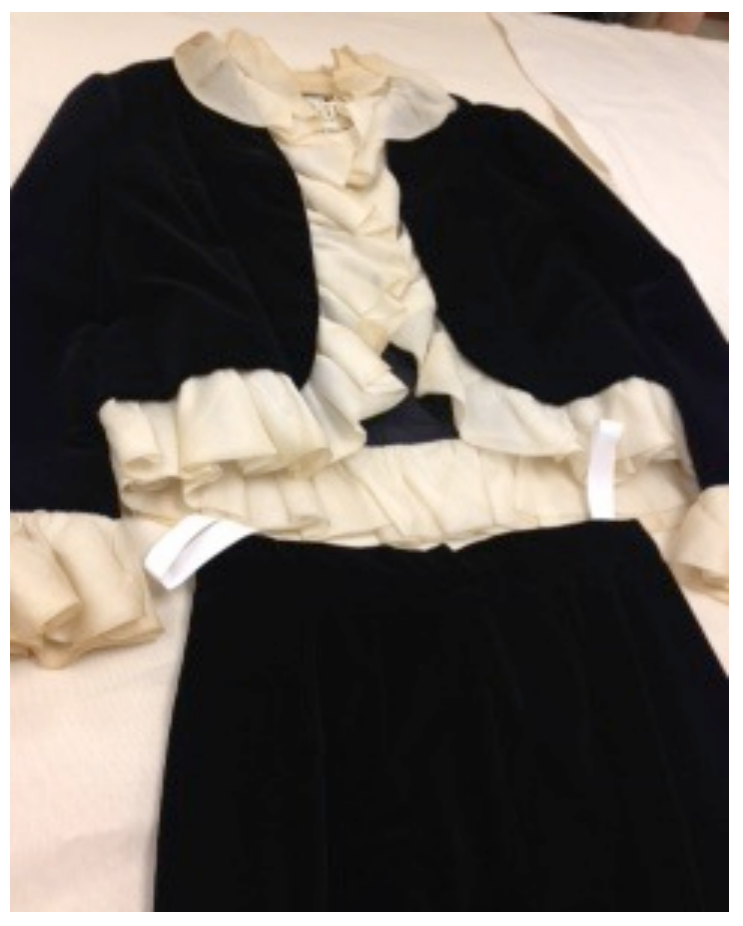

Fig. 9 - Patrick de Barentzen velvet evening jacket and skirt (FRC 1997.04.031).

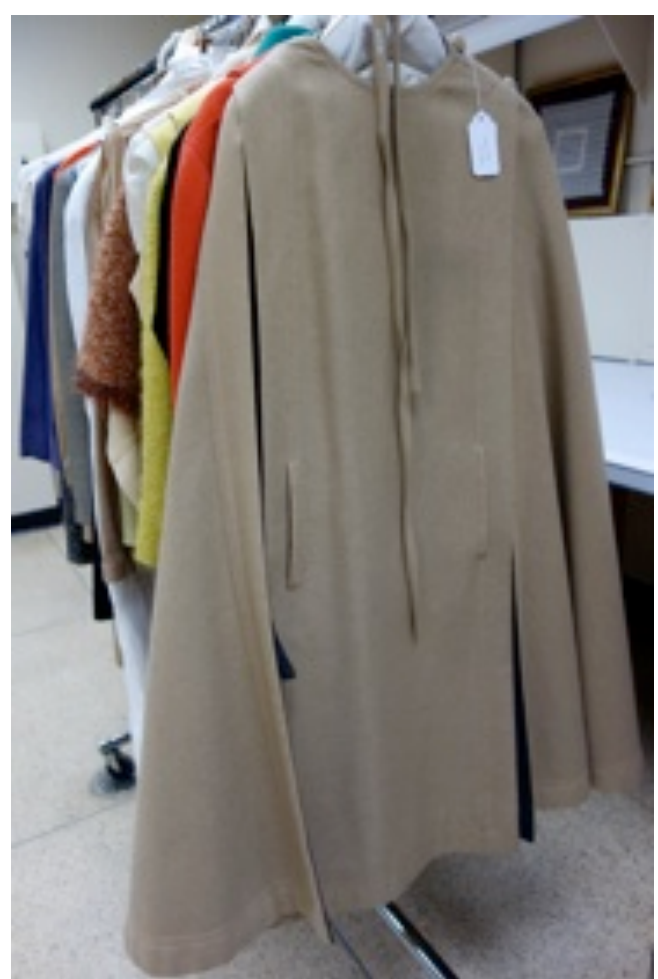

Fig. 10 - Nina Ricci wool cape (FRC 1997.04.049). 


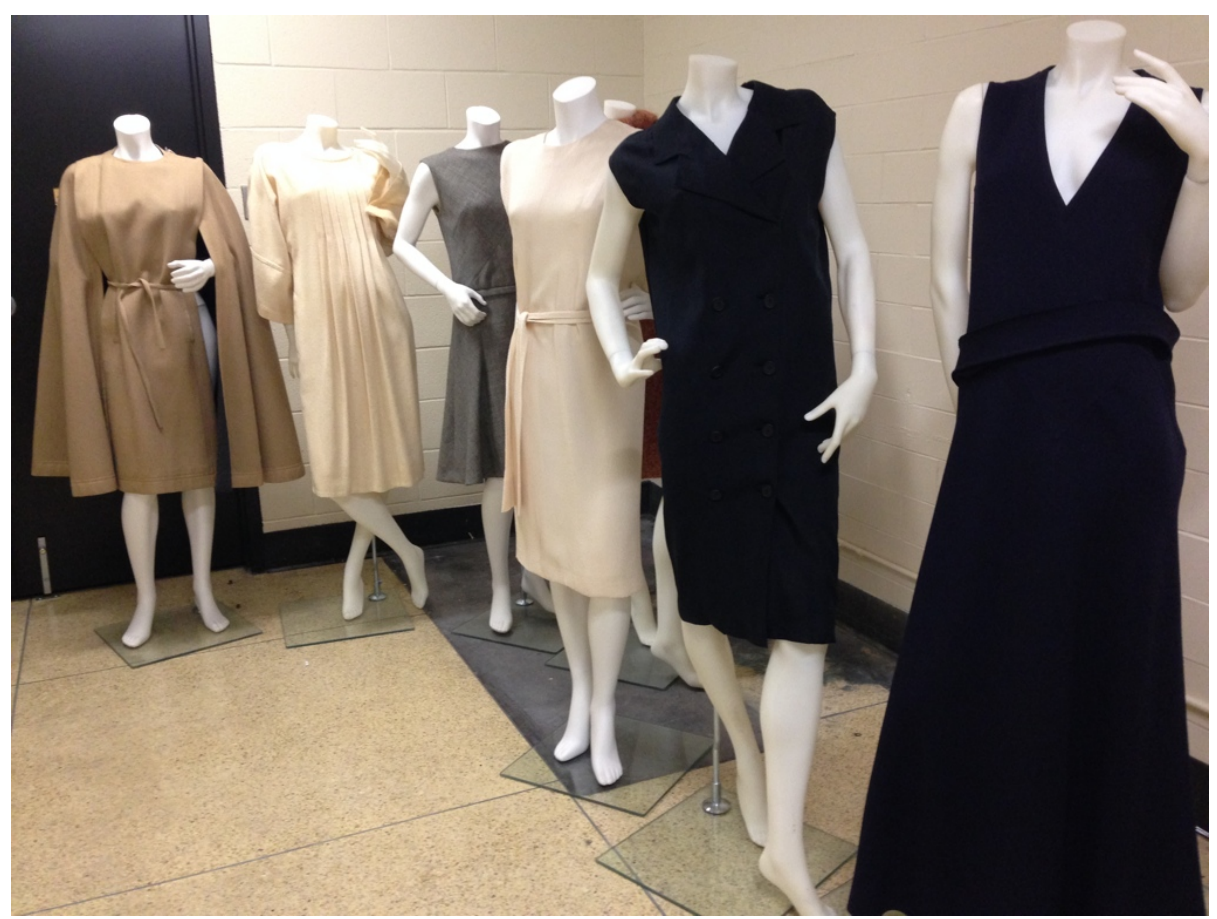

Fig. 11 - A selection from Moon's wardrobe (FRC 1997.04.049; FRC 1997.04.042; FRC 1997.04.028; FRC 1997.04.050; FRC 1997.04.052; FRC 1997.04.058).

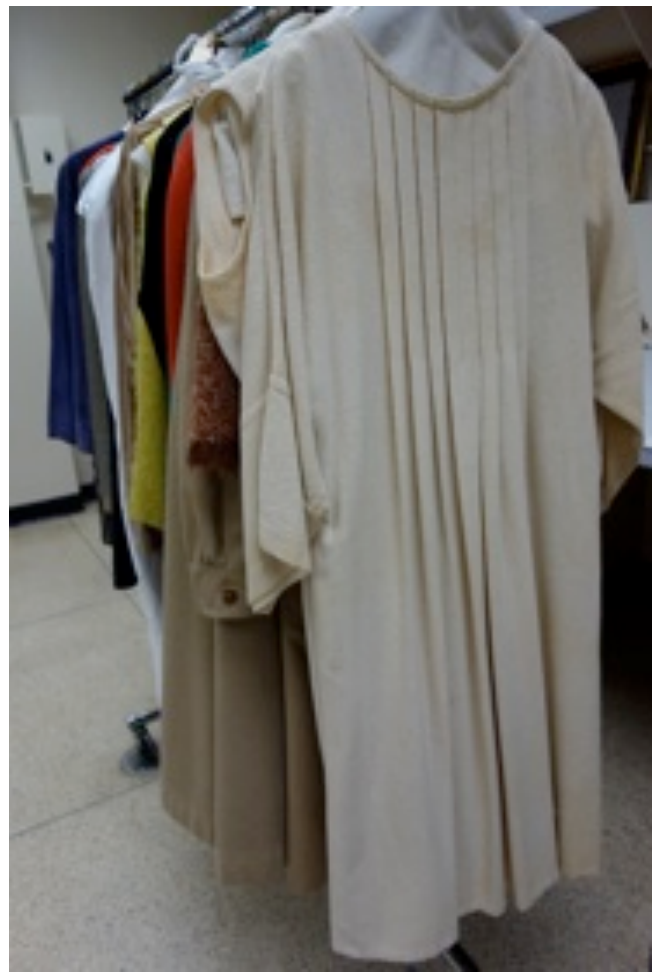

Fig. 12 - Gudule wool bouclé smock dress (FRC 1997.04.042). 


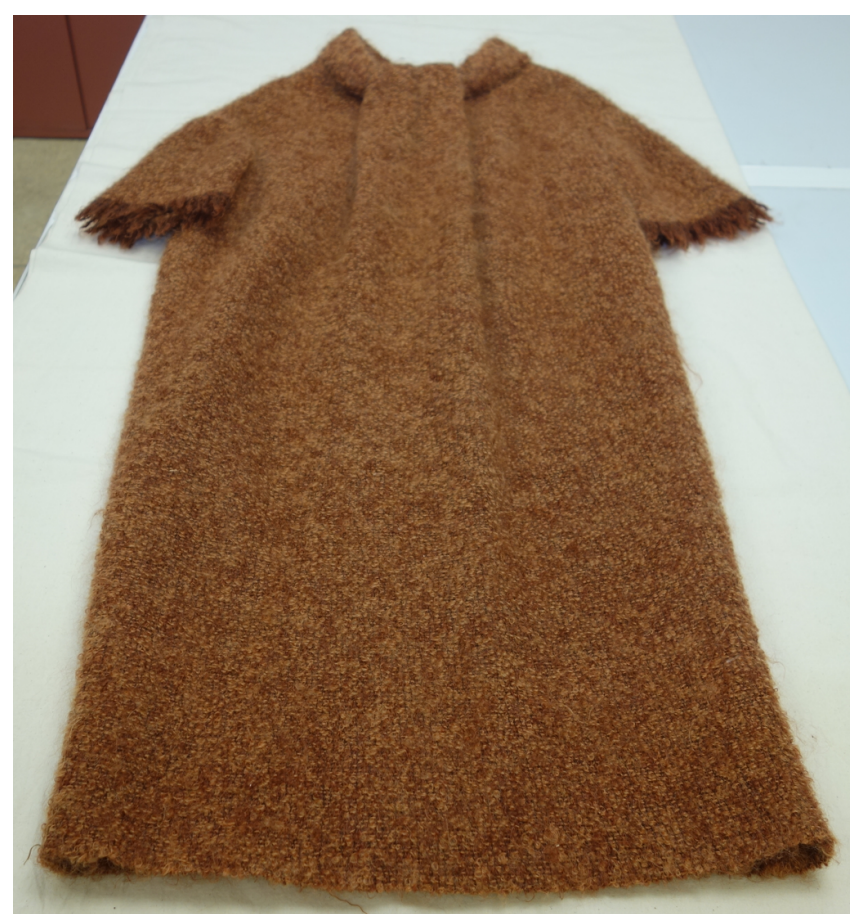

Fig. 13 - Fabiani bouclé wool dress (FRC 1997.04.036).

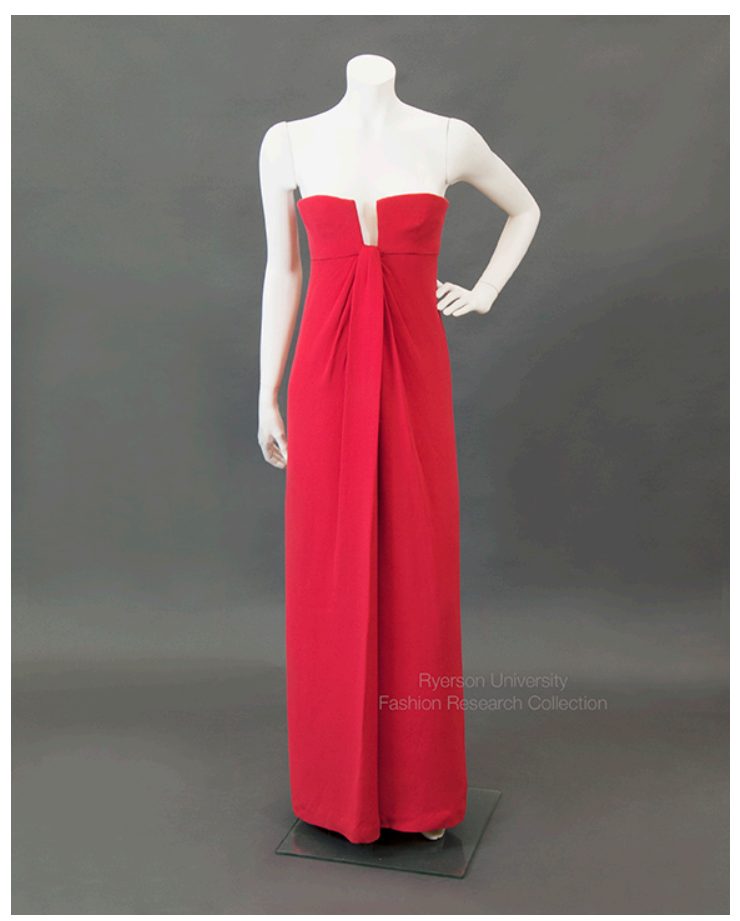

Fig. 14 - Valentino evening gown (FRC 1997.04.009). Photo by Jazmin Welch, Courtesy of the Ryerson Fashion Research Collection. 


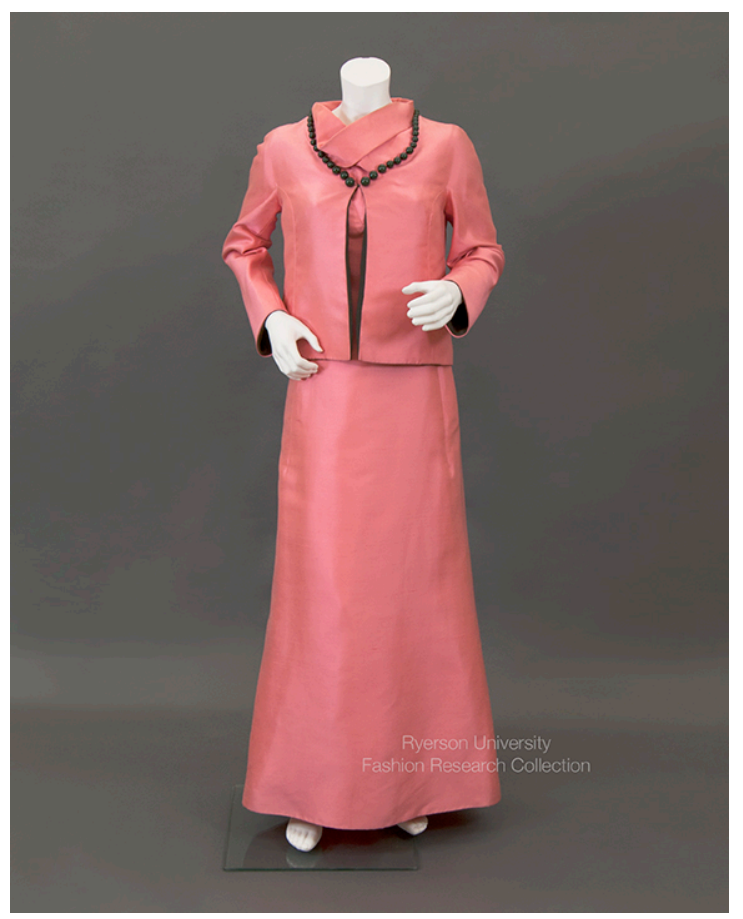

Fig. 15 - Nina Ricci raw silk evening gown and jacket (FRC 1997.04.048). Photo by Jazmin Welch, Courtesy of the Ryerson Fashion Research Collection.

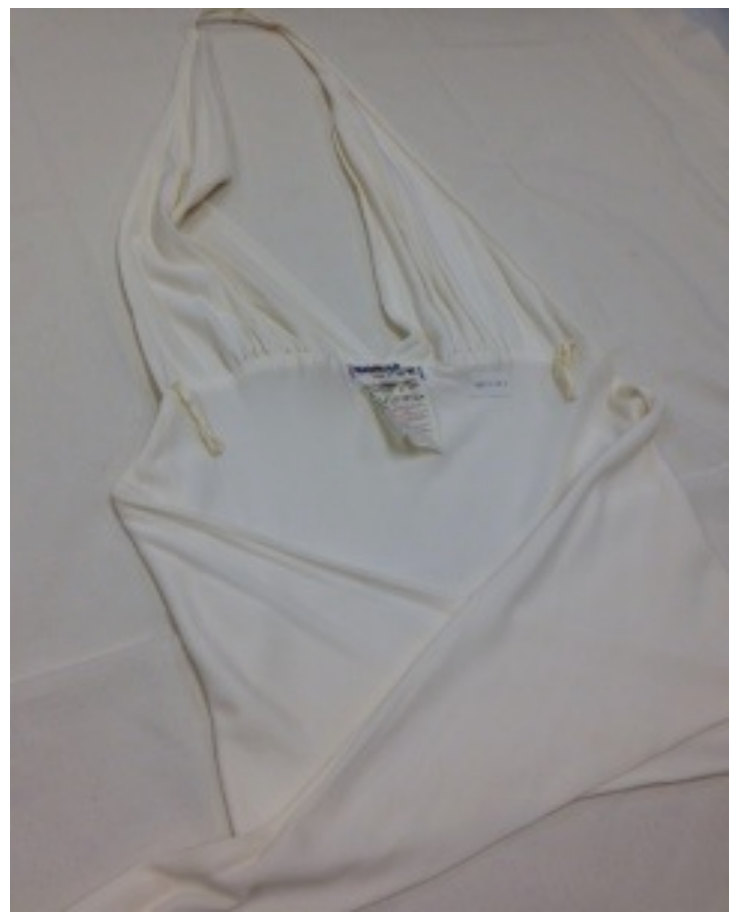

Fig. 16 - Saint Laurent jersey halter top (FRC 1997.04.038). 


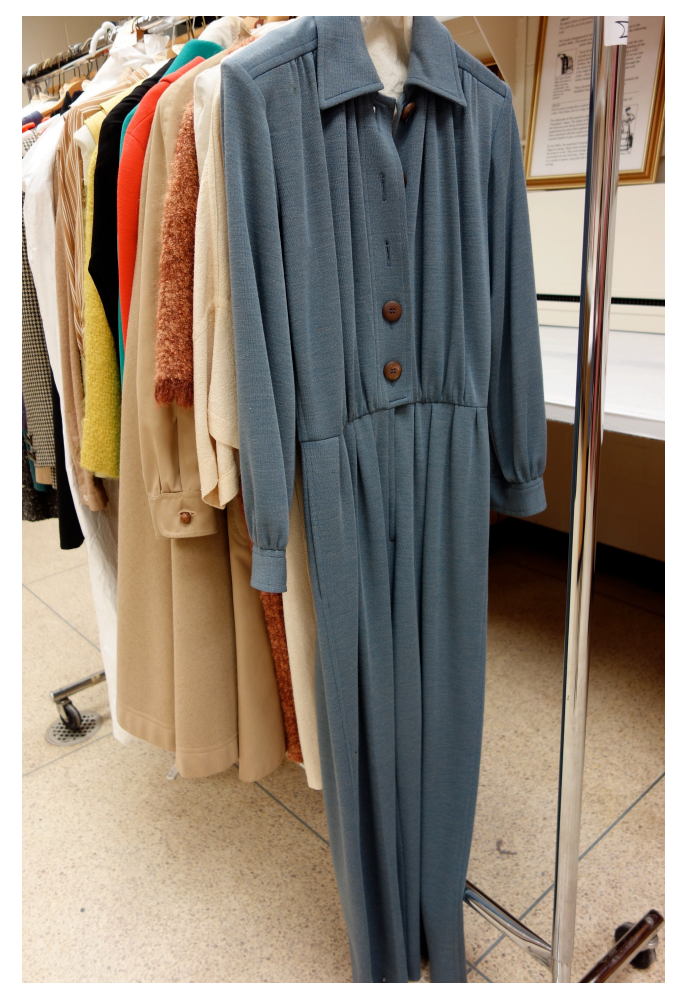

Fig. 17 - Saint Laurent wool jumpsuit (FRC 1997.04.039).

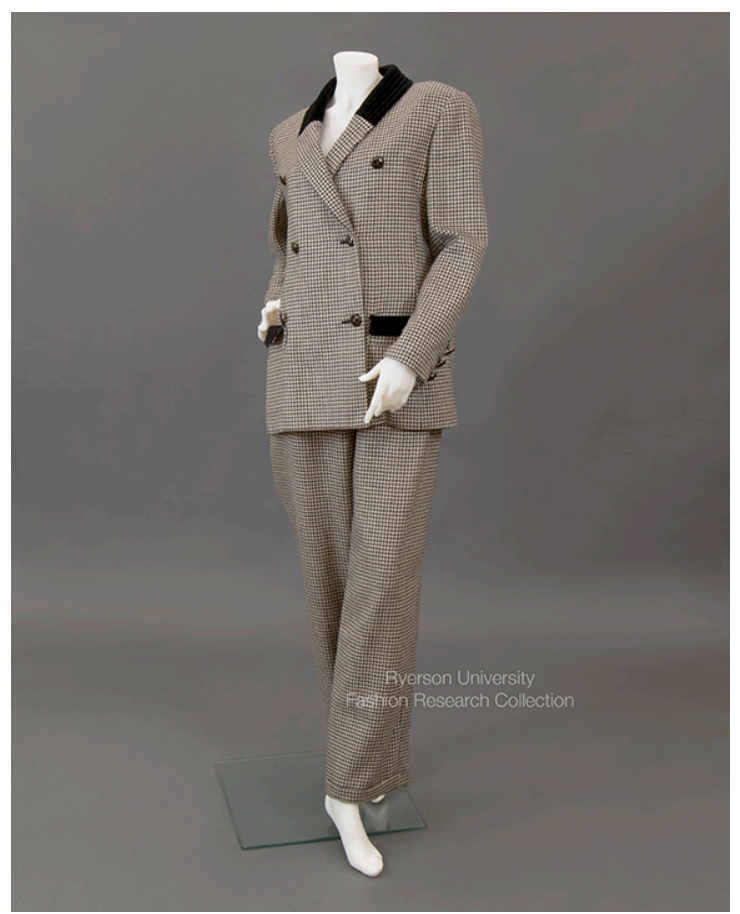

Fig. 18 - Valentino wool trouser suit (FRC 1997.04.040). Photo by Jazmin Welch, Courtesy of the Ryerson Fashion Research Collection. 


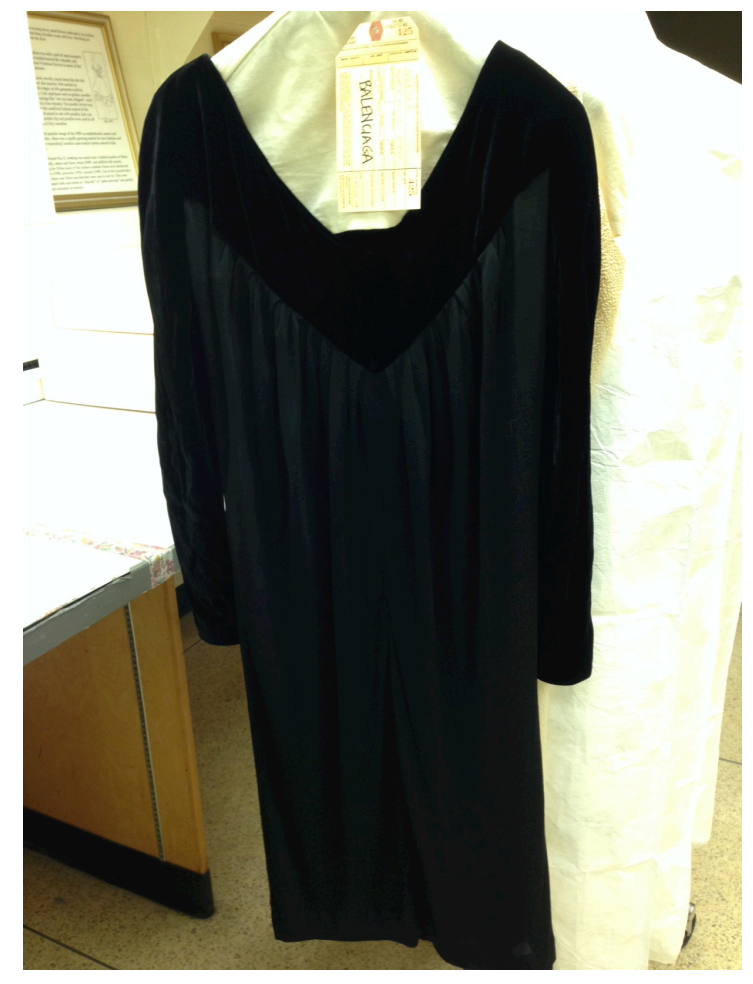

Fig. 19 - Balenciaga velvet and jersey cocktail dress (FRC 1997.04.051).

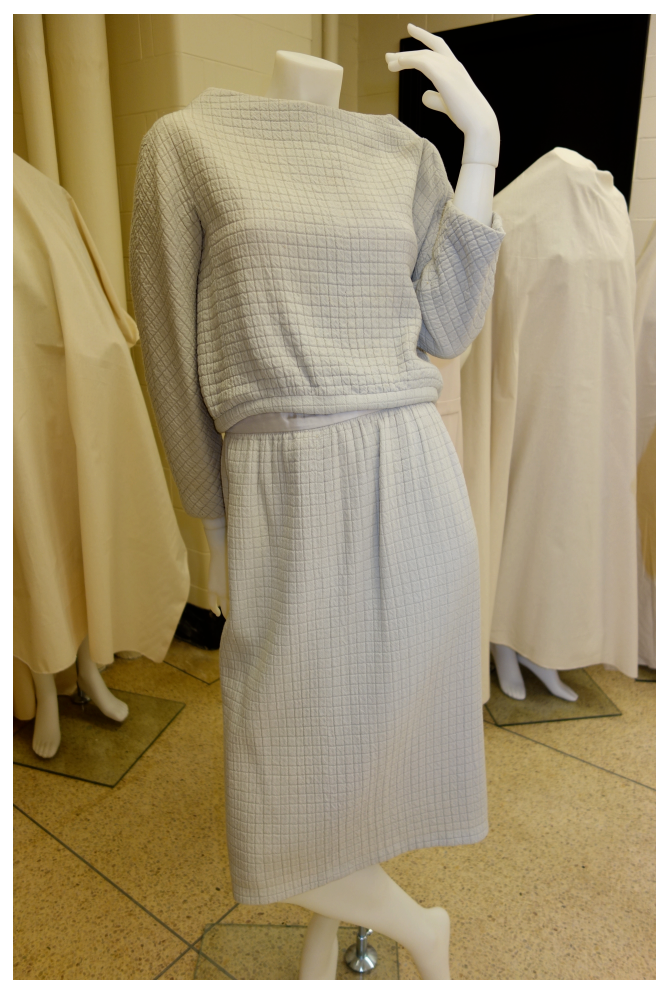

Fig. 20 - Holt Renfrew quilted top and skirt (FRC 1997.04.055). 


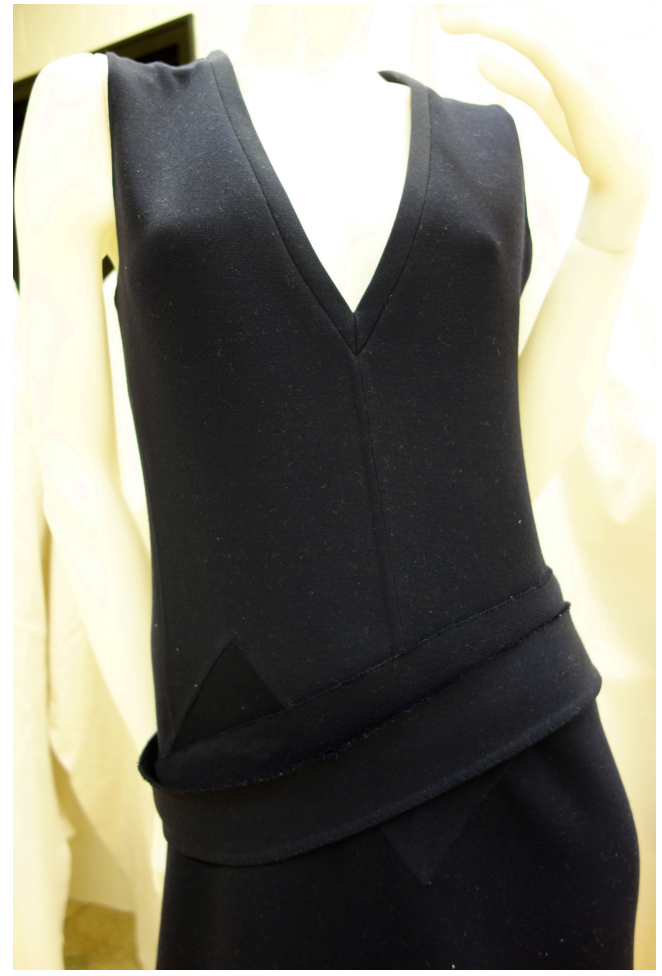

Fig. 21 - Holt Renfrew wool sleeveless evening dress (FRC 1997.04.058).

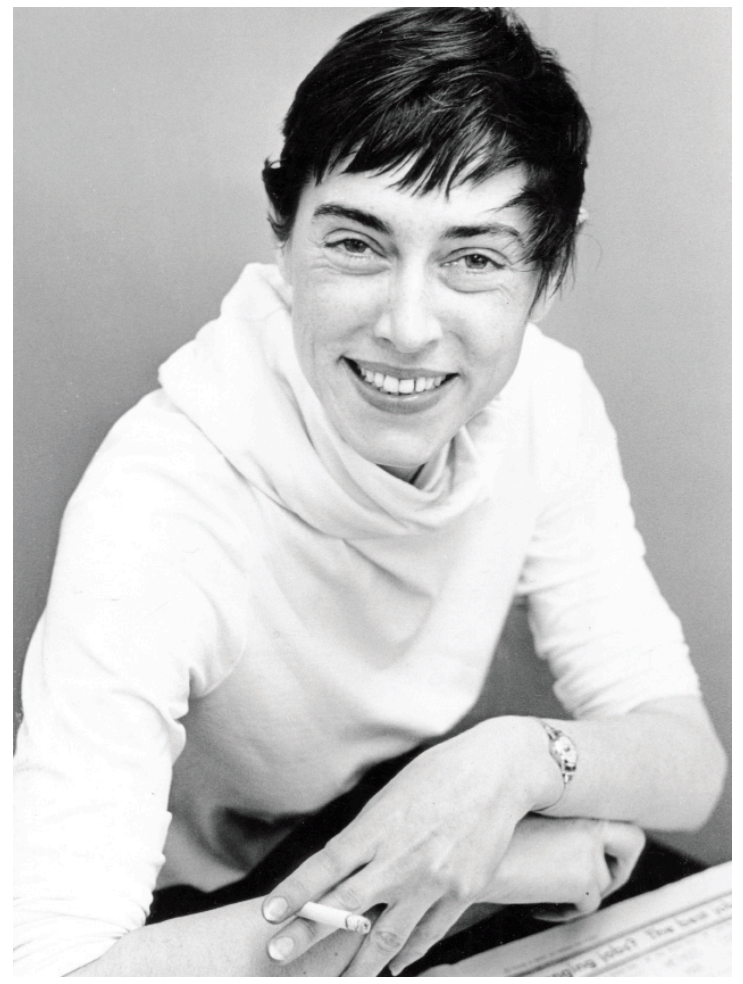

Fig. 22 - Barbara Moon in 1965, The Globe and Mail, in "Full Moon." Ryerson Review of Journalism Summer 2010, p. 46. 


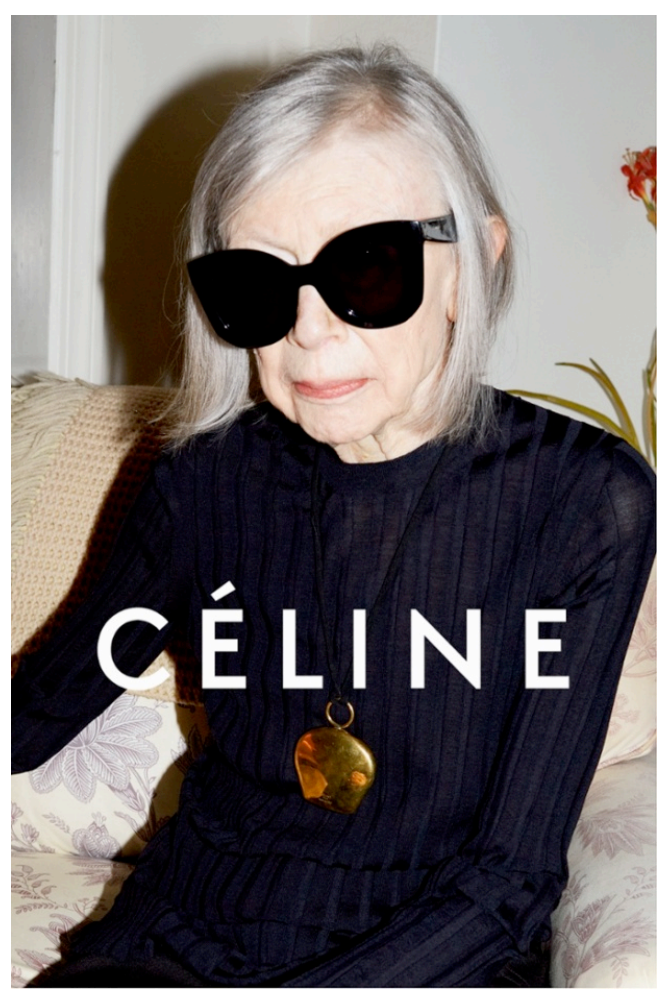

Fig. 23 - Joan Didion in Céline Spring 2015 campaign. "It's great that Céline is celebrating Joan Didion - but to sell accessories?”, The Guardian Jan. 12, 2015, Web, retrieved Feb. 20, 2015.

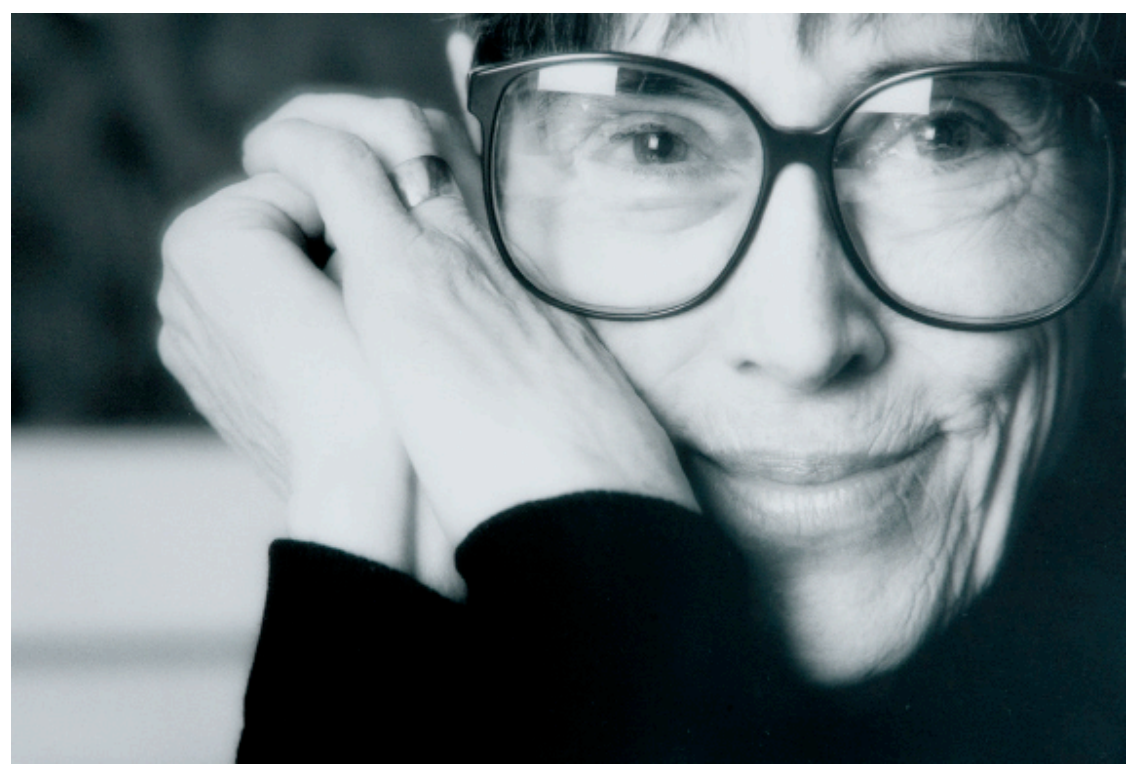

Fig. 24 - Barbara Moon, in "Full Moon.” Ryerson Review of Journalism Summer 2010, p. 45. 


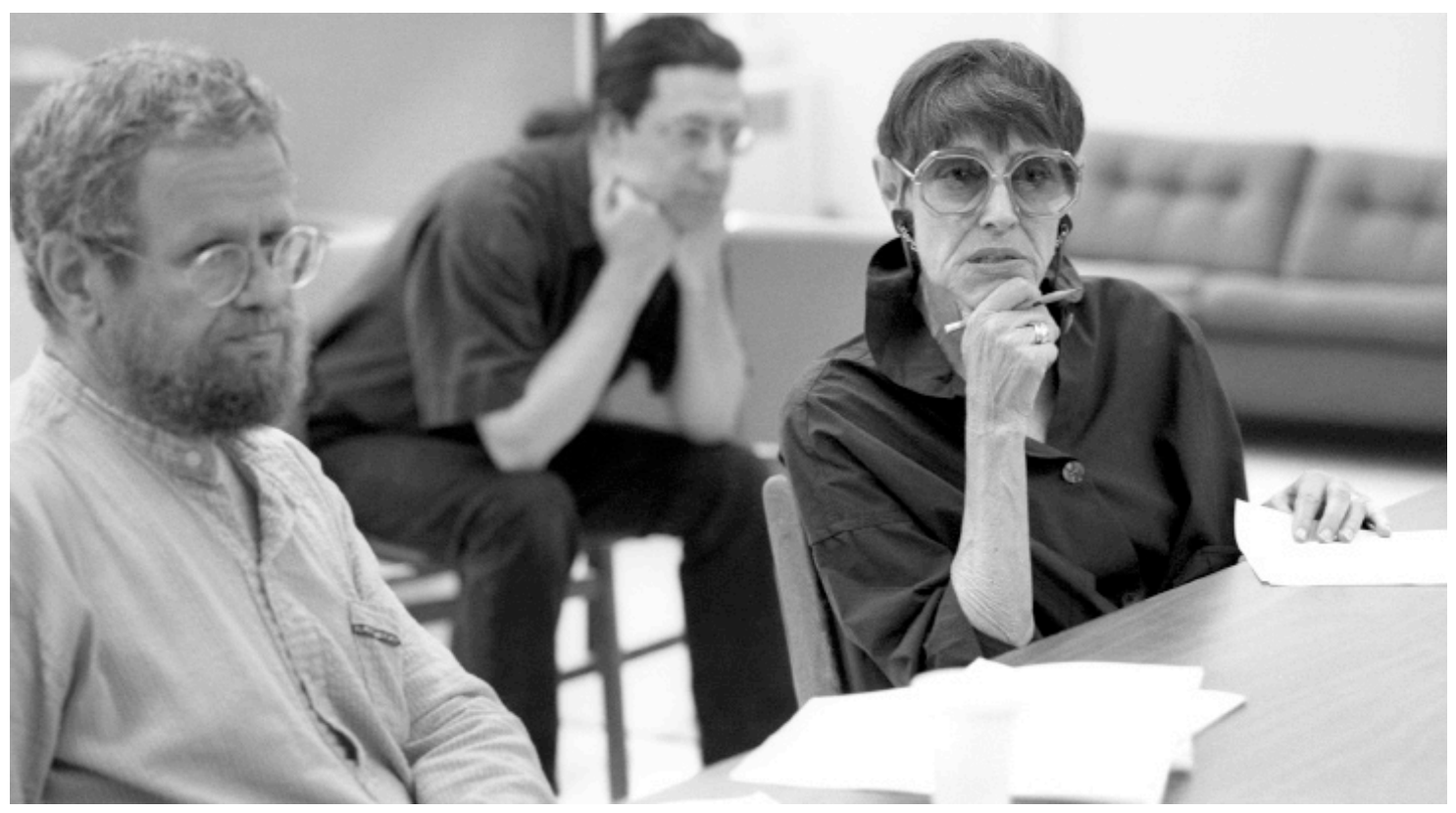

Fig. 25 - Barbara Moon, photo by Don Lee, The Banff Centre, in "Full Moon." Ryerson Review of Journalism Summer 2010, p. 48. 


\section{Works Cited}

Accardo, Alain, and Philippe Corcuff. La sociologie de Bourdieu. Bordeaux: Le Mascaret, 1989.

Print.

Aston, Suzy, and Sue Ferguson. “Maclean's: The First 100 Years.” Maclean's. n. pag. Web. 26 Feb. 2014.

Back, Kurt W. "Modernism and Fashion.” The Psychology of Fashion. Ed. Michael R. Solomon. Lexington, Mass.: Lexington Books, 1985. Print.

Beasley, Maurine H., and Sheila J. Gibbons. Taking Their Place: A Documentary History of Women and Journalism. State College, PA: Strata Pub., 2003. Print.

Benson, Lenore. "Fashion Editors." A-Z of Fashion. The Berg Fashion Library, 2005. n. pag. Web. 8 Jan. 2015.

Bern, AC. "The Working Life of Gwyned Filling, the 'Career Girl' of 1948." The Billfold 15 Jan. 2015. n. pag. Web. 15 Jan. 2015.

Blumer, Herbert. "Fashion: From Class Differentiation to Collective Selection.” The Sociological Quarterly 10.3 (1969): 275-291. JSTOR. Ryerson Library. Web. 2 Feb. 2014.

Bourdieu, Pierre. "Haute couture et haute culture.” Questions de sociologie. Paris: Minuit, 1984. Print.

Bourdieu, Pierre. La distinction: critique sociale du jugement. Paris: Minuit, 1979. Print.

Bourdieu, Pierre. “Mais qui a créé les ‘créateurs'?” Questions de sociologie. Paris: Minuit, 1984. Print.

Bowles, Hamish. “The Hamishsphere: The Top Ten Looks from the Valentino Archives.” Vogue 5 Dec. 2011. n. pag. Web. 6 Mar. 2015. 
Breward, Christopher. "Fashion Capitals." Fashion. Oxford; New York: Oxford University Press, 2003. Print.

Breward, Christopher. "The Dolly Bird: Chelsea and Kensington 1960-70." Fashioning London: Clothing and the Modern Metropolis. Oxford; New York: Berg, 2004. Print.

Brown, Bill. "Thing Theory.” Critical Inquiry 28.1 (2001): 1-22. JSTOR. Ryerson Library. Web. 7 Apr. 2015.

Chambers, Deborah, Linda Steiner, and Carole Fleming. Women and Journalism. London: Routledge, 2004. MyiLibrary. Ryerson Library. Web. 8 Mar. 2014.

Clarke, Alison, and Daniel Miller. "Fashion and Anxiety." Fashion Theory: The Journal of Dress, Body \& Culture 6.2 (2002): 191-213. Ingenta Connect. Ryerson Library. Web. 3 Dec. 2014. Conekin, Becky E. Lee Miller in Fashion. London: Thames \& Hudson, 2013. Print. Crane, Diana and Laura Bovone. "Approaches to Material Culture: The Sociology of Fashion and Clothing." Poetics 34 (2006): 319-333. ScienceDirect. Ryerson Library. Web. 8 Mar. 2014.

Davis, Fred. "Clothing and Fashion as Communication." The Psychology of Fashion. Ed.

Michael R. Solomon. Lexington, Mass.: Lexington Books, 1985. Print.

Dwight, Eleanor. Diana Vreeland. New York: HarperCollins, 2002. Print.

Entwistle, Joanne. "Power Dressing and the Fashioning of the Career Woman." Buy This Book: Studies in Advertising and Consumption. Ed. M. Nava, A. Blake, B. Richards, and I. MacRury. London: Routledge, 1997. Print.

Entwistle, Joanne. “The Dressed Body.” Body Dressing. The Berg Fashion Library, 2001. n. pag. Web. 3 Dec. 2014. 
Entwistle, Joanne. The Fashioned Body: Fashion, Dress, and Modern Social Theory. Cambridge: Polity Press, 2000. Print.

Esten, John. Diana Vreeland: Bazaar Years. New York: Universe, 2001. Print.

Friedan, Betty. The Feminine Mystique. New York: Norton, 1963. Print.

Fuchs, Penny Bender. "Women in Journalism Oral History Collection of the Washington Press Club Foundation." Journalism History 28.4 (2003): 191-6. ProQuest. Ryerson Library. Web. 3 Feb. 2015.

Fulford, Robert. “Her Elements of Style.” Maclean's 24 Apr. 2009. n. pag. Web. 15 Jan. 2015. Goffman, Erving. The Presentation of Self in Everyday Life. New York; Toronto: Anchor Books, 1959. Print.

Golbin, Pamela. Balenciaga Paris. Paris: Arts décoratifs, 2006. Print.

Gould, Carol S. "Glamour as an Aesthetic Property of Persons." The Journal of Aesthetics and Art Criticism 63.3 (2005): 237-247. Scholars Portal. Ryerson Library. Web. 8 Jan. 2015.

Guy, Alison, and Maura Banim. "Personal Collections: Women's Clothing Use and Identity." Journal of Gender Studies 9.3 (2000): 313-327. Taylor and Francis Online. Ryerson Library. Web. 2 Oct. 2013.

Hauser, Kitty. "A Garment in the Dock; Or, How the FBI Illuminated the Prehistory of A Pair of Denim Jeans." Journal of Material Culture 9.3 (2004): 293-313. Scholars Portal. Ryerson Library. Web. 14 Apr. 2014.

Head, Edith, and Joe Hyams. How to Dress for Success. New York: Random House, 1967. Print. Janes, J. Robert. “I Remember Barbara Moon.” The Globe and Mail 24 Apr. 2009. n. pag. Web. 15 Jan. 2015. 
Join-Diéterle, Catherine. Givenchy: 40 Years of Creation. Paris: Paris-Musées, 1991. Print.

Jouve, Marie-Andrée. Balenciaga. New York: Rizzoli, 1989. Print.

Kaiser, Susan, Joan Chandler, and Tania Hammidi. "Minding Appearances in Female Academic Culture." Through the Wardrobe. The Berg Fashion Library, 2001. n. pag. Web. 8 Dec. 2014.

Kaiser, Susan. "Minding Appearances: Style, Truth, and Subjectivity." Body Dressing. The Berg Fashion Library, 2001. n. pag. Web. 3 Dec. 2014.

Kawamura, Yuniya. “Adoption and Consumption of Fashion.” Fashion-ology. The Berg Fashion Library, 2004. n. pag. Web. 1 Feb. 2014.

Kesterton, Wilfred H. A History of Journalism in Canada. Toronto: McClelland and Stewart, 1967. Print.

Kieran, Sheila. "I Remember Barbara Moon." The Globe and Mail 22 Jun. 2009: S9. ProQuest. Ryerson Library. Web. 1 Mar. 2014.

Kopytoff, Igor. "The Cultural Biography of Things: Commoditization as Process.” The Social Life of Things: Commodities in Cultural Perspective. Ed. Arjun Appadurai. Cambridge: Cambridge University Press, 1986. 64-91. Blackboard. Ryerson University. 17 Jan. 2014.

Loschek, Ingrid. "Clothes as Form." When Clothes Become Fashion: Design and Innovation Systems. The Berg Fashion Library, 2009. n. pag. Web. 29 Mar. 2015.

Major, John. "Givenchy, Hubert de.” A-Z of Fashion. The Berg Fashion Library, 2005. n. pag. Web. 13 Jan. 2015.

Manguel, Alberto. “I Remember Barbara Moon.” The Globe and Mail 5 May 2009. n. pag. Web. 15 Jan. 2015. 
Martin, Sandra. "Barbara Moon, 82: Writer, Editor.” The Globe and Mail 22 Apr. 2009: S8. ProQuest. Ryerson Library. Web. 1 Mar. 2014.

Marzolf, Marion. Up from the Footnote: A History of Women Journalists. New York: Hastings House, 1977. Print.

Miller, Daniel. Stuff. Cambridge: Polity Press, 2010. Print.

Miller, Lesley Ellis. Balenciaga. London: V\&A Publications, 2007. Print.

Mills, Kay. A Place in the News: From the Women's Pages to the Front Page. New York: Columbia University Press, 1990. Print.

Mohrt, Françoise. The Givenchy Style. Paris: Assouline, 1998. Print.

Molloy, John T. The Woman's Dress for Success Book. New York: Warner Books, 1977. Print. Muggli, Mark Z. “The Poetics of Joan Didion’s Journalism.” American Literature 59.3 (1987): 402-421. JSTOR. Ryerson Library. Web. 7 Apr. 2015.

Palmer, Alexandra. Couture and Commerce: The Transatlantic Fashion Trade in the 1950s. Vancouver: UBC Press, 2001. Print.

Palmer, Alexandra. Dior. London: V\&A, 2009. Print.

Parkins, Ilya. "Christian Dior: Nostalgia and the Economy of Feminine Beauty." Poiret, Dior and Schiaparelli: Fashion, Femininity and Modernity. The Berg Fashion Library, 2012. n. pag. Web. 8 Jan. 2015.

Parkins, Ilya. "Elsa Schiaparelli and the Epistemology of Glamorous Silence.” Topia 25 (2011): 190-195. Ryerson Library. Web. 8 Jan. 2015.

Persaud, Seema. “Full Moon.” Ryerson Review of Journalism Summer 2010. Web. 15 Jan. 2015. Pochna, Marie France. Dior. New York: Assouline, 2004. Print. 
Prown, Jules David. "Mind in Matter: An Introduction to Material Culture Theory and Method." Material Life in America, 1600-1860. Ed. Robert Blaire St. George. Boston: Northeastern University Press, 1988. 17-38. Blackboard. Ryerson University. 17 Jan. 2014.

Rabolt, Nancy J., and Mary Frances Drake. "Women's Career Dressing Decisions.” The Psychology of Fashion. Ed. Michael R. Solomon. Lexington, Mass.: Lexington Books, 1985. Print.

Riello, Giorgio. "Things That Shape History: Material Culture and Historical Narratives." History and Material Culture: A Student's Guide to Approaching Alternative Sources. Ed. Karen Harvey. London; New York: Routledge, 2009. 24-46. Blackboard. Ryerson University. 17 Jan. 2014.

Robinson, Gertrude Joch. Gender, Journalism, and Equity: Canadian, U.S., and European Experiences. Cresskill, N.J.: Hampton Press, 2005. Print.

Rocamora, Agnès. "Fields of Fashion: Critical Insights Into Bourdieu's Sociology of Culture." Journal of Consumer Culture 2.3 (2002): 341-362. Scholars Portal. Ryerson Library. Web. 2 Feb. 2014.

Rose, Rebecca. "You've Come a Long Way." Ryerson Review of Journalism Spring 2008. Web. 8 Jan. 2015.

Rudd, Nancy A., and Sharron J. Lennon. "Social Power and Appearance Management among Women.” Appearance and Power. The Berg Fashion Library, 1999. n. pag. Web. 8 Dec. 2014.

Simmel, Georg. "Fashion." The American Journal of Sociology 62.6 (1957): 541-558. JSTOR. Ryerson Library. Web. 3 Mar. 2014. 
Steele, Valerie. "A Museum of Fashion Is More Than a Clothes-Bag." Fashion Theory 2.4 (1998): 327-336. Ryerson Library. Web. 31 Oct. 2013.

Steiner, Linda. "Newsroom Accounts of Power at Work." News, Gender, and Power. Ed. Cynthia Carter, Gill Branston, and Stuart Allan. London; New York: Routledge, 1998. ebrary Reader. Ryerson Library. Web. 10 Feb. 2015.

Stuart, Amanda Mackenzie. Empress of Fashion: A Life of Diana Vreeland. New York: HarperCollins, 2012. Print.

Sturken, Marita, and Lisa Cartwright. Practices of Looking: An Introduction to Visual Culture. New York; Oxford: Oxford University Press, 2009. Print.

Sutherland, Fraser. The Monthly Epic: A History of Canadian Magazines. Toronto: Fitzhenry \& Whiteside, 1989. Print.

Thesander, Marianne. The Feminine Ideal. London: Reaktion Books, 1997. Print. van Zoonen, Liesbet. "One of the Girls? The Changing Gender of Journalism.” News, Gender, and Power. Ed. Cynthia Carter, Gill Branston, and Stuart Allan. London; New York: Routledge, 1998. ebrary Reader. Ryerson Library. Web. 8 Mar. 2014.

Voss, Kimberly Wilmot, and Lance Speere. "Fashion as Washington Journalism History: Eleni Epstein and Her Three Decades at the Washington Star.” Media History Monographs 16.3 (2013). n. pag. Academic OneFile. Ryerson Library. Web. 3 Feb. 2015.

Wilson, Elizabeth. “A Note on Glamour.” Fashion Theory 11.1 (2007): 95-108. Ingenta Connect. Ryerson Library. Web. 8 Jan. 2014.

Wilson, Elizabeth. Adorned in Dreams: Fashion and Modernity. London; New York: I.B. Tauris, 2003. Print. 
Woodward, Sophie. "Understanding Women and Their Wardrobes." Why Women Wear What They Wear. The Berg Fashion Library, 2007. n. pag. Web. 3 Dec. 2014. 